\title{
Polar mesosphere summer echoes (PMSE): review of observations and current understanding
}

\author{
M. Rapp and F.-J. Lübken \\ Leibniz Institute of Atmospheric Physics, Schlossstr. 6, 18225 Kühlungsborn, Germany \\ Received: 10 June 2004 - Published in Atmos. Chem. Phys. Discuss.: 24 August 2004 \\ Revised: 15 November 2004 - Accepted: 22 November 2004 - Published: 21 December 2004
}

\begin{abstract}
Polar mesosphere summer echoes (PMSE) are very strong radar echoes primarily studied in the VHF wavelength range from altitudes close to the polar summer mesopause. Radar waves are scattered at irregularities in the radar refractive index which at mesopause altitudes is effectively determined by the electron number density. For efficient scatter, the electron number density must reveal structures at the radar half wavelength (Bragg condition for monostatic radars; $\sim 3 \mathrm{~m}$ for typical VHF radars). The question how such small scale electron number density structures are created in the mesopause region has been a longstanding open scientific question for almost 30 years. This paper reviews experimental and theoretical milestones on the way to an advanced understanding of PMSE. Based on new experimental results from in situ observations with sounding rockets, ground based observations with radars and lidars, numerical simulations with microphysical models of the life cycle of mesospheric aerosol particles, and theoretical considerations regarding the diffusivity of electrons in the ice loaded complex plasma of the mesopause region, a consistent explanation for the generation of these radar echoes has been developed. The main idea is that mesospheric neutral air turbulence in combination with a significantly reduced electron diffusivity due to the presence of heavy charged ice aerosol particles (radii $\sim 5-50 \mathrm{~nm}$ ) leads to the creation of structures at spatial scales significantly smaller than the inner scale of the neutral gas turbulent velocity field itself. Importantly, owing to their very low diffusivity, the plasma structures acquire a very long lifetime, i.e., $10 \mathrm{~min}$ to hours in the presence of particles with radii between 10 and $50 \mathrm{~nm}$. This leads to a temporal decoupling of active neutral air turbulence and the existence of small scale plasma structures and PMSE and thus readily explains observations proving the absence of neutral air turbulence at PMSE altitudes. With this expla-
\end{abstract}

Correspondence to: M. Rapp

(rapp@iap-kborn.de) nation at hand, it becomes clear that PMSE are a suitable tool to permanently monitor the thermal and dynamical structure of the mesopause region allowing insights into important atmospheric key parameters like neutral temperatures, winds, gravity wave parameters, turbulence, solar cycle effects, and long term changes.

\section{Introduction}

The polar mesosphere in summer is host to a number of fascinating geophysical phenomena that are primarily caused by its extreme thermal structure. Owing to the gravity wave driven mean meridional circulation with upwelling and adiabatically expanding air masses above the summer pole, mean minimum temperatures of $\sim 130 \mathrm{~K}$ are reached at the mesopause at around $88 \mathrm{~km}$ (e.g., Lübken, 1999). These extremely low temperatures marginally allow ice particles to form and grow at altitudes between $\sim 80$ and $90 \mathrm{~km}$, in spite of the minute abundance of water vapor with typical volume mixing ratios of only some ppm (e.g., Seele and Hartogh, 1999). Under favourable conditions the largest of these ice particles (with radii larger than $\sim 20 \mathrm{~nm}$ ) can even be visually observed in the form of noctilucent clouds (= NLC) which have been discovered as early as 1883 (Leslie, 1885; Jesse, 1885). With the advent of the MST radar (MST = mesosphere-stratosphere-troposphere) 100 years later, it was then found that also the smaller subvisible ice particles lead to measurable signatures in the form of strong radar echoes. These are nowadays known as polar mesosphere summer echoes or PMSE (Ecklund and Balsley, 1981; Röttger et al., 1988; Hoppe et al., 1988).

In recent years, these high atmospheric ice clouds have reached a considerable scientific interest since it was suspected that the mesopause environment should change due to anthropogenic activity. For example, models showed that the increase of atmospheric carbon dioxide concentrations

(C) 2004 Author(s). This work is licensed under a Creative Commons License. 


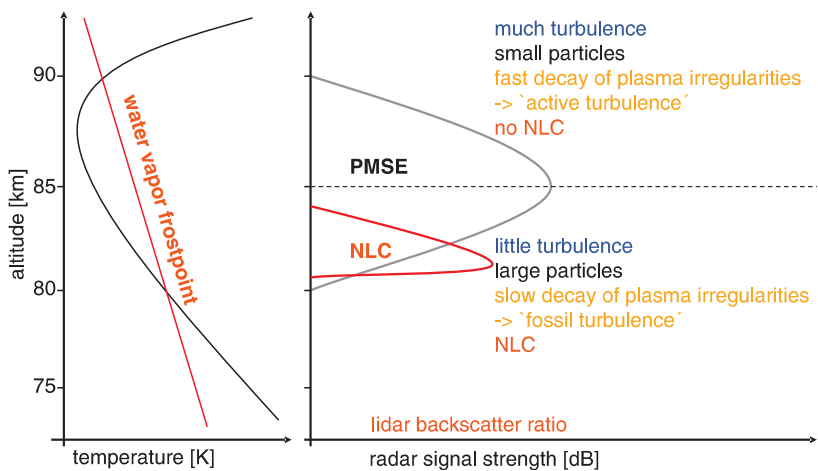

Fig. 1. Left panel: Schematic of the altitude profile of the temperature and the frost point of water vapor. Right panel: Schematic of the altitude distribution of PMSE (black line, grey shading) and NLC (red line) and the relevant physical mechanisms at different altitudes.

should lead to a temperature decrease in the mesopause region (Roble and Dickinson, 1989) and it was also argued that increasing atmospheric concentrations of methane should lead to enhanced water vapor at mesopause altitudes (Thomas et al., 1989).

At the current stage the discussion as to whether we already observe long term changes in mesospheric ice particle properties is controversial (von Zahn, 2003; Thomas et al., 2003). However, it is evident that for a scientifically based judgement about these issues we require a detailed and rigorous understanding of the physical processes involved. While the basic physics of noctilucent clouds has been quite well understood (e.g., Thomas, 1991; Gadsden and Schröder, 1989), the understanding of polar mesosphere summer echoes has bothered the scientific community until only recently (Cho and Röttger, 1997; Rapp and Lübken, 2003a).

In order to ease the reading of this review, we summarize the now available understanding of PMSE as follows (see Fig. 1): the altitude range between 80 and $90 \mathrm{~km}$ in the summer polar mesopause region is just the altitude range where ice particles exist. Being formed close to the point with coldest temperatures $(\sim 88 \mathrm{~km})$, ice particles sediment and grow, until below $\sim 85 \mathrm{~km}$, radii have become as large as $\sim 20 \mathrm{~nm}$. With this size they can be optically observed as NLC, for example with the naked eye or with lidars. All these ice particles are immersed in the plasma of the D-region. Hence, electrons attach to the ice surfaces such that the particles become charged. In addition, the $80-90 \mathrm{~km}$ altitude range is the region in the atmosphere where gravity waves propagating from below grow unstable and produce turbulence. The charged ice particles are transported by the turbulent velocity field leading to small scale structures in the spatial distribution of the charged particles and - because of charge neutrality requirements - to small scale structures in the spatial distribution of the electron number density. Hence, the trans-

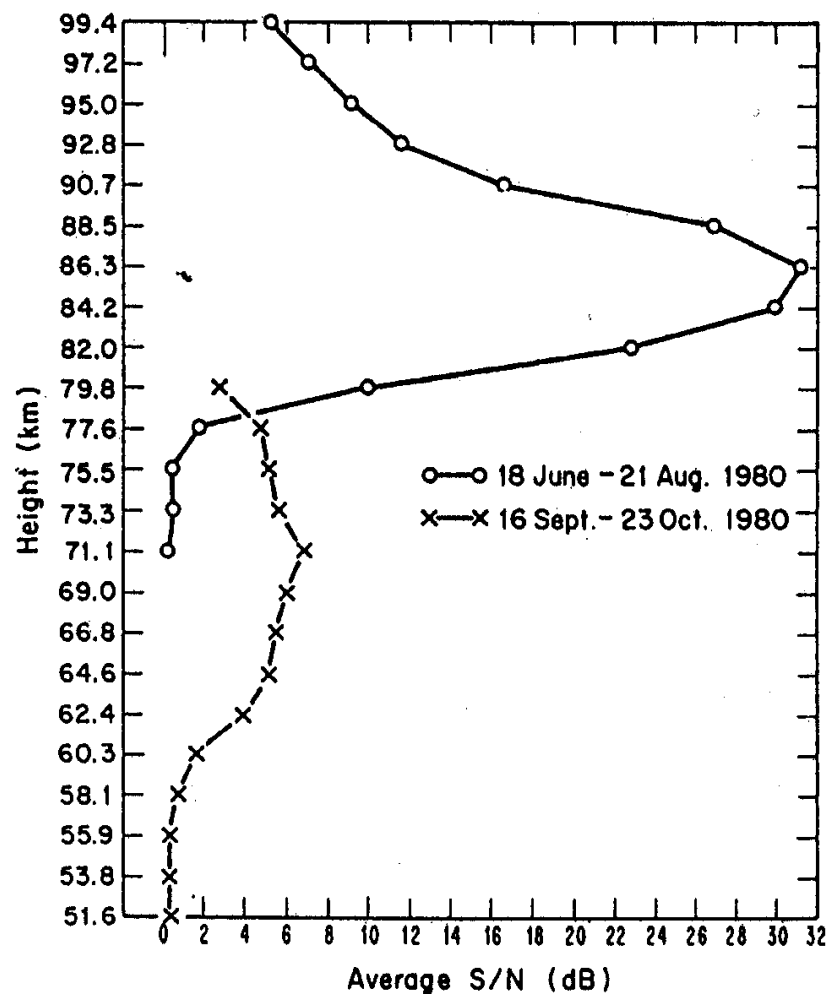

Fig. 2. Time averaged profiles of signal to noise ratio (in decibels) for typical summer and winter periods. This figure is reproduced from Ecklund and Balsley (1981), copyright by the American Geophysical Union.

port of charged ice particles by the turbulent velocity field leads to the occurrence of irregularities in the radio refractive index (which is effectively determined by the electron number density at these altitudes) which is observed on the ground as PMSE. Importantly, the radius of the ice particle determines the lifetime of the irregularities. Typical values for the lifetime are just a few minutes for small radii at altitudes above $\sim 85 \mathrm{~km}$ and several ten minutes to hours for the larger radii below. Hence, at altitudes above $\sim 85 \mathrm{~km}$, PMSE can only exist during phases of active neutral air turbulence. In contrast, the long lifetime below this altitude 'freezes' in the plasma structures such that PMSE also occurs in the absence of neutral air turbulence. Since these frozen in structures once originated from turbulent advection, they are also often termed 'fossil'-turbulent structures.

The complex physical explanation shortly summarized above has become available through a multitude of observational and theoretical efforts. In this manuscript we attempt to describe the experimental and theoretical milestones that have led to the understanding sketched above. In Sect. 2 we summarize the most important experimental findings on PMSE based on classical radar measurements, in situ rocket probings and also active radar experiments where electromagnetic waves have been used to modify the PMSE 
environment directly from the ground and observe the corresponding response of the PMSE layer. In Sect. 3 we proceed with an overview of our theoretical understanding of the relevant physical mechansms including a detailed description of the most recent progress. This latest understanding of the physics of PMSE is discussed in depth in Sect. 4 followed by our conclusions and an outlook where we try to identify important open issues for future investigations.

\section{Experimental facts}

\subsection{Initial observations and basic physical problem}

At the end of the 1970s, VHF radars operating at frequencies of $\sim 50 \mathrm{MHz}$ discovered very strong radar echoes from around the summer mesopause region at altitudes between $\sim 80$ and $90 \mathrm{~km}$ both at polar and mid latitudes (Ecklund and Balsley, 1981; Czechowsky et al., 1979). The first long term data set covering observations at Poker Flat, Alaska $\left(65^{\circ} \mathrm{N}\right)$ between February 1979 and December 1980 revealed a strong seasonal variation of both the observed echo power and the altitude range where the echoes were observed (Ecklund and Balsley, 1981). Figure 2 shows the time averaged altitude profiles of signal to noise ratio (SNR) for typical summer and winter periods taken from this study. Evidently, during the summer months the average signal peak is located considerably higher (i.e., at $\sim 86 \mathrm{~km}$ ) than during winter time, where only weak echoes (average SNR ratios $\sim 5 \mathrm{~dB}$ ) are received from altitudes below $\sim 75 \mathrm{~km}$. During summer time, however, the echoes are extremely strong reaching a maximum average SNR of $\sim 30 \mathrm{~dB}$. Due to their predominant appearance in the polar regions these strong echoes are commonly called polar mesosphere summer echoes or PMSE (Röttger et al., 1988; Hoppe et al., 1988).

Radar waves are scattered by irregularities in the refractive index which at altitudes around $85 \mathrm{~km}$ is effectively determined by the electron number density (e.g., Sato, 1989, page 23-25). In general, one distinguishes between incoherent scatter (or Thomson scatter) which is due to the thermal random motion of the electrons and coherent scatter, i.e., the scatter at ordered structures in the electron density distribution. Coherent scatter only occurs when the refractive index irregularity spectrum possesses significant spectral power at scales around the radar half wavelength (= Bragg condition for monostatic radars) which is $3 \mathrm{~m}$ for a $50 \mathrm{MHz}$ radar (Tatarskii, 1971). The irregularities leading to the weak radar backscatter outside the polar summer season at altitudes below say $\sim 75 \mathrm{~km}$ have been traced back to neutral air turbulence (Woodman and Guillen, 1974; Balsley et al., 1983; Røyrvik and Smith, 1984) which in turn is generated by breaking gravity waves propagating upwards from the troposphere (note though that recent experimental evidence of so called 'polar mesosphere winter echoes' indicates that at least some of these echoes at lower altitudes

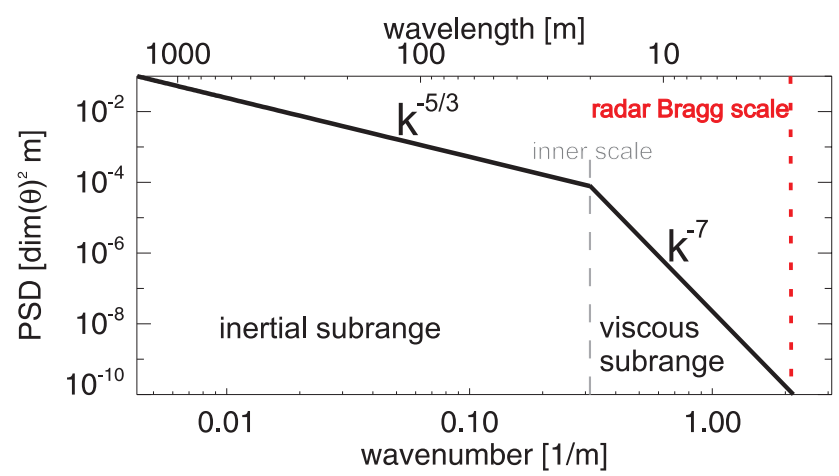

Fig. 3. Idealized power spectrum of a passive turbulent tracer $\theta$ for typical mesospheric conditions. The inertial and viscous subranges are characterized by a wavenumber dependence proportional to $k^{-5 / 3}$ and $\sim k^{-7}$, respectively. The upper ordinate converts wavenumbers to lengths. The grey dashed line indicates the inner scale (see text for details) and the red dashed line indicates the Bragg scale of a $50 \mathrm{MHz}$ radar.

may not be understandable in the scope of pure turbulent activity; Kirkwood et al., 2002a, 2003). However, early efforts to explain the significantly stronger echoes from the summer polar mesopause region by neutral air turbulence led to a paradox that was already identified in the early work on the subject (Balsley et al., 1983): In Fig. 3 we present a typical power spectrum of a tracer (like neutral air density fluctuations) for turbulent motions in the middle atmosphere. This power spectrum reveals two distinct parts. The first part is marked by a wavenumber dependence of $k^{-5 / 3}$ and is called the inertial subrange, because at these scales the flow is dominated by inertial forces. The second part of the spectrum is called the viscous subrange and is characterized by a much faster drop off of the spectral power, i.e., it is proportional to $\sim k^{-7}$. In this subrange, the tracer variance is effectively destroyed by molecular diffusion (e.g., Heisenberg, 1948). Note that the absolute power of the tracer variance strongly depends on the background gradient of the tracer distribution, i.e., at a given length scale, the tracer fluctutaions are the larger the larger the background gradient is (in the extreme opposite case of a zero background gradient, small scale fluctuations can certainly not be created by the turbulent eddies). From this figure, it is evident that in order to satisfy the Bragg criterium, the radar half wavelength must be located in the inertial subrange of the turbulent power spectrum since for smaller scales, i.e., in the viscous subrange, irregularities practically do not exist. The smallest scale to which the inertial subrange extends, depends on two quantities: the turbulence strength expressed by the turbulent energy dissipation rate $\epsilon$ ( $=$ the rate at which turbulent kinetic energy is dissipated into heat) and the kinematic viscosity $v$ which parameterizes the strength of molecular diffusion. A minimum necessary turbulent energy dissipation rate can be estimated by equating the inner scale $l_{0}^{H}=9.9 \cdot\left(v^{3} / \epsilon\right)^{\frac{1}{4}}$ (= the transition 


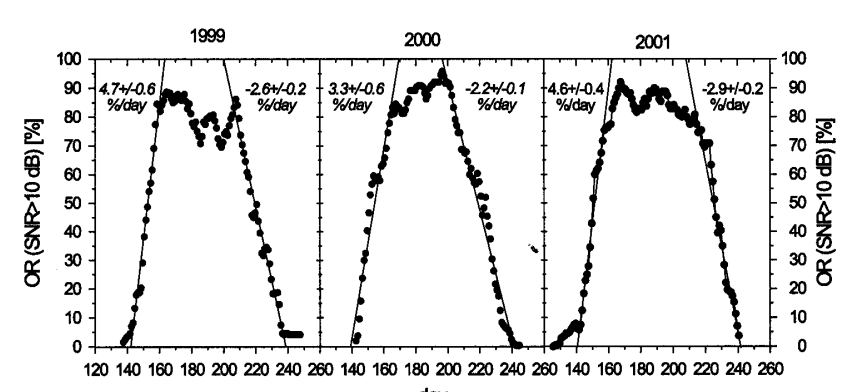

day

Fig. 4. Seasonal variation of the occurrence rate of PMSE with a SNR ratio larger than $10 \mathrm{~dB}$ after observations with the ALWIN radar on the North-Norwegian island Andøya during the years 1999, 2000, and 2001. This figure is reproduced from Bremer et al. (2003), copyright by the American Geophysical Union.

scale between the inertial and the viscous subrange; see also Lübken et al., 1993b) and the radar Bragg scale. Using a typical kinematic viscosity for an altitude of $85 \mathrm{~km}$ of $1 \mathrm{~m}^{2} / \mathrm{s}$, this estimate yields $\epsilon \approx 100 \mathrm{~W} / \mathrm{kg}$ equivalent to a heating rate of $d T / d t=90000 \mathrm{~K} / \mathrm{d}$. This heating rate is three orders of magnitude larger than all other relevant heating and cooling rates at the same altitudes and is clearly unrealistic (e.g., Mlynczak, 2000; Lübken, 1997).

Ever since the initial observations, it has hence been a major goal of both experimental and theoretical investigations on PMSE to resolve this paradox and identify the physical processes responsible for the creation of structures in the electron number density where under normal conditions they should not exist. In the following subsections, we present an overview of the milestones regarding the available observational work on PMSE forming the background of our current knowledge. Note that given the wealth of experimental investigations we are aware of the fact that the results presented can only be a selection of some of the relevant work in the field. For further reading we also refer to the excellent previous review articles by Cho and Kelley (1993) and Cho and Röttger (1997).

\subsection{Climatology}

\subsubsection{Seasonal variation}

As already evident from the pioneer work by Ecklund and Balsley (1981), PMSE reveal a pronounced seasonal variation. Figure 4 shows the seasonal variation of the occurrence rate of PMSE as observed with the $53 \mathrm{MHz}$ ALWIN radar $($ ALWIN $=$ ALOMAR Wind radar; ALOMAR $=$ Arctic Lidar Observatory for Middle Atmosphere Research) on the North-Norwegian island Andøya $\left(69.3^{\circ} \mathrm{N}, 16.0^{\circ} \mathrm{E}\right)$ during the years 1999, 2000, and 2001 (Bremer et al., 2003; Latteck et al., 1999a). The main characteristics are the steep increase during end of May/beginning of June, a rather high level near $90 \%$ in the middle of June until the middle/end of

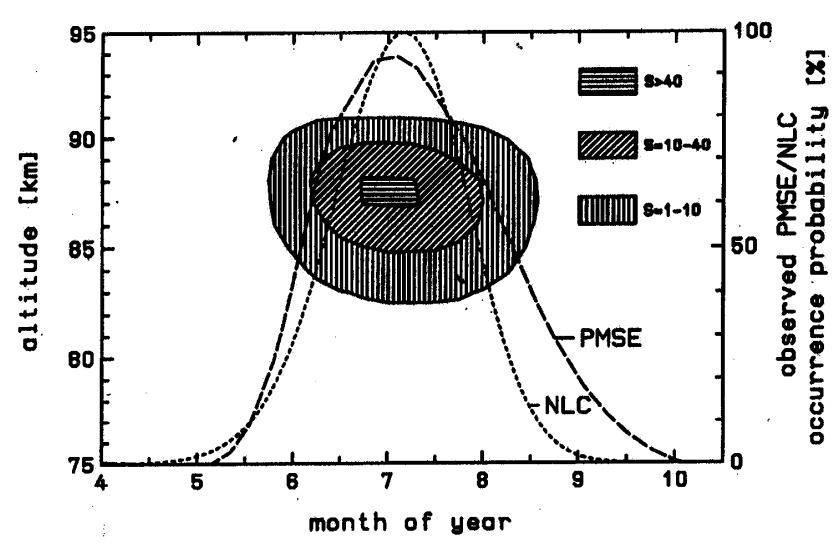

Fig. 5. Contour plot of the degree of saturation $S$ as a function of season and altitude (shaded areas) derived from a falling sphere temperature and density climatology and model water vapor mixing ratios from Garcia and Solomon (1994). In addition, relative occurrence probabilities are shown (normalized to $100 \%$ at the maximum) for PMSE (dashed line) and NLC (dotted line). This figure is reproduced from Lübken (1999), copyright by the American Geophysical Union.

July, and a more gradual decrease during August. The observations shown in Fig. 4 are in general agreement with independent observations from different radars located at about the same geographical latitude (e.g., Balsley and Huaman, 1997; Kirkwood et al., 1998). Intrigued by the fact that the seasonal variation of the NLC occurrence rate is very similar (Gadsden, 1998), several authors have tried to relate the occurrence of PMSE to the occurrence of ice particles that may form in the period from end of May until the end of August because of the very low temperatures of the mesopause region (e.g., Lübken, 1999). Figure 5 shows a comparison of the NLC- and PMSE-occurrence rate as a function of season and the time and altitude range during which the degree of water ice saturation $\mathrm{S}$ is larger than 1 (Lübken, 1999). $\mathrm{S}$ is the ratio between the actual water vapor partial pressure and the saturation vapor pressure over ice which Lübken (1999) derived from a climatology of temperatures and air densities obtained with the falling sphere technique and water vapor mixing ratios from model simulations (Garcia and Solomon, 1994). The saturation water vapor pressure over ice was derived from the empirical formula of Marti and Mauersberger (1993). It is evident from this comparison that PMSE occur in exactly the height and time interval where ice particles can exist in the mesopause region and confirms earlier considerations that ice particles may play a decisive role in the creation of the radar echoes (Cho and Kelley, 1993; Cho and Röttger, 1997). Note that since the work of Lübken (1999) better data on both water vapor in the mesopause region and an updated empirical formula for the saturation vapor pressure have become available (Seele and Hartogh, 1999; Körner and Sonnemann, 2001; McHugh et al., 2003; Mauersberger and Krankowsky, 2003). However, including 
Table 1. PMSE studies at different frequencies.

\begin{tabular}{|c|c|c|c|}
\hline $\begin{array}{l}\text { Frequency } \\
\text { (Bragg scale) } \\
{[\mathrm{MHz}(\mathrm{m})]}\end{array}$ & Location & Reference & $\begin{array}{r}\text { Reflectivity } \\
{\left[\mathrm{m}^{-1}\right]}\end{array}$ \\
\hline $2.78(53.9)$ & Troms $\varnothing,\left(69^{\circ} \mathrm{N}\right)$ & Bremer et al. (1996b) & \\
\hline $8-9(18.8)$ & Vasil'surk, Russia $\left(56^{\circ} \mathrm{N}\right)$ & Karashtin et al. (1997) & \\
\hline $3.3,4.9,7.6$ & Gakona, Alaska, $\left(62^{\circ} \mathrm{N}\right)$ & Kelley et al. (2002) & \\
\hline $9,11,13.15$ & Hankasalmi, Finnland, $\left(62^{\circ} \mathrm{N}\right)$ & Ogawa et al. (2003) & \\
\hline $49.6(3.0)$ & Troms $\emptyset,\left(69^{\circ} \mathrm{N}\right)$ & Röttger et al. (1990) & $2.0 \cdot 10^{-12}$ \\
\hline $50.0(3.0)$ & Poker Flat $\left(65^{\circ} \mathrm{N}\right)$ & Ecklund and Balsley (1981) & \\
\hline & & Kelley and Ulwick (1988) & $9.0 \cdot 10^{-15}$ \\
\hline $51.5(2.9)$ & Resolut Bay $\left(75^{\circ} \mathrm{N}\right)$ & Huaman et al. (2001) & \\
\hline $53.5(2.8)$ & Andøya, $\left(69^{\circ} \mathrm{N}\right)$ & Inhester et al. (1990) & $4.0 \cdot 10^{-12}$ \\
\hline $53.5(2.8)$ & Svalbard, $\left(78^{\circ} \mathrm{N}\right)$ & Röttger (2001) & $2.2 \cdot 10^{-14}$ \\
\hline \multirow[t]{3}{*}{$224(0.67)$} & Troms $\varnothing,\left(69^{\circ} \mathrm{N}\right)$ & Hoppe et al. (1988) & $1.5 \cdot 10^{-16}$ \\
\hline & & Röttger et al. (1988) & \\
\hline & & Hocking and Röttger (1997) & $1.3 \cdot 10^{-15}$ \\
\hline $500(0.3)$ & Svalbard, $\left(78^{\circ} \mathrm{N}\right)$ & Röttger (2001) & $5.3 \cdot 10^{-19}$ \\
\hline $933(0.16)$ & Troms $\varnothing,\left(69^{\circ} \mathrm{N}\right)$ & Röttger et al. (1990) & $1.2 \cdot 10^{-18}$ \\
\hline $1290(0.12)$ & Sondrestrom, $\left(67^{\circ} \mathrm{N}\right)$ & Cho and Kelley (1992) & \\
\hline
\end{tabular}

this new information does not change the general conclusion that the PMSE- and ice particle- existence period and altitude region are identical.

\subsubsection{Latitudinal variation}

Apart from the aforementioned measurements at $\sim 65-69^{\circ} \mathrm{N}$, PMSE have also been observed as far North as $75^{\circ} \mathrm{N}$ and $78^{\circ} \mathrm{N}$ (Huaman et al., 2001; Rüster et al., 2001; Lübken et al., 2004) and as far South as $52-54^{\circ} \mathrm{N}$ where the echoes are then consequently called 'mesosphere summer echoes' or MSE (Czechowsky et al., 1979; Reid et al., 1989; Thomas et al., 1992; Latteck et al., 1999b; Zecha et al., 2003). While a lot of general features like the typical echo strengths and the altitude region of occurrence are independent of the geographic latitude, it has been found that the occurrence rate shows a pronounced gradient with latitude (all values for 1 July): the occurrence rate drops from almost $100 \%$ at $78^{\circ} \mathrm{N}$ (Lübken et al., 2004), $\sim 90 \%$ at $69^{\circ} \mathrm{N}$ (Bremer et al., 2003), to only $\sim 10-20 \%$ at $54^{\circ} \mathrm{N}$ (Zecha et al., 2003). This general picture is in line with recent $3 \mathrm{~d}$-model results of the thermal and dynamical structure of the mesosphere suggesting colder temperatures closer to the pole and hence a more favorable environment for the formation of ice particles (von Zahn and Berger, 2003). This picture is only 'disturbed' by the observations at Resolut Bay $\left(75^{\circ} \mathrm{N}\right)$ where low occurrence frequencies of less than $\sim 50 \%$ have been reported (Huaman et al., 2001).

Note though that occurrence frequencies reported from different stations and radars must be considered with some caution since the radars are not identical in design and hence do not have the same absolute sensitivity. In particular, it must be noted that the VHF radar at Resolut Bay operated at a significantly smaller peak transmitted power (i.e., only $12 \mathrm{~kW}$ compared to $36 \mathrm{~kW}$ in the case of the radars at $69^{\circ} \mathrm{N}$ and $54^{\circ} \mathrm{N}$, and even $60 \mathrm{~kW}$ in the case of the SOUSY Svalbard radar at $78^{\circ} \mathrm{N}$ ). Unfortunately, absolutely calibrated volume reflectivities from these radars are only available for some selected case studies (see Sect. 2.3.1) since absolute calibrations are extremely difficult to obtain. Nevertheless, in future experiments every effort should be undertaken to obtain PMSE measurements using calibrated signal strengths, since only this will allow to perform unambiguous comparisons of observations at different sites.

PMSE have also been observed at Southern latitudes even though significantly less frequent than in the Northern hemisphere (Balsley et al., 1993, 1995; Woodman et al., 1999; Ogawa et al., 2002; Hosokawa et al., 2004). Possible hemispheric differences in the thermal and dynamical structure have been discussed (Dowdy et al., 2001; Becker and Schmitz, 2003; Siskind et al., 2003; Chu et al., 2003), however, the experimental data base is scarce such that the reason for the apparent hemispheric asymmetry remains to be identified (Lübken et al., 1999).

\subsubsection{Long term and short term variations}

Recently, first results on long term changes of PMSE properties have been reported. Bremer et al. (2003) considered mean PMSE occurrence frequencies for the years 1994 through 2001 and found a significant positive correlation with the solar Ly- $\alpha$ radiation (the Ly- $\alpha$ flux varies by about 
EISCAT VHF Radar $(224 \mathrm{MHz})$

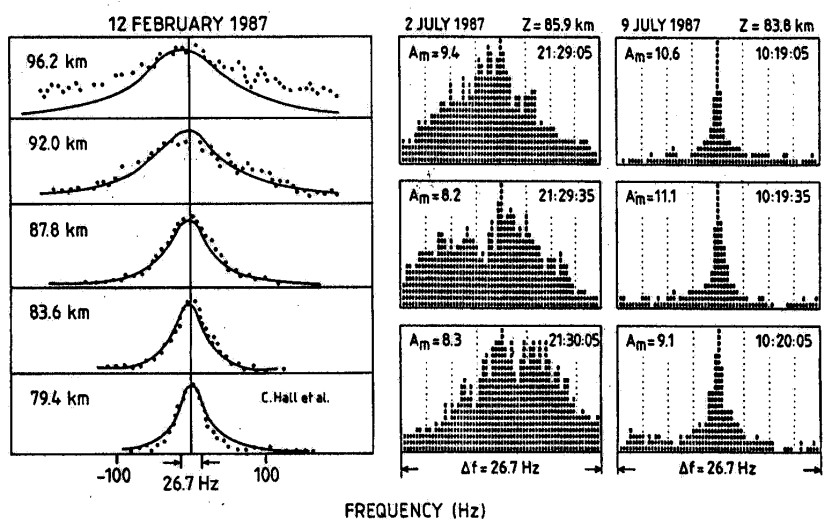

Fig. 6. Spectra of incoherent scatter signals (left panel) and of coherent-scatter polar mesosphere summer echoes measured with the EISCAT $224 \mathrm{MHz}$ radar in Troms $\varnothing$. This figure is reproduced from Röttger and LaHoz (1990).

a factor of 2 during one 11-year solar cycle). The authors concluded that the observed variation is due to changes in the background ionization that is mainly controlled by the ionization of NO due to Ly- $\alpha$. These arguments are in line with considerations by Rapp et al. (2002a) who argued that moderate changes of ionization should lead to a positive correlation with the PMSE signal strength.

On shorter time scales a variety of other physical processes altering PMSE properties have been identified. For example, Kirkwood and Rechou (1998) and Kirkwood et al. (2002b) demonstrated that PMSE were modulated by 5-day planetary waves. Hoffmann et al. (1999) reported a strong semidiurnal variation of both the SNR and the altitude where the maximum SNR was observed. This variation is in phase with similar semidiurnal variations in NLC properties (like centroid altitude and brightness) and has been traced back to the action of the semidiurnal tide with minor contributions from the diurnal variation of ionization (von Zahn et al., 1998; von Zahn and Bremer, 1999; Klostermeyer, 1999a). Other reasons for short term variability have been identified as solar and geomagnetic activity (Bremer et al., 1996a, 2001) as well as dynamical phenomena like e.g. gravity waves that mainly move the PMSE layers up and down and lead to substantial vertical velocities in PMSE reaching values of $\sim \pm 5 \mathrm{~m} / \mathrm{s}$ (e.g., Hoppe and Fritts, 1994, 1995; Rüster et al., 1996). In addition, low frequency gravity waves may occasionally also have a profound influence on the occurrence of PMSE (Chilson et al., 1997).

\subsection{Properties of PMSE layers}

\subsubsection{Radar frequency dependence}

One of the most striking properties of PMSE is the pronounced dependence of the absolute observed volume reflec- tivity (= the backscattering cross section per unit volume) on the radar frequency: since the first observations at $50 \mathrm{MHz}$, PMSE have been observed at a variety of frequencies between $2.78 \mathrm{MHz}$ and $1.29 \mathrm{GHz}$. Table 1 gives an overview of different studies published to date together with some of the most important results, including reported absolute volume reflectivities. Even though the different measurements of volume reflectivities were not performed at the same location and time (and must hence be compared with a cautionary note in mind since the geopyhsical situation is certainly different), it is evident from Table 1 that the volume reflectivity shows a tremendous decrease with increasing frequency (or decreasing Bragg scale). For example, from $50 \mathrm{MHz}$ to $500 \mathrm{MHz}$, the Bragg scale changes by only one order of magnitude, i.e., from $3 \mathrm{~m}$ to $30 \mathrm{~cm}$, but the corresponding reflectivities change by as much as 6 orders of magnitude. This frequency dependence certainly poses severe constraints on any physical explanation of PMSE - we will come back to this issue when we discuss possible physical explanations (see Sect. 3.3.2).

\subsubsection{Spectral shape}

Further information on the physical mechanism responsible for the creation of the electron irregularities leading to PMSE is obtained from the Doppler-broadened spectra of the received signals. As explained in detail for example in Hocking (1989), the Doppler spectral width yields information on the velocity variance of the detected scatterers in the radial direction (= the pointing direction of the radar beam). The highest precision data on PMSE spectral widths obtained so far have been measured with the EISCAT VHF radar operating at $224 \mathrm{MHz}$ (Röttger et al., 1988). This radar possesses the advantage of a narrow beam (i.e., only $1 \mathrm{~km}$ horizontal extent at $\sim 85 \mathrm{~km}$ ) such that the spectra are not significantly affected by effects like beam- or shear-broadening (Hocking, 1989). Figure 6 shows a comparison of the spectra of incoherent signals from the ionosphere (left panel) and coherent signals from a PMSE (right panel) after Röttger and $\mathrm{LaHoz}$ (1990). Figure 6 shows several interesting features: First of all, the comparison of the absolute spectral widths of incoherent and coherent spectra clearly demonstrates the completely different physical processes underlying the spectra: while the incoherent scatter spectra (being due to the Brownian motion of the electrons) show a typical width on the order of $\sim 100 \mathrm{~Hz}$ at $83.6 \mathrm{~km}$, corresponding spectra from the coherent echoes are much narrower, i.e., the broadest spectra only yield widths of $10-15 \mathrm{~Hz}$ and can be as narrow as $\sim 1$ Hz. Following Hocking (1985), Röttger et al. (1988) related these widths to turbulent rms-velocity fluctuations with corresponding values between $0.5-10 \mathrm{~m} / \mathrm{s}$. Rms-fluctuations as small as $0.5 \mathrm{~m} / \mathrm{s}$ underline the paradox already mentioned above: according to Hocking (1985) and Gibson-Wilde et al. (2000) the rms-velocity fluctuations $w_{r m s}$ may be converted to a turbulent energy dissipation rate by $\epsilon=2 \cdot \omega_{B} \cdot w_{r m s}^{2}$ where 
$\omega_{B}=\sqrt{\frac{g}{T}\left(\frac{d T}{d z}+\frac{g}{c_{p}}\right)}$ is the Brunt-Väisälä frequency (where $T$ is temperature, $g$ is the acceleration due to gravity, and $c_{p}$ is the specific heat of air at constant pressure). Using a typical value of $\omega_{B}=10^{-2} 1 / \mathrm{s}$ we see that $w_{r m s}=0.5 \mathrm{~m} / \mathrm{s}$ corresponds to $\epsilon=5 \times 10^{-3} \mathrm{~W} / \mathrm{kg}$. On the other hand, to have the inner scale of turbulence equal to the Bragg scale (which is $67 \mathrm{~cm}$ in the case of the EISCAT $224 \mathrm{MHz}$ radar), $\epsilon=5 \times 10^{4} \mathrm{~W} / \mathrm{kg}$ would be required. Hence, there is a discrepancy of seven orders of magnitude (!) between the required turbulent energy dissipation rate to explain the scatter as being due to pure neutral air turbulence and the value derived from the spectral width of the radar signal.

In addition, Röttger and LaHoz (1990) pointed out that also the spectral shape of the PMSE is significantly different from the usually assumed Lorentzian shape of incoherent scatter spectra (e.g., Hoppe and Hansen, 1988). Rather, the PMSE spectra appear as a superposition of several narrow band spectra (Fig. 6, spectra for 2 July 1987) or as a single high amplitude spike superimposed on a weaker and wider spectral background (Fig. 6, spectra for 9 July 1987). Röttger and LaHoz hypothesized that these signatures were due to fairly small and localized refractive index structures coexisting within the radar beam (i.e., within a volume of $1 \mathrm{~km}$ in vertical and $2 \mathrm{~km}$ in horizontal extent) which move with different velocities. This would further imply that the structures causing PMSE are unlikely to be filling the scattering volume homogeneously.

\subsubsection{Aspect sensitivity}

A further property of the radar echoes that can potentially teach us a lot about the physics of the scattering process and the nature of the scatterers is the so called aspect sensitivity. The aspect sensitivity describes the radar signal dependence when the beam is tilted from the vertical direction. In general, a strong signal decrease with increasing beam tilting angle implies that the observed scatterers are specular (like in the case of Fresnel scatter, i.e., scattering on single pronounced gradients in the electron number density that extent horizontally over several kilometers), whereas no signal dependence on the tilting angle is usually identified with isotropically oriented scattering structures as they would be expected in the case of three-dimensionally isotropic turbulence.

Quantitatively, the aspect sensitivity is usually expressed as the half width, $\theta_{S}$, of the angular polar diagram of the backscatter (Hocking et al., 1986). Hence, large values of $\theta_{S}$ imply a small aspect sensitivity and vice versa. Czechowsky et al. (1988) reported the first measurements of the aspect sensitivity of PMSE and found indeed a significant aspect sensitivity with $\theta_{s}$ between 2 and $10^{\circ}$. Interestingly, the results of Czechowsky et al. (1988) show large aspect sensitivities (small $\theta_{s}$ ) in the lower part of the PMSE layer coincident with rather small values of the observed spectral width and small aspect sensitivities (large $\theta_{S}$ ) in the upper part of the

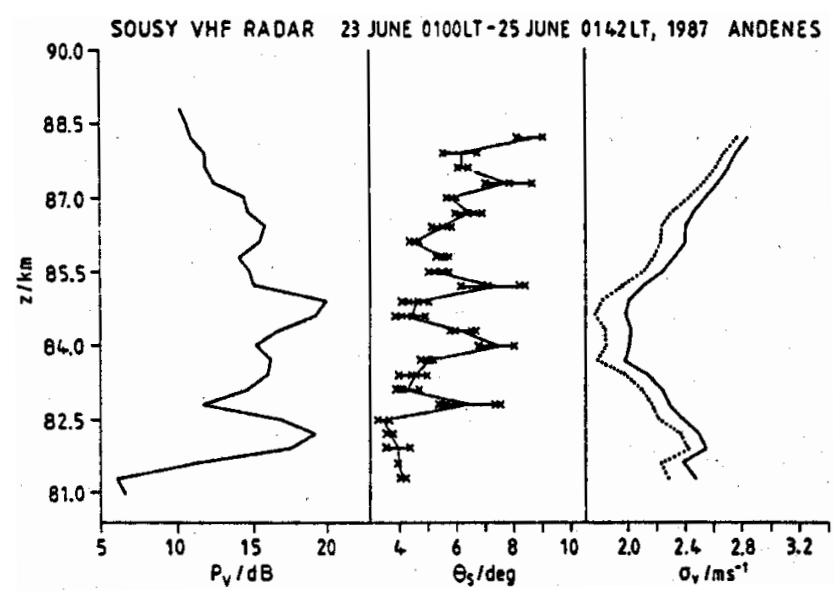

Fig. 7. (a) Mean power $\left(P_{V}\right)$ measured in the vertical beam direction for a two day period, (b) aspect sensitivity parameter $\left(\theta_{S}\right)$, and (c) mean spectral width for the vertical beam uncorrected (solid line) and corrected (dashed line) for beam broadening. This figure is reproduced from Czechowsky et al. (1988), copyright by the American Geophysical Union.

layer together with a considerably larger spectral width (see Fig. 7). This morphology of aspect sensitivity and spectral width suggests that in the upper part of the PMSE the scatterers are more isotropic ('turbulent') whereas they appear to be strongly stratified (specular or 'non-turbulent') in the lower part of the layer. Czechowsky and Rüster (1997) report that in $90 \%$ of their observations PMSE appear to have narrow spectral width and strong aspect sensitivity, whereas in $10 \%$ of their measurements they found cells of enhanced turbulence characterized by extremely broad spectral width that appear predominantly in the upper part of the PMSE-region, i.e., above $86 \mathrm{~km}$. Similar features were later confirmed by several independent investigators (e.g., Hoppe et al., 1990; Zecha et al., 2001, 2003; Chilson et al., 2002).

\subsection{Rocket borne observations}

Apart from the wealth of radar studies, PMSE have been investigated during several sounding rocket campaigns. In Table 2 we state a list of the campaigns conducted to date together with suitable references. The most important results derived from these measurements are summarized below.

\subsubsection{Evidence for ice particles causing PMSE}

While satellite measurements have recently proven that the particles forming NLC are indeed made of water ice (Hervig et al., 2001) a similar direct confirmation is missing so far for PMSE. However, very strong indirect evidence that PMSE are created through the involvement of water ice particles comes from in situ temperature measurements during the simultaneous observation of PMSE and common volume observations of PMSE and NLC (see Sect. 2.5). Inhester et al. 


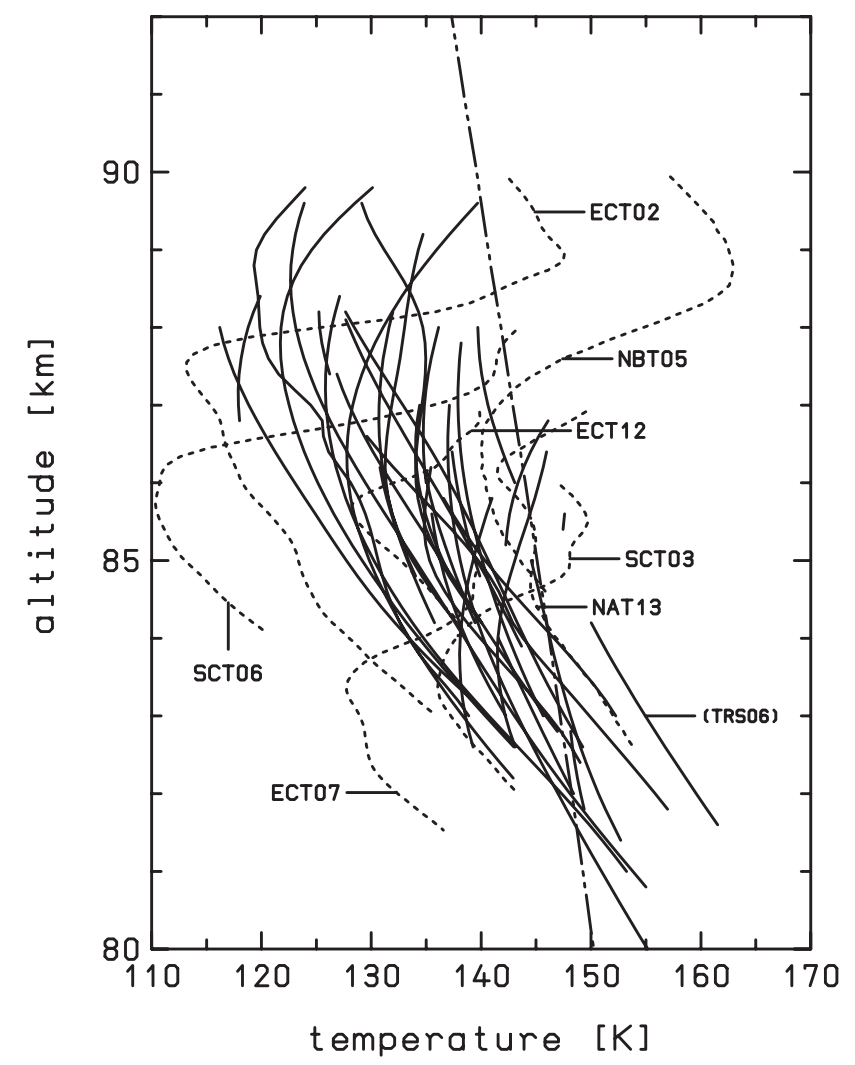

Fig. 8. Temperature profiles measured within PMSE layers. Measurements by the falling sphere technique (solid lines) and by the TOTAL/CONE ionization gauges (dotted lines) are shown. The dotted-dashed line presents the frost point temperature profile using the model $\mathrm{H}_{2} \mathrm{O}$ values from Körner and Sonnemann (2001). This figure is reproduced from Lübken et al. (2002), copyright by the American Geophysical Union.

(1994) reported a first systematic comparison of 22 temperature profiles measured with so called falling spheres and radar observations of PMSE (see e.g. Schmidlin, 1991, for a detailed discussion of the falling sphere technique). Inhester et al. (1994) found that the PMSE occurred in exactly the altitude range where the temperatures allowed the ice particles to exist. Recently, Lübken et al. (2002) have provided an update of this data base and compared additional falling sphere temperature measurements and temperature measurements that were performed with active ionization gauges with simultaneously measured PMSE profiles. The significant advantage of the ionization gauge measurements is their much better altitude resolution which is only $200 \mathrm{~m}$ independent of altitude and their high accuracy of better than 2\% (Rapp et al., 2001, 2002b). Hence, these measurements allow for a much more precise comparison of temperatures with PMSE since they also show the small scale structure of the temperature profile like for example gravity wave induced local temperature minima or maxima. Such features cannot be resolved by the falling sphere technique since the typical altitude res- olution of falling sphere measurements at PMSE altitudes is $\sim 5 \mathrm{~km}$ (Schmidlin, 1991). Figure 8 shows a comparison of these temperature measurements with the frost point temperature for water ice (calculated from the density climatology from Lübken, 1999, and water vapor mixing ratios from Körner and Sonnemann, 2001) in the altitude range where PMSE was observed during $\pm 0.5 \mathrm{~h}$ around the rocket launch. (This time interval was chosen in order to account for potential horizontal differences in the PMSE characteristics between the location of the radar and the location of the temperature measurements at a typical horizontal distance of $\sim 50 \mathrm{~km}$ ). Figure 8 shows that the majority of falling sphere temperatures and ionization gauge temperatures are lower than the frost point temperature, i.e., they allow for the existence of ice particles. There are only two remarkable 'outliers', i.e., the profiles from the falling sphere flight TRS06 and the ionization gauge flight NBT05 where the temperatures reach rather large values of $\sim 160 \mathrm{~K}$, which is approximately $10 \mathrm{~K}$ above the frost point temperature. However, in both cases a closer inspection of the PMSE measured during these rocket flights showed in fact that the PMSE had disappeared a few minutes prior to the sounding rocket flights. This is a remarkable correlation between the appearance of PMSE and the thermal structure and provides very strong evidence that PMSE are indeed directly linked to the existence of ice particles.

\subsubsection{Neutral air turbulence measurements}

As described above, the first attempts to explain PMSE also considered neutral air turbulence as a possible mechanism to create the fluctuations in the electron number density in one or the other way (see also Sect. 3), but this was soon contested and debated in view of the newer observations at even smaller wavenumbers with the EISCAT radars (Röttger et al., 1988; Hoppe et al., 1988).

During the NLC91 campaign, Lübken et al. (1993b) performed the first direct measurements of the turbulent energy dissipation rate in a PMSE layer. They measured fluctuations of neutral air density as a conservative and passive tracer for neutral air turbulence (see Lübken, 1992, for details on this technique) and identified turbulent fluctuations only in the upper part of the altitude range where the CUPRI radar (CUPRI $=$ Cornell University Portable Radar Interferometer, see Swartz et al., 1993) observed strong PMSE and concluded that processes different from neutral air turbulence must be responsible for the creation of at least the lower PMSE layer. These findings were further supported by different spectral shapes of electron irregularities in the upper and lower part of the PMSE as well as different spectral width of the radar signals in the two altitude parts (Ulwick et al., 1993; Cho et al., 1993).

Since these first observations of neutral air turbulence in the vicinity of PMSE, 12 additional rocket borne turbulence measurements at PMSE altitudes have been performed (2 

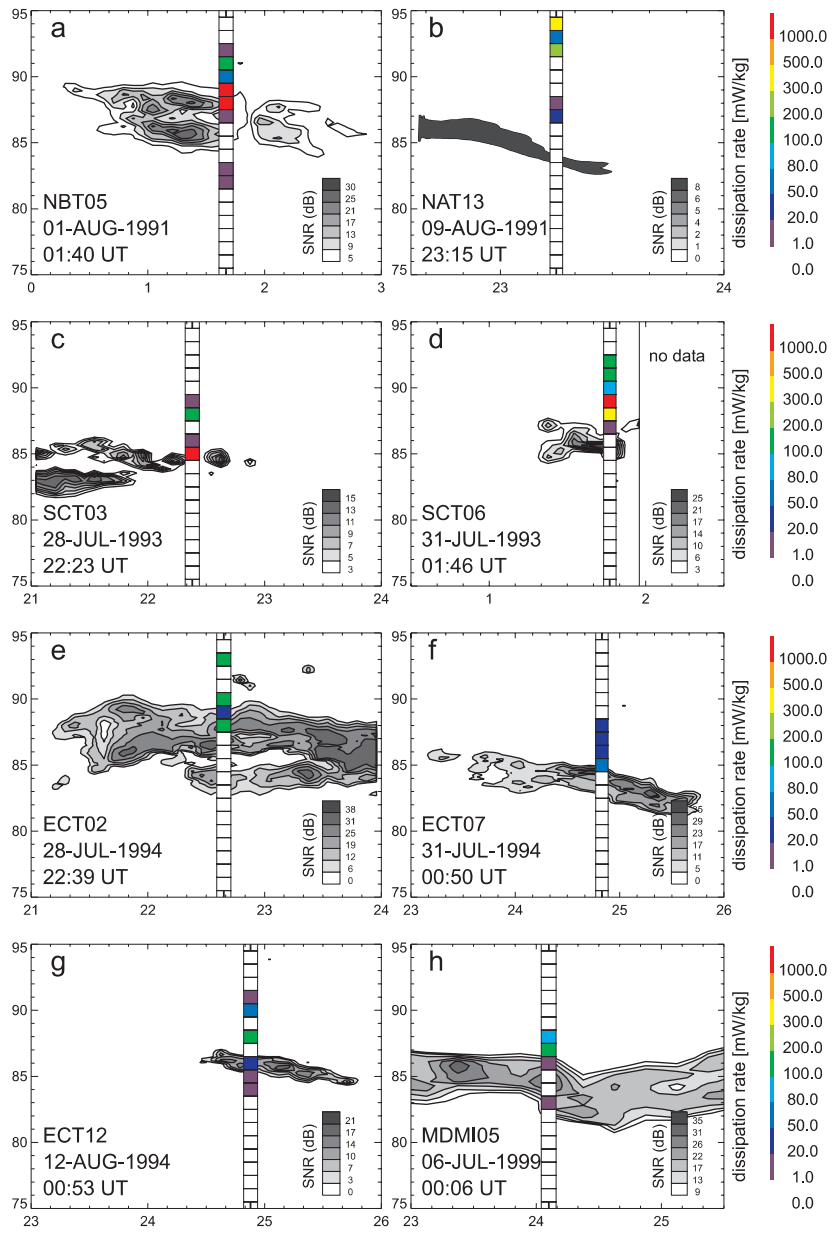

Fig. 9. Comparison of turbulent energy dissipation rates $\epsilon$ (color coded) and the PMSE intensity for 8 sounding rocket flights. This figure is reproduced from Lübken et al. (2002), copyright by the American Geophysical Union.

during the NLC91 campaign, 2 during the SCALE campaign, 3 during the ECHO campaign, 1 during the DROPPS campaign, 2 during the SOLSTICE campaign and 3 during the MIDAS/MACWAVE campaign; see Table 2). The results from the first 8 launches were summarized by Lübken et al. (2002). The turbulence measurements during the SOLSTICE campaign are reported in Müllemann et al. (2003) and results from the three sounding rocket flights during the MIDAS/MACWAVE campaign have just recently been published in Strelnikov et al. (2003) and Rapp et al. (2004), respectively. Individual comparisons of PMSE observations and turbulence measurements are shown in Fig. 9. It is evident from this figure that there is clearly no one to one correlation between the occurrence of turbulence and the occurrence of PMSE. Lübken et al. (2002) performed a statistical analysis of these data and found that in more than $50 \%$ of all altitude bins where PMSE was observed there was no neutral air turbulence present. If, however, turbulence and PMSE

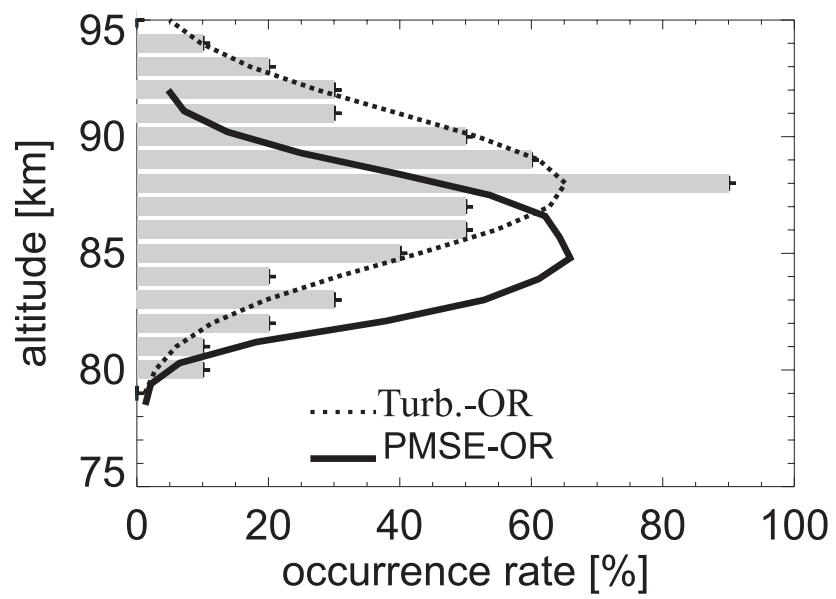

Fig. 10. Occurrence rates of PMSE (solid line) and neutral air turbulence (histogram and dashed line) according to Rapp and Lübken (2003a).

occurred at the same altitudes it regularly only happened in the upper portion of the PMSE layer (i.e., in flight NBT05, SCT06, ECT02, ECT07, MDMI05; it is worth noting here that this is also consistent with radar observations showing enhanced spectral widths predominantly in the upper altitude range of the PMSE layers; see for example Czechowsky et al.,1988). In addition, it must be noted that turbulence was often observed at altitudes where no PMSE was present, i.e., normally above the PMSE layer and in two cases (NBT05, ECT12) also below the PMSE layer. The more recent observations by Müllemann et al. (2003), Strelnikov et al. (2003), and Rapp et al. (2004) confirm this general picture of the morphology of turbulence and PMSE.

To summarize, in Fig. 10 we compare the occurrence rate of PMSE with the occurrence rate of neutral air turbulence as determined from the sounding rocket flights mentioned above (see Rapp and Lübken, 2003a, for details how these occurrence rates were determined). Figure 10 shows that in a climatological sense neutral air turbulence indeed occurs in the entire altitude range where PMSE is observed. At altitudes above $\sim 86 \mathrm{~km}$ the turbulence occurrence rate is even larger than the PMSE occurrence rate. At lower altitudes, however, the PMSE occurrence rate is significantly larger than the turbulence occurrence rate, for example at $85 \mathrm{~km}$ PMSE occur with a rate of $\sim 65 \%$ whereas turbulence only occurs with a rate of $\sim 35 \%$. Hence, at the lower altitudes in the PMSE altitude range, neutral air turbulence can clearly not directly account for the occurrence of PMSE.

\subsubsection{Electron biteouts and small scale plasma structures}

One of the most prominent features of the PMSE environment is the fact that the electron number density appears to be frequently disturbed in the altitude region of the radar echoes. Figure 11 shows one of the earliest observations from the 
Table 2. Sounding rocket campaigns dedicated to the study of PMSE.

\begin{tabular}{lrrr}
\hline Campaign & Location & Date & Reference \\
\hline STATE & Poker Flat, Alaska & June 1983 & Ulwick et al. (1988) \\
MAC/SINE & Andøya, Norway & July 1987 & Inhester et al. (1990) \\
NLC91 & Kiruna, Sweden & July/August 1991 & Goldberg et al. (1993) \\
SCALE & Andøya, Norway & July/August 1993 & Blix (1999) \\
ECHO & Andøya, Norway & July/August 1994 & Havnes et al. (1996b) \\
DROPPS & Andøya, Norway & July 1999 & Goldberg et al. (2001) \\
SOLSTICE & Andøya, Norway & June 2001 & Smiley et al. (2003) \\
MIDAS/MACWAVE & Andøya, Norway & July 2002 & Blix et al. (2003a) \\
\hline
\end{tabular}

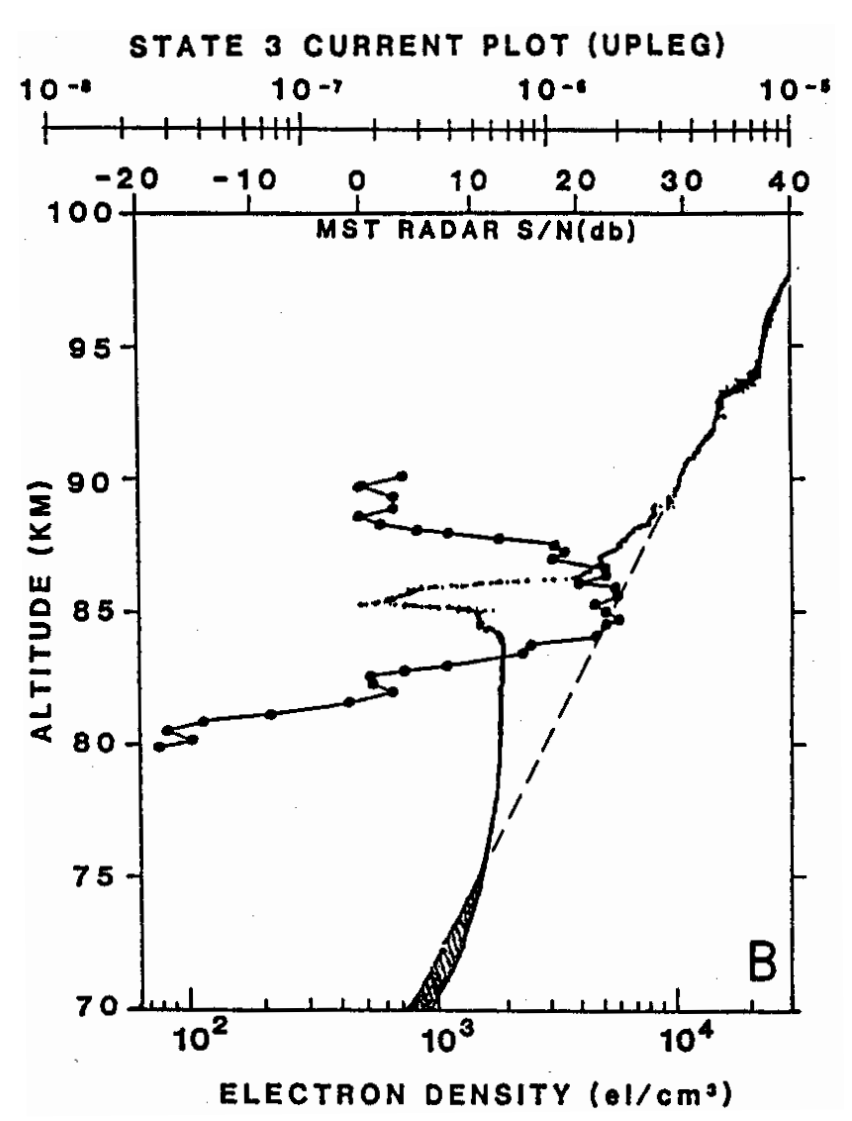

Fig. 11. Height profiles of rocket borne DC probe measurements of the electron number density (solid line) and VHF radar echoes (solid circles) for the STATE-3 rocket flight conducted on 17 June 1983 from Poker Flat, Alaska. The dashed line illustrates a more typical D-region electron number density. This figure is reproduced from Ulwick et al. (1988), copyright by the American Geophysical Union.

STATE campaign in 1983 (Ulwick et al., 1988). Figure 11 shows that the electron number density is depleted by as much as a factor of ten in the altitude region where strong echoes were observed from the Poker Flat VHF radar. Ever since the STATE observations, similar depletions of the electron number density, also called 'biteouts', were observed in almost all rocket borne electron number density measurements in the vicinity of PMSE (see Table 2 for suitable references) and could also be detected with incoherent scatter radars in the UHF wavelength range (Röttger et al., 1990). Hence, they must be considered as a typical feature of the PMSE environment. In Sect. 3 we address our understanding of this feature in detail and show that the electron biteouts are direct evidence for the presence of charged ice aerosol particles at PMSE altitudes. Note also that such biteouts were observed much earlier than PMSE itself (e.g., Pedersen et al., 1969) - see Lübken and Rapp (2001) and Friedrich et al. (1994) for overviews of plasma measurements in the high latitude summer mesopause region.

Apart from this large scale characteristics of the electron number density in the PMSE altitude range, Ulwick et al. (1988) further showed that the observed radar echoes are quantitatively characterized by the structure of the electron profile at the radar Bragg scale: following the work of Røyrvik and Smith (1984) (who made similar rocket measurements in order to explain VHF echoes at $\sim 70 \mathrm{~km}$ altitude observed at Jicarmarca, Peru, $11.95^{\circ} \mathrm{S}$ ) they directly computed the radar signal to noise ratio from the power spectral density of the measured electron number density irregularities at the Bragg scale and found a very good quantitative agreement. These results were later confirmed by several independent investigators (Inhester et al., 1990; Lübken et al., 1993b; Blix et al., 2003c) and hence showed that the characteristics of PMSE observations are consistent with the assumption of volume scatter from electron number density irregularities and can not be due to specular reflections from single steep gradients as they appear for example at the edges of the electron biteouts (see also Hocking and Röttger, 1997, for a discussion of the feasibility of specular reflection to explain PMSE). Still, it must be noted that the aspect sensitivity of PMSE shows that the scattering structures can not be purely isotropic. See Sect. 2.3.3 for a more detailed discussion of this particular point. 


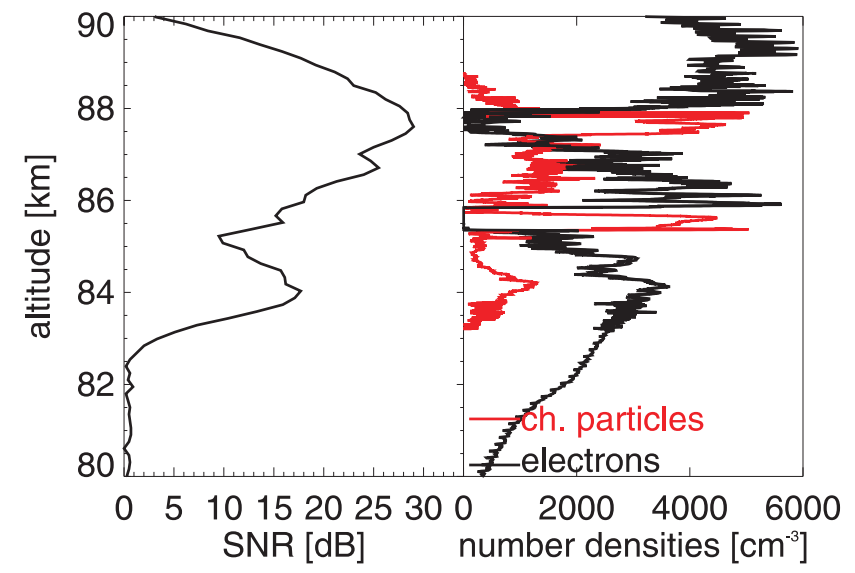

Fig. 12. Left panel: Profile of the radar signal to noise ratio (SNR) measured with the ALOMAR-SOUSY VHF radar during sounding rocket flight ECT02. Right panel: profiles of electron number densities (black line) and aerosol charge number densities (red line) measured during sounding rocket flight ECT02. These data are taken from Havnes et al. (1996b) and Lübken et al. (1998).

\subsubsection{Observation of charged ice particles}

While the observation of electron biteouts, the occurrence of PMSE in the vicinity of noctilucent clouds (see Sect. 2.5), and the tight coupling of the seasonal dependence of PMSE and NLC occurrence provided strong evidence that PMSE are closely related to aerosol particles, the first direct in situ measurement of (charged) ice particles ${ }^{1}$ in an PMSE environment must be considered as one of the major steps towards an understanding of PMSE. The pioneering work was done by Havnes et al. (1996b) who applied a Faraday-cup-like instrument (the 'DUSTY'-detector) to measure the charge number density associated with the particles. Figure 12 shows the first altitude profile of charged aerosol particles measured during the ECHO sounding rocket campaign from the Norwegian Andøya Rocket Range on 28 July 1994. Havnes et al. (1996b) observed negatively charged particles in two distinct layers, one centered at $87.5 \mathrm{~km}$ and the other centered at $85.5 \mathrm{~km}$ altitude. Most interestingly, the measurement of the number density of free electrons made on the same sounding rocket revealed two distinct electron biteouts exactly at the same altitudes indicating that biteouts form because the aerosol particles act as an efficient sink for electrons (and hence acquire a net negative charge; see Sect. 3). During the same campaign, Havnes et al. (1996b) also observed a layer of positively charged aerosol particles collocated with an electron enhancement (instead of the more common biteout) in the altitude range where a noctilucent

\footnotetext{
${ }^{1}$ Note that we distinguish between particles and large cluster ions: while the largest cluster ions reported from measurements in the mesosphere so far had masses of less than a couple of hundred amu, particles are considered to be more massive than several thousand amu.
}

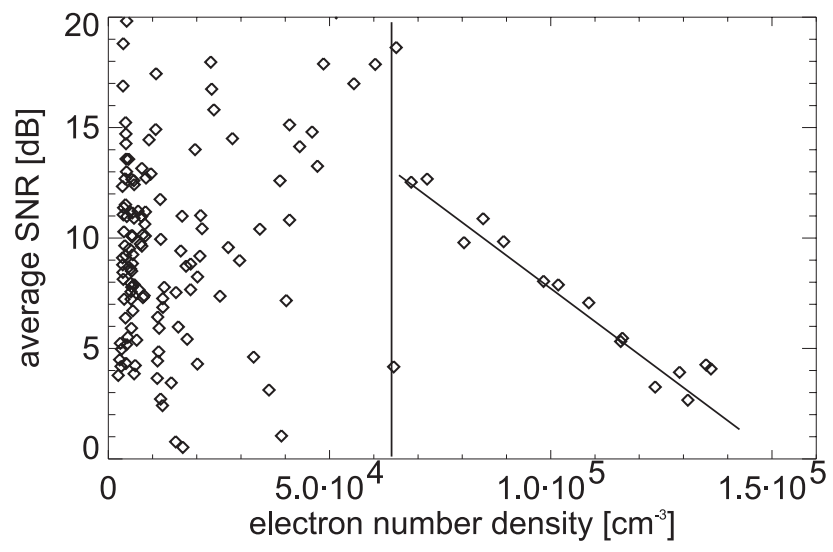

Fig. 13. Scatter plot showing the dependence of the PMSE SNR values on the electron number densities at $87 \mathrm{~km}$ during the major solar proton event on 14 July 2000 . While no correlation is detectable for electron number densities lower than $\sim 7 \cdot 10^{4} / \mathrm{cm}^{3}$ a clear anti-correlation is observed for higher electron number densities. This figure is reproduced from Rapp et al. (2002a), copyright by the American Geophysical Union.

cloud was observed by a ground based lidar. These measurements are however much more difficult to explain than the observations of negatively charged particles. In subsequent campaigns, several investigations have provided further evidence for the existence of negatively charged aerosol particles in PMSE (Havnes et al., 2001; Mitchell et al., 2001, 2003; Smiley et al., 2003). Concerning positively charged particles there seem to be further indications that they do exist (Mitchell et al., 2001, 2003; Smiley et al., 2003), however, our current understanding of these measurements is far from being conclusive.

\subsubsection{The charge balance at PMSE altitudes}

As seen in the previous section, the plasma environment of PMSE is characterized by the presence of electrons, positive ions and charged particles. In the theoretical treatment of PMSE (see Sect. 3 below) it was suggested that the relative abundance of these different species is a critical parameter. Following the work by Cho et al. (1992), this relative abundance is typically quantified by the ratio between the charge number density of the aerosol particles $\left(\left|Z_{A}\right| N_{A}\right)$ and the free electron number density $\left(N_{e}\right)$ and several authors claimed that this ratio should be larger than $\sim 1$ for PMSE to occur (i.e., the charge balance should be dominated by the abundance of charged aerosol particles, see e.g., Cho et al., 1992; Hagfors, 1992).

First doubts if this condition is indeed satisfied under real PMSE conditions arose when Havnes et al. (2001) reported measurements of the aerosol charge number density and the electron number density from a miniaturized sounding rocket launched into a PMSE event. These measurements showed 

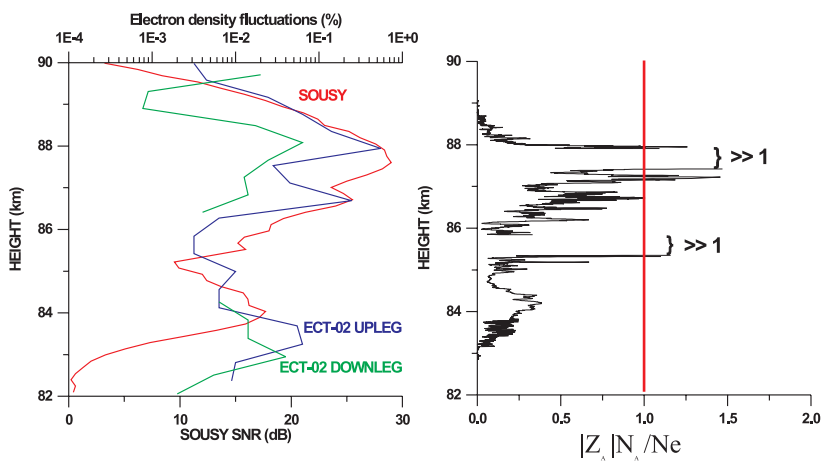

Fig. 14. Left panel: Comparison of radar power in $\mathrm{dB}$ and electron number density fluctuations in $\%$ at $3 \mathrm{~m}$ scale measured on both upleg and downleg of the ECT02 flight. Right panel: Calculated ratio between aerosol charge number density $\left(\left|Z_{A}\right| N_{A}\right)$ and electron density $\left(N_{e}\right)$ for the upleg part of the ECT02 flight. The red vertical red lines mark ratios of $\left|Z_{A}\right| N_{A} / N_{e}=1$. This figure is reproduced from Blix et al. (2003c), copyright by the American Geophysical Union.

a nice correspondence between the general occurrence of charged particles and PMSE, however, Havnes et al. (2001) also noted that PMSE occurred in altitude regions where the ratio $\left|Z_{A}\right| N_{A} / N_{e}$ was as small as 0.05 .

In a completely different study, Rapp et al. (2002a) investigated the PMSE dependence on the background electron number density during the strong solar proton event on 14 July 2000. These authors found a significant negative correlation between electron number densities determined from flux measurements of energetic protons from the geostationary GOES-8 and ACE satellites and PMSE observed with the ALWIN VHF radar at the Andøya Rocket Range $\left(69^{\circ} \mathrm{N}\right)$ for electron number densities larger than a threshold value of $\sim 7 \cdot 10^{5} / \mathrm{cm}^{3}$ (see Fig. 13). Rapp et al. (2002a) argued that the overall decay of the PMSE during a significant rise of the background ionization was expected on the ground of the Cho et al. (1992) theory since a rise in $N_{e}$ would correspond to a decrease in $\left|Z_{A}\right| N_{A} / N_{e}$ such that at a certain threshold value the electron diffusivity should not be reduced any more. However, these authors were also puzzled by the fact that the PMSE was unaffected for a very wide range of electron number densities, i.e., between some $10^{3}$ electrons $/ \mathrm{cm}^{3}$ up to $\sim 7 \cdot 10^{5} / \mathrm{cm}^{3}$ and pointed out that current knowledge about the abundance of aerosol particles at mesopause altitudes and their charging properties could not explain that $\left|Z_{A}\right| N_{A} / N_{e}$ remained larger than $\sim 1$ for all these electron number densities. Rapp et al. (2002a) concluded that '.. either our current understanding of the nucleation of ice particles in the polar summer mesopause region is incomplete or that current PMSE theories (i.e., the Cho et al., 1992-theory) fail in their interpretation of the role of charged aerosol particles'.

Motivated by these observations, Blix et al. (2003c) performed a detailed comparison of $\left|Z_{A}\right| N_{A} / N_{e}$ and PMSE pro- files. These authors derived $\left|Z_{A}\right| N_{A} / N_{e}$ from in situ measurements of either positive ion and electron number densities (making use of the assumption of local charge neutrality, i.e., the assumption that the sum of all charges over length scales significantly larger than the Debye-length of the plasma is zero) or directly from aerosol charge number densities and electron number densities. As an example, Fig. 14 shows the comparison of the $\left|Z_{A}\right| N_{A} / N_{e^{-}}$and PMSE profile as measured on sounding rocket ECT02 during the ECHO campaign (see Table 2). The comparison of electron number density fluctuations at the Bragg scale $(3 \mathrm{~m})$ and the power received by the ALWIN radar shown in the left panel of Fig. 14 showed that the radar echoes were indeed due to the small scale structure of the electron number density as expected. (Technically speaking, this consistency also proves that the sounding rocket indeed probed the PMSE observed with the ground based VHF radar.) The comparison of $\left|Z_{A}\right| N_{A} / N_{e}$-values within the PMSE layer shown in the right panel, however, showed that $\left|Z_{A}\right| N_{A} / N_{e}$ was smaller than 1 in almost the entire altitude range where PMSE (and strong fluctuations in the electron number density) were observed. Blix et al. (2003c) considered a total of four sounding rocket flights and found that only in $15 \%$ of all altitude bins with PMSE $\left|Z_{A}\right| N_{A} / N_{e}$-values larger than 1 were observed and that even in $\sim 75 \%$ of all altitude bins $\left|Z_{A}\right| N_{A} / N_{e}$ was smaller than 0.5 .

Taken together, these observations showed that the plasma environment of PMSE does not need to be dominated by the concentration of charged aerosol particles, though the presence of these charged particles is indeed a necessary condition for the existence of the radar echoes.

\subsubsection{Electric field measurements in PMSE}

Electric field measurements in PMSE layers have proven to be extremely difficult to perform because of the severe interaction of the charged aerosol particles with the supersonically moving sounding rocket payload. Zadorozhny et al. (1993) reported strong electric fields on the order of $\sim 1 \mathrm{~V} / \mathrm{m}$ in a PMSE layer, however, based on laboratory investigations on the impact of supersonic water clusters on their electric field mill, they later published corrections with values of about the same order of magnitude (Zadorozhny et al., 1997). In a more recent investigation, Holzworth et al. (2001), applying a different technique, also found strong $\mathrm{V} / \mathrm{m}$ perturbations at PMSE altitudes. However, Holzworth et al. (2001) also showed that these signatures were artificially created by payload/charged particle flow interactions during the traverse of the PMSE layer and concluded that if there was any DCelectric field, it was smaller than just a few ten $\mathrm{mV} / \mathrm{m}$. Pfaff et al. (2001) analyzed the same data set for small scale irregularities and identified small scale structures with amplitudes of $\sim 10 \mathrm{mV} / \mathrm{m}$ that they claimed were not artificially created but geophysical. In summary, electric field measurements conducted to date do not yield a conclusive picture such that 


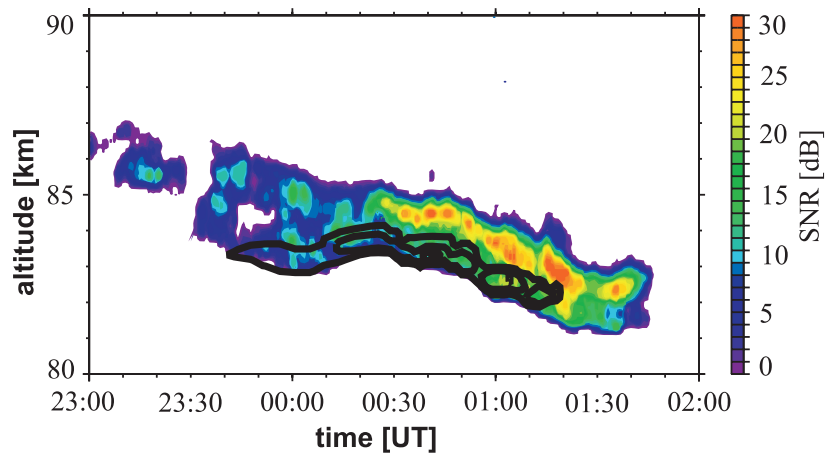

Fig. 15. Radar signal to noise ratio (SNR, colored contours) detected with the ALOMAR SOUSY radar as a function of altitude and time. The black isolines mark the noctilucent cloud detected by the ALOMAR RMR lidar. This figure is reproduced from Nussbaumer et al. (1996), copyright by the American Geophysical Union.

further experimental efforts are needed to obtain quantitative results on the strength of large and small scale electric fields at PMSE altitudes.

\subsection{Common volume observations with NLCs}

Also common volume observations of noctilucent clouds and PMSE confirmed the close relationship between the radar echoes and ice particles in the mesopause region. Nussbaumer et al. (1996) presented the first common volume observation of a noctilucent cloud with the ALOMAR RMRlidar and a PMSE with the ALOMAR SOUSY radar at the Andøya Rocket Range (von Zahn et al., 2000; Singer et al., 1995). As shown in Fig. 15, these authors found a close relationship between the two phenomena with the NLC layer located at the lower edge of the PMSE layer in most of the cases. von Zahn and Bremer (1999) significantly expanded the data base presented in this first study by analyzing a total of 22 joint NLC/PMSE observations and basically confirmed the close relationship between NLC and PMSE. Altogether, they identified three distinct empirical types of PMSE/NLC observations: in the standard case (= type 1 ; in $66 \%$ of all observations), NLC and PMSE occurred simultaneously in the same volume, with the NLC layer located in the lower part of the PMSE layer and with identical lower edges. Type 2 allowed for temporal differences between the layers, i.e., at times there were NLC present but no PMSE (in 16\% of all observations), and type 3 allowed for spatial differences between the layers, i.e., at times the NLC was not located at the lower edge of the PMSE (in 21\% of all observations). The close coupling of NLC and PMSE is further strong evidence that ice particles play a substantial role for the creation of the radar echoes. In particular, the frequent occurrence of type 1 observations leads to the conclusion that NLC are evidence of the particles that have grown large enough to be visually observable whereas PMSE are related to both large
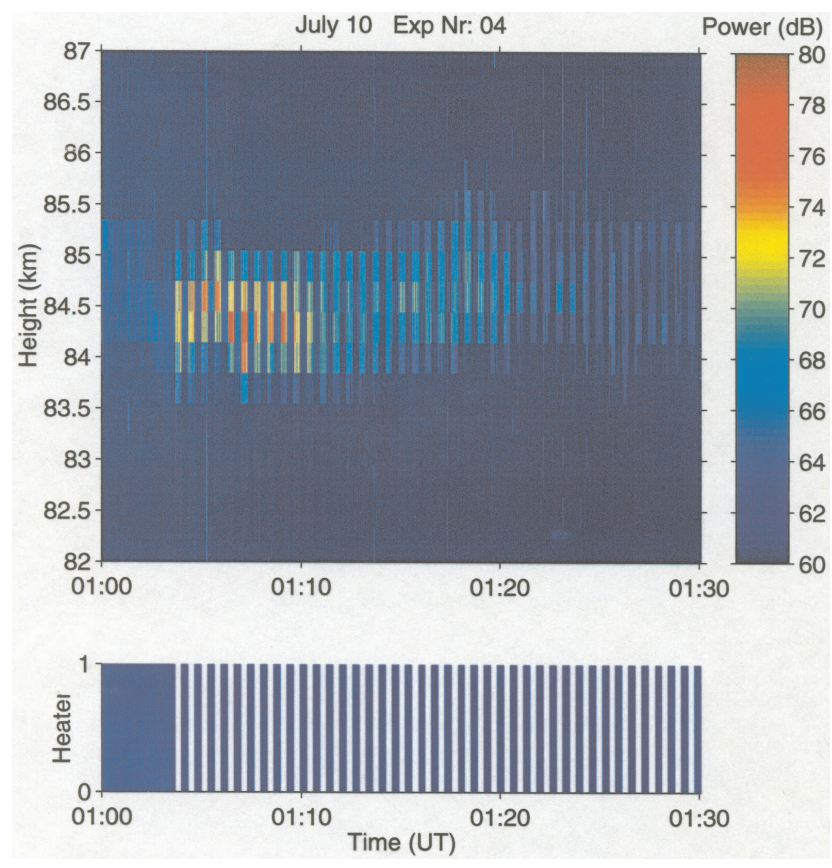

Fig. 16. Upper panel: PMSE observed with the EISCAT VHF radar at Troms $\varnothing$ on 10 July 1999 . The lower bar code indicates when the heater was turned on (blue) and off (white), respectively. This figure is reproduced from Chilson et al. (2000), copyright by the American Geophysical Union.

(i.e., when they coincide with NLC) but also the smaller ice particles that are not yet visually observable. These conclusions are in line with the standard growth and sedimentation scenario of mesospheric ice particles. In this scenario it is considered that the ice particles nucleate at the altitude with largest supersaturation (i.e., close to the mesopause) and then grow by further condensation of water vapor onto their surface. Then the particles sediment down due to gravity, and gain further size until they are large enough to be visually observed as NLC (see also Turco et al., 1982, and Sect. 3.1).

\subsection{Active modulation of PMSE: the heating experiments}

Recently, Chilson et al. (2000) have opened a new experimental 'window' for the study of PMSE: these authors used a powerful HF heater in order to modify the electron temperature at altitudes where PMSE was simultaneously observed with the EISCAT VHF radar to temperatures of $\sim 3000 \mathrm{~K}$ (Belova et al., 2001). Stunningly, the PMSE immediately disappeared when the electron gas was heated and immediately reappeared when the heater was switched off (see Fig. 16).

While Chilson et al. (2000) used a rather short cycling of heater 'on' and 'off' phases, Havnes et al. (2003) applied a different heating sequence with a short heating period followed by a long heater 'off' phase. As shown in Fig. 17, these authors observed a strengthening of the PMSE after the 

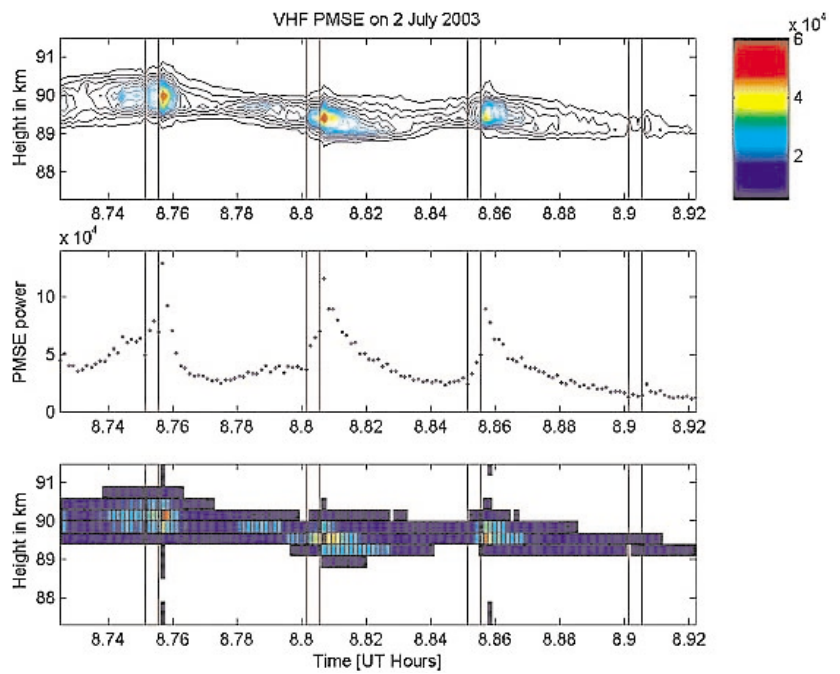

Fig. 17. String of four PMSE 'overshoots' in a 12-min interval on 2 July 2003. The bottom figure shows the raw data observed with the EISCAT VHF radar, while the top figure shows the same data but smoothed. The middle figure shows the sum of the three highest intensities at each time sample and is a measure of the total PMSE intensity as a function of time. The vertical lines indicate the periods when the heater was switched on. This figure is reproduced from Havnes et al. (2003), copyright by the American Geophysical Union.

initial reduction during the periods of enhanced electron temperatures.

Both effects, the weakening of the PMSE at times of enhanced electron temperatures and the strengthening if a long recovery time during two heater 'on' phases is allowed for, have been convincingly explained in the meantime. For a detailed description of the theoretical understanding of both effects see Sect. 3.3.3.

\section{Physical mechanisms}

\subsection{Ice particles in the polar summer mesopause}

As repeatedly mentioned above, there is compelling evidence that the presence of ice particles is a major prerequisite for the existence of PMSE. Thus we start our review of the current understanding of PMSE with a short description of the general microphysical life cycle of ice particles in the vicinity of the polar summer mesopause.

Starting with the comprehensive pioneering work by Turco et al. (1982) microphysical models of the generation and growth of mesospheric aerosol particles have been a major tool for identifying the relevant physical processes. After this initial study, similar microphysical models were successfully applied to the interpretation of satellite borne observations of polar mesospheric clouds (PMC $=$ NLC observed from space) with the SME satellite (Jensen and Thomas, 1988;
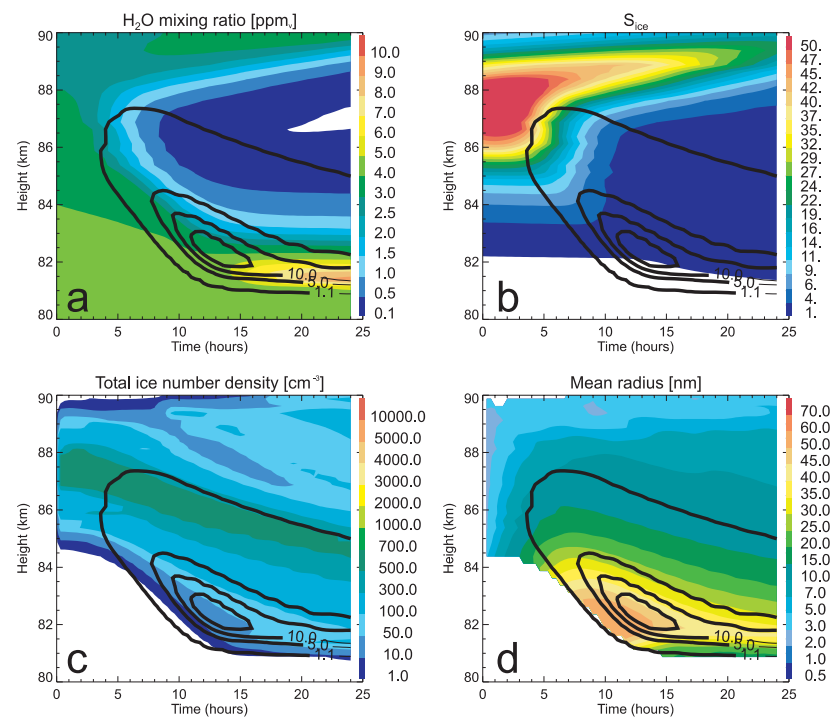

Fig. 18. Time-altitude dependence of water vapor mixing ratio, saturation ratio, total ice number density and mean ice radius during the formation and growth of a noctilucent cloud. The black isolines overlayed on each plot show lines of constant backscatter ratio as it would be observed by a lidar with a laser wavelength of $532 \mathrm{~nm}$ (after Rapp et al., 2002b, copyright by the American Geophysical Union).

Jensen et al., 1989; Jensen and Thomas, 1994) and to the interpretation of combined rocket borne and ground based measurements of relevant parameters like the local thermal and dynamical structure and the brightness of the ice particles when being probed by a lidar (Rapp et al., 2002b).

These models treated three completely interactive constituents: meteoric smoke particles which act as the condensation nuclei of the ice particles, ice particles, and mesospheric water vapor. The height profile and the size distribution of meteoric smoke particles were calculated as described in Hunten et al. (1980). For the ice particles, microphysical processes like nucleation, condensational growth, and coagulation were treated, as well as particle sedimentation and transport. Figure 18 shows the results of such a microphysical model simulation taken from the work by Rapp et al. (2002b). Figure 18 reveals the picture of the well known growth and sedimentation scenario of mesospheric ice particles. Ice particle nucleation on meteoric smoke particles takes place at the altitudes with the lowest temperatures and hence largest saturation ratios $\mathrm{S}$ (= ratio between water vapor partial pressure and saturation pressure over water ice), i.e., between 84 and $90 \mathrm{~km}$ altitude yielding ice particle number densities close to $\sim 10^{3} \mathrm{~cm}^{-3}$. The particles then sediment down due to their gravity and further grow by direct condensation of water vapor onto their surface reaching maximum mean particle radii between 40 and $50 \mathrm{~nm}$. The potential optical signature of these ice particles is indicated by the black isolines which show values of the backscatter ratio BSR that 
would be observed by a lidar at $532 \mathrm{~nm}$ wavelength (BSR $=$ total received signal at a certain altitude divided by the signal due to pure molecular Rayleigh scattering. BSR $>1$ when Mie scattering due to ice particles enhances the scatter significantly over the Rayleigh background). The maximum brightness is reached at altitudes of $\sim 81.5 \mathrm{~km}$ with corresponding particle radii of $\sim 40 \mathrm{~nm}$ and number densities of $50-100 \mathrm{~cm}^{-3}$. These numbers are generally consistent with values derived from multi-color lidar observations by von Cossart et al. (1999). Figure 18a further shows that the formation and growth of the ice particles leads to significant redistribution of water vapor due to the freeze drying effect (because the ice particles 'consume' the available water vapor when they grow) and subsequent deposition of the ice contained water vapor at the bottom of the cloud. Note that recent satellite water vapor measurements indeed find evidence for this local water vapor maximum at the cloud bottom height (e.g., Summers et al., 2001; McHugh et al., 2003).

Besides these studies that aimed at understanding the general microphysics, progress has also been made in the modeling of large scale and even global structures of these ice clouds. In particular, Berger and von Zahn (2002) and von Zahn and Berger (2003) have recently presented the first model study of global features of the mesospheric ice particle population by combining a microphysical ice particle model with a 3-dimensional general circulation model of the middle atmosphere.

\subsection{Aerosol charging}

As seen in Sect. 2.4.4, mesospheric ice particles modify the charge balance of the ionospheric D-region plasma. This is particularly evident from the observations of strong depletions in the electron number density at PMSE altitudes which show that the aerosol particles act as a sink for the electrons and hence become negatively charged. Reid (1990) was the first to consider this process quantitatively: based on the electron and positive ion capture rates due to Natanson (1960) he studied the concentration of singly and doubly charged ice particles and the feedback of their charging on the background electron and positive ion number density as a function of the number density of available ice particles. Keeping also the ice-equivalent water vapor content inside reasonable limits, Reid (1990) concluded that several thousand ice particles per cubic-centimeter with a radius of $\sim 10 \mathrm{~nm}$ were the most likely candidate to explain the observed biteouts in the free electron number density. Consequently, most of the ice particles should be singly negatively charged. The drawback of this study, however, was its restriction to singly and doubly charged particles such that Jensen and Thomas (1991) developed this model further by allowing for an arbitrary negative particle charge and derived the statistical charge distribution as a function of particle radius for standard background conditions of the D-region (production rate of electrons and pos-

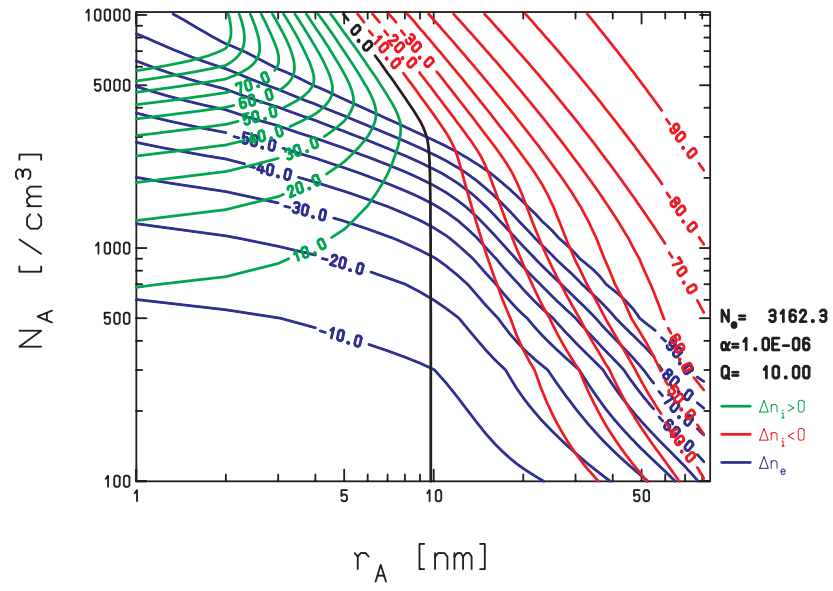

Fig. 19. Relative disturbance of electron (blue lines) and positive ion number density (green and red lines), $\Delta n_{e}$ and $\Delta n_{i}$ in percent, as a function of the particle radius, $\mathrm{r}_{A}$, and number density, $\mathrm{N}_{A}$. The calculations have been perfomed for an electron/ion production rate $\mathrm{Q}=10 /\left(\mathrm{cm}^{3} \mathrm{~s}\right.$ ) and a recombination coefficient $\alpha=10^{-6} \mathrm{~cm}^{3} / \mathrm{s}$ (Rapp and Lübken, 2001).

itive ions $\mathrm{Q}=10^{7} \mathrm{~m}^{-3} \mathrm{~s}^{-1}$ and electron-positive ion recombination rate $\alpha=10^{-12} \mathrm{~m}^{3} \mathrm{~s}^{-1}$, corresponding to an undisturbed plasma density of $\sqrt{Q / \alpha} \approx 3 \cdot 10^{9} \mathrm{~m}^{-3}$ which is a reasonable value for the polar D-region; Friedrich and Torkar, 2001). Jensen and Thomas (1991) found an average aerosol charge of $-1 e$ for particles with radii between 1 and $10 \mathrm{~nm}$, and then a linear increase of the aerosol charge, i.e., $\sim-2 e$ for $30 \mathrm{~nm}$ particles and $-3 e$ for particles with a radius of $50 \mathrm{~nm}$ (with $e$ being the elementary charge). These results were then further generalized by Rapp and Lübken (2001) who also systematically considered the dependence of the aerosol charge on the background plasma conditions and studied the expected response not only of the electron number density but also the positive ion number density. Figure 19 shows the change of the electron and positive ion number density relative to a background where no particles are present as a function of both particle number density $N_{A}$ and particle radius $r_{A}$. Rapp and Lübken (2001) pointed out that the ice particles leave a characteristic 'fingerprint' in the plasma if the effect on both electrons and ions is considered: while the electron number density is expected to be depleted for all aerosol particle parameters considered, the positive ion number density can be either depleted (when being controlled by the capture on the ice particles) or even enhanced (when being controlled by the recombination with electrons). Hence, Rapp and Lübken (2001) showed that the combined measurement of the disturbance in the electrons and ions allows for a characterization of the aerosol particles themselves. This idea was then applied by Lübken and Rapp (2001) who derived aerosol parameters like radii and number densities from the observation of positive ion and electron disturbances under PMSE and/or NLC conditions. In summary, the interaction of the 


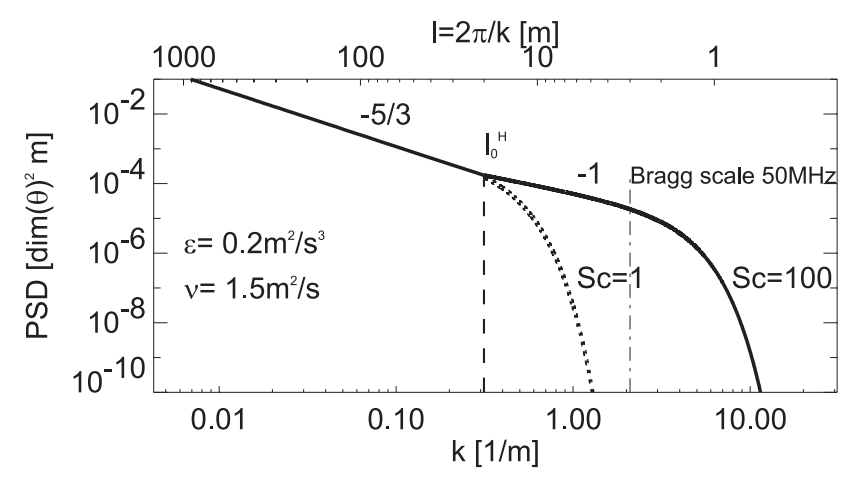

Fig. 20. Power spectral densities (PSD) of a passive tracer $\theta$ for two different Schmidt numbers of $\mathrm{Sc}=1$ and $\mathrm{Sc}=100$, respectively. The upper ordinate converts wavenumbers to lengths. The numbers ' $-5 / 3$ ' and ' -1 ' indicate the wavenumber power law at the scales shown. The vertical dashed line indicates the inner scale (see text for details) and the vertical dashed dotted line indicates the Bragg scale of a $50 \mathrm{MHz}$ radar.

electrons and positive ions with mesospheric aerosol particles appears to be quantitatively understood. Nevertheless, it must be noted that so far there is no physical explanation for the occasional observation of positively charged aerosol particles (see Sect. 2.4). It has been proposed that photo emission of 'dirty' ice particles may be involved (Havnes et al., 1990), however, quantitative calculations of the charging of ice aerosol particles by photo emission are hampered by the fact that the details of the complex index of refraction of such 'dirty' ice particles are not yet available (Rapp and Lübken, 1999).

3.3 Turbulence with high Schmidt number: the hydrodynamic theory of PMSE

\subsubsection{The concept}

The first breakthrough in our understanding of PMSE was achieved through the work of Kelley et al. (1987) who proposed that electron diffusivity around the polar summer mesopause region could be reduced due to the presence of large positive ion clusters. If a tracer diffusivity $\mathrm{D}$ is considerably smaller than the kinematic viscosity of air $v$, or in other words, if the Schmidt number $\mathrm{Sc}=\nu / \mathrm{D}$ is considerably larger than 1 then fluctuations in the tracer field can extend to much smaller scales than the fluctuations of the turbulent velocity field. This basic result of the theory of turbulent tracer advection goes back to Batchelor (1959) who demonstrated that tracer structures at scales around the inner scale are compressed by a pure strain motion due to the velocity gradient $(\sim \sqrt{\epsilon / v})$ acting on scales around the inner scale $l_{0}^{H}$ (= the transition scale between the inertial and the viscous subrange). This strain leads to the creation of structures significantly smaller than $l_{0}^{H}$ which subsequently can only be erased by the action of molecular diffusion. If, however, the

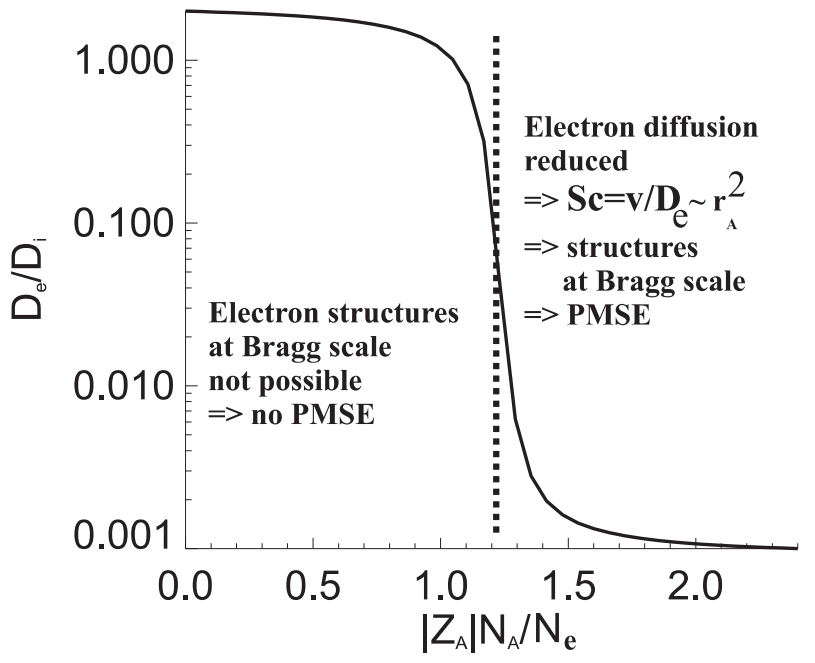

Fig. 21. Electron diffusion coefficient $D_{e}$ in units of the positive ion diffusion coefficient $D_{i}$ as a function of the ratio between the aerosol charge number density $\left|Z_{A}\right| N_{A}$ and the free electron number density $N_{e}$ according to Cho et al. (1992), copyright by the American Geophysical Union.

diffusion coefficient of the tracer is much smaller than the kinematic viscosity of air (being responsible for the damping of the velocity fluctuations) tracer structures can persist at scales $\ll l_{0}^{H}$ (see Fig. 20). Batchelor (1959) further estimated the shape of the tracer spectrum beyond $l_{0}^{H}$ and found that the spectrum should reveal a so called viscous convective subrange characterized by a $k^{-1}$ dependence (where $k$ is the wavenumber). Note that indeed this spectral behaviour has been verified by laboratory investigations on high Schmidt number tracers (Gibson and Schwartz, 1963; Gibson et al., 1970) and by direct numerical simulation methods (Bogucki et al., 1997). Quantitative considerations based on Kelley et al. (1987)'s ideas and the available experimental knowledge on proton hydrates in the polar summer mesopause region (Johannessen and Krankowsky, 1972; Kopp et al., 1985) showed, however, that the mass of the positive ions was far too small in order to lead to an electron Schmidt number $\gg 1$ required to explain the PMSE observations. Subsequently, Cho et al. (1992) considered larger particles, namely charged ice particles. Cho et al. (1992) applied the multipolar diffusion theory of Hill (1978) to a diffusion system consisting of electrons, positive ions and charged aerosol particles. They found that if somewhat more than $50 \%$ of the overall negative charge is bound on the aerosol particles, i.e., $\left|Z_{A}\right| N_{A} / N_{e}>1.2\left(\left|Z_{A}\right|:\right.$ number of charges per particle, $N_{A}$ : particle number density, $N_{e}$ : electron number density), the electron diffusivity should drop down by several orders of magnitude to the value of the aerosol diffusivity (see Fig. 21).

Thus at the time of Cho et al. (1992)'s work the picture of our understanding of PMSE seemed to be complete: The presence of neutral air turbulence in combination with a 


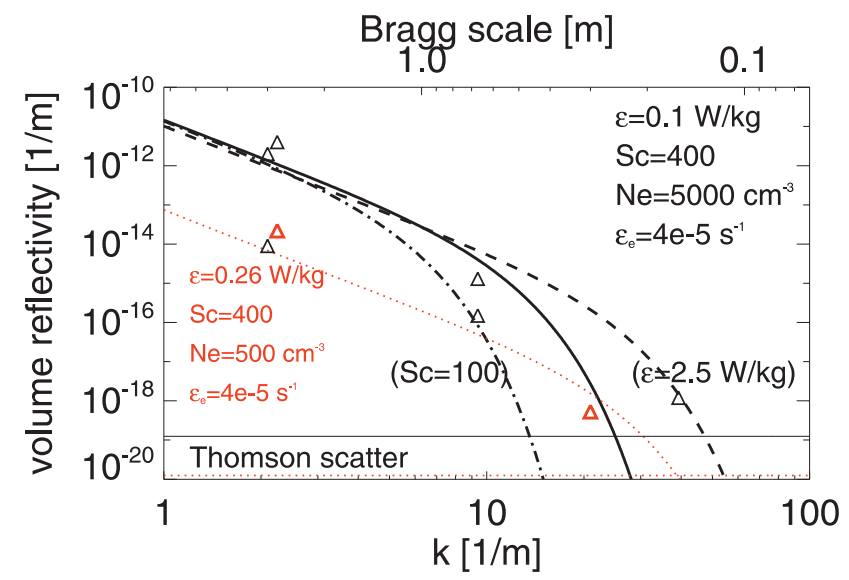

Fig. 22. Measured (symbols) and calculated volume reflectivities (lines) for different radar Bragg wave numbers (lower abscissa) and Bragg scale (upper abscissa), respectively. Parameters used in the calculations for all black lines are given in the black colored insert. Parameters used in the calculations for all red lines are given in the red colored insert. The horizontal lines indicate the incoherent scatter reflectivity (Thomson scatter) for an electron number density of $5000 \mathrm{~cm}^{-3}$ (black) and $500 \mathrm{~cm}^{-3}$ (red), respectively. The two red symbols mark the observations reported by Röttger (2001).

reduced diffusivity of electrons due to the presence of a considerable amount of charged aerosol particles seemed to be sufficient to explain the existence of the electron irregularities at the Bragg scale and subsequently this concept was further elaborated and applied by several authors (Klostermeyer, 1997, 1999b; Chaxel, 1997; Hill et al., 1999). However, the observation by Lübken et al. (1993b) (see Sect. 2.4.2) that soon followed the publication of the theory created a dilemma since they showed that one of the crucial requirements of the Cho et al. (1992)-theory, i.e., the presence of neutral air turbulence, was not fulfilled. This dilemma triggered a variety of approaches that tried to explain PMSE in the complete absence of neutral air turbulence (see Sect. 3.6). A solution to this dilemma is presented in Sect. 3.5.

\subsubsection{Absolute volume reflectivities}

Recent observations of turbulent energy dissipation rates and Schmidt-numbers around the polar summer mesopause now also allow for a quantitative comparison of observed and computed radar volume reflectivities based on the above described theory (Lübken et al., 1994, 1998, 2002). In Fig. 22 we compare the measured absolute reflectivities stated in Table 1 with calculations of the volume reflectivity based on a Schmidt-number dependent turbulence model (Driscoll and Kennedy, 1985) (for details on the calculation of the volume reflectivity based on the Driscoll and Kennedy-model see Giebeler, 1995). Figure 22 shows that with reasonable values for the Schmidt-number (Lübken et al., 1998), the turbulent energy dissipation rate (Lübken et al., 2002), the

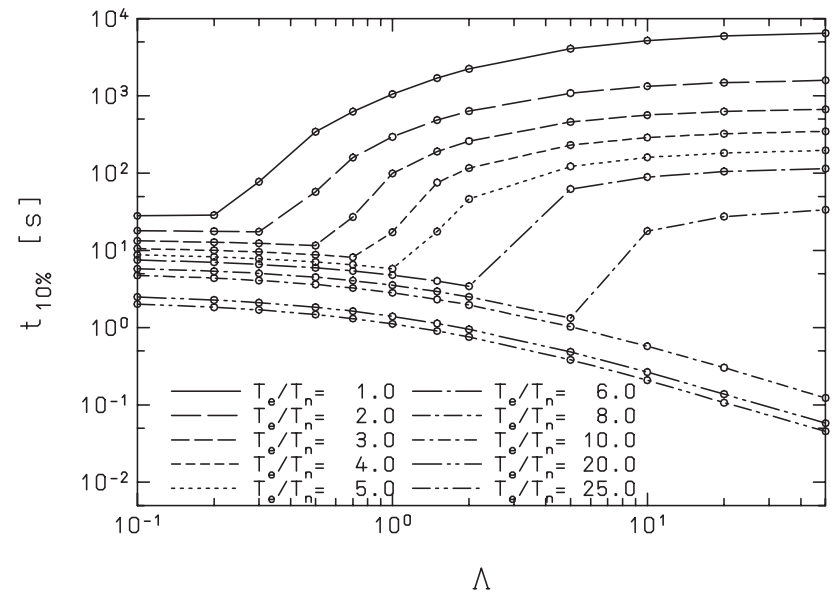

Fig. 23. Decay times of a Gaussian electron perturbation (with a width $=67 \mathrm{~cm}$ ) as a function of $\Lambda=\left|Z_{A}\right| N_{A} / N e$ for the case of positive ions and singly negatively charged aerosol particles with a radius of $10 \mathrm{~nm}$ and different values of $\mathrm{T}_{e} / \mathrm{T}_{n}$. This figure is reproduced from Rapp and Lübken (2000), copyright by the American Geophysical Union.

electron number density $N_{e}$ and the electron irregularity dissipation rate $\epsilon_{e}$ (Giebeler, 1995) the observations at $50 \mathrm{MHz}$, $224 \mathrm{MHz}$ and $500 \mathrm{MHz}$ can be readily explained (thick black line). It is also interesting to note that using the same parameters but $\epsilon=2.5 \mathrm{~W} / \mathrm{kg}$ (which is the largest value that has so far been reported Lübken et al., 2002) also allows to explain the observed reflectivity at $933 \mathrm{MHz}$ (thick dashed line). Note further that the product $N_{e}^{2} \cdot \epsilon_{e}$ is $\propto \Delta N_{e}$, where $\Delta N_{e}$ an absolute small scale fluctuation of the electron number density (Driscoll and Kennedy, 1985). Hence, $N_{e}^{2} \cdot \epsilon_{e}$ characterizes the absolute magnitude of the electron number density fluctuations due to turbulence and determines the absolute level of the calculated reflectivity. With this information in mind, we also see that the considerably lower values reported by Röttger (2001) can be directly explained in the scope of the Cho et al. (1992)-theory (red dotted line). In summary, the Cho et al. (1992)-theory can explain PMSE observations at all radar frequencies provided that indeed neutral air turbulence is present.

\subsubsection{Evidence for electron diffusivity controlling PMSE}

As described in Sect. 2.6 the observations of an active modulation of PMSE through RF-heating of the ambient electrons have opened a new experimental window for the study of PMSE. Rapp and Lübken (2000) interpreted the observations by Chilson et al. (2000) in the scope of the electron temperature dependence of the electron diffusion in the vicinity of charged aerosol particles and found that an electron temperature rise indeed explains the observed features. Figure 23 shows calculated decay times for idealized disturbances of Gaussian shape in the electron number density in 


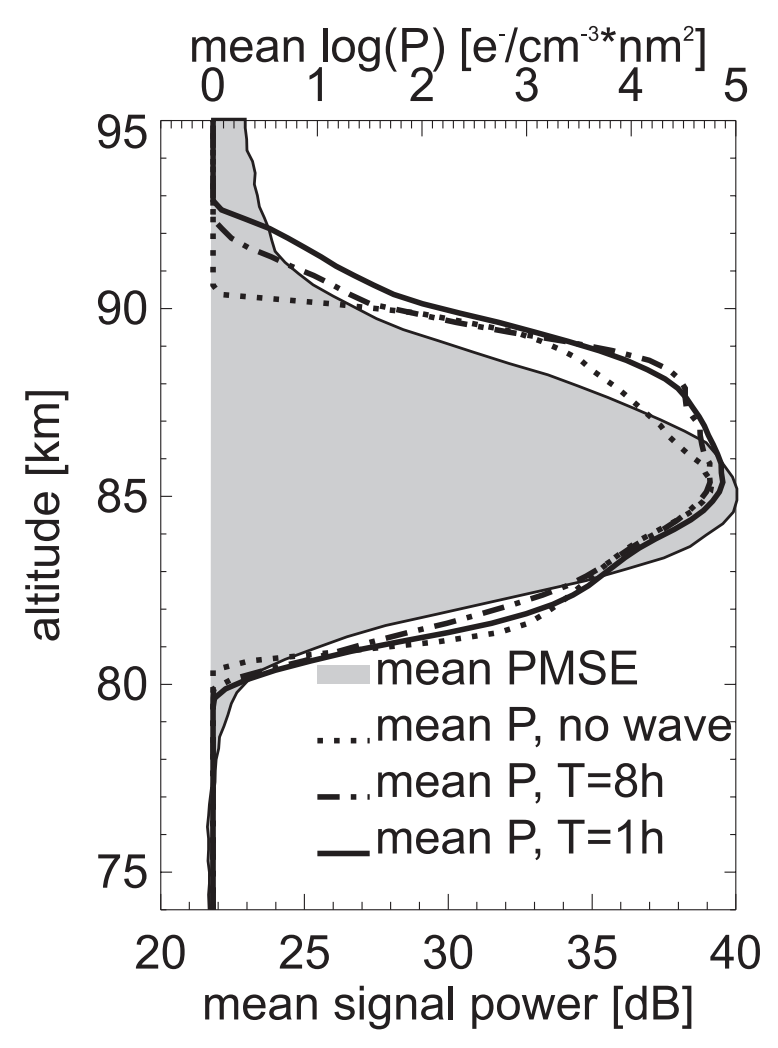

Fig. 24. Grey shaded area: Mean observed PMSE signal power during the months June and July 2000. Dotted line: Mean proxy profile obtained by time averaging $24 \mathrm{~h}$ CARMA model simulations. Solid, dotted, and dashed-dotted line: Mean proxy profiles obtained from CARMA simulations including gravity wave activity for wave periods of $8 \mathrm{~h}$ and $1 \mathrm{~h}$, respectively. This figure is reproduced from Rapp et al. (2003c), copyright by the American Geophysical Union.

the presence of similar disturbances in the negatively charged aerosol number density and positive ion number density (see the figure caption of Fig. 23 for further details). The calculations were performed for different values of $\left|Z_{A}\right| N_{A} / N_{e}$ and $T_{e} / T_{n}$, where $T_{e}$ is the electron temperature and $T_{n}$ the temperature of the neutral gas. Note that during heating only the electron temperature is affected whereas the positive ion temperature and the temperatures of the neutral gas and the aerosol particles do not change (e.g., Rietveld et al., 1986). Similar to the results of Cho et al. (1992), Fig. 23 shows that for considerably large values of $\left|Z_{A}\right| N_{A} / N_{e}$ and $T_{e} / T_{n}=1$, the decay times are much larger than without charged aerosol particles (i.e., $\left|Z_{A}\right| N_{A} / N_{e} \ll 1$ ), indicative of a significantly reduced electron diffusivity and hence the possibility to maintain fluctuations in the electron gas at the radar Bragg scale. Belova et al. (2001) have estimated that during the heating pulse, the electron temperature rises by about a factor of $T_{e} / T_{n}=20$, i.e., to a temperature of $\sim 2500 \mathrm{~K}$. With this $T_{e} / T_{n}$-ratio and for $\left|Z_{A}\right| N_{A} / N e \geq 1$, Fig. 23 predicts the decay time to decrease by several orders of magnitude leading to a fast disappearance of the PMSE.
In addition, the calculations of Rapp and Lübken (2000) suggested that when the heater is off, the electrons immediately acquire the neutral gas temperature due to collisions with the neutral molecules and diffuse back to their original positions since the disturbance in the charged aerosol particle distribution has not been affected by the heating. In a second investigation, Rapp and Lübken (2003b) have further shown that the PMSE decay and reappearance are expected to happen on time scales on the order of $1 \mathrm{~ms}$ which is also in accordance with a recent reanalysis of the original Chilson et al. (2000)-data by Belova et al. (2003).

With a similar theoretical approach, Havnes (2004) have recently also succeeded to explain the PMSE overshoot effect reported by Havnes et al. (2003) (see Sect. 2.6). In addition to the electron temperature dependence of the multipolar diffusion system, Havnes also considered the timeand temperature-dependent charging of the aerosol particles. Havnes (2004) showed that during periods of enhanced electron temperatures the aerosol particles acquire a larger negative charge (because the charging rates are temperature dependent) leading to a steepening of aerosol charge density gradients. After the heating was switched off, the structures in the electron gas reformed, this time, however, also with steeper gradients in order to compensate for the enhanced gradients in the aerosol charge density distribution. This finally leads to a stronger PMSE signal than before the heater was switched on.

The combined experimental and model results from Chilson et al. (2000), Belova et al. (2003), Havnes et al. (2003), Rapp and Lübken (2000, 2003b), and Havnes (2004) hence provide strong direct evidence that the reduction of electron diffusivity due to the presence of charged aerosol particles and their charging due to diffusional fluxes of electrons onto their surface are two key physical processes leading to PMSE.

\subsection{A microphysical proxy for PMSE}

As demonstrated in Sect. 3.1, microphysical models satisfactorily describe the physics of the formation and growth of mesospheric ice particles. Furthermore, models of the charging of aerosol particles and their multipolar diffusion readily account for a variety of observations like in situ observations of charged particles and electron biteouts and also the active modulation of PMSE through RF-heating. Subsequently, Rapp et al. (2003c) combined a microphysical ice particle model with an aerosol charging model hence allowing to simulate not only neutral but also charged aerosol particles. In order to test the idea that the main features of PMSE depend on microphysical properties of these charged aerosol particles, they suggested a simple empirical proxy for PMSE that can be studied with the available microphysical models. Rapp et al. (2003c) assumed that the most important physical process creating PMSE is the reduction of electron diffusivity due to the presence of charged aerosol particles. If this 
were the case, PMSE signal strength should be proportional to the charge number density $\left(\left|Z_{A}\right| N_{A}\right)$ and the square of the radius of these particles $\left(r_{A}^{2}\right)$ since the aerosol particle diffusion coefficient is expected to vary like $1 / r_{A}^{2}$ (e.g., Cho et al., 1992). Taken together, the proxy $P$ was defined as

$P=\left|Z_{A}\right| N_{A} \cdot r_{A}^{2}$.

Rapp et al. (2003c) showed that the proxy calculations indeed reproduce the observed mean PMSE profile. Figure 24 compares mean proxy profiles derived from averaging $24 \mathrm{~h}$ model simulation runs for different background conditions (i.e., undisturbed and with two different gravity waves) with the mean PMSE signal strength as observed during the months June and July 2000. Evidently, the main features like altitude range and the altitude of the average PMSE maximum are nicely reproduced. In addition, the proxy calculations further suggested that individual PMSE (i.e., not averaged) should usually have their absolute maximum close to the lower edge of the layer due to the predicted dependence of the PMSE signal on the particle radius which is largest at the bottom of the ice cloud. This can be seen in Fig. 25 where we show profiles of the proxy and the lidar backscatter ratio, the charge number density and the ice particle radius at an arbitrarily selected time during a model simulation. Evidently, the proxy profile peaks at the altitude where the particles have grown largest, i.e., to radii of $\sim 50 \mathrm{~nm}$ at an altitude of $82 \mathrm{~km}$, whereas the maximum particle charge number density occurs considerably higher, i.e., at $85 \mathrm{~km}$ instead of $82 \mathrm{~km}$. In fact, a statistical analysis of PMSE data from three complete PMSE seasons studied with the ALWIN VHF radar confirms that the PMSE maximum is usually located in the lower part of the PMSE layer (see Fig. 8 in Rapp et al., 2003c).

In summary, the overall good agreement of proxy- and PMSE-properties strongly supported the view that charged aerosol particles and their influence on electron diffusivity are the key physical process for our understanding of PMSE. This triggered Rapp and Lübken (2003a) to reconsider the corresponding theory. Their main results are discussed in the next section.

3.5 The diffusion of electrons in the vicinity of charged particles revisited

Based on the pioneer-work of Hill (1978), Rapp and Lübken (2003a) have recently reconsidered the diffusion of electrons in the presence of charged particles and positive ions. In such a plasma, the diffusion of the differently charged species is coupled through the Coulomb interaction between all the constituents. Since there are Coulomb forces between the positive ions and electrons on the one hand and charged particles and electrons on the other hand, it turns out that such a system possesses two distinct diffusion modes characterized by two different eigenvalues for the electron diffusion coefficient. In short, the one diffusion coefficient has the same

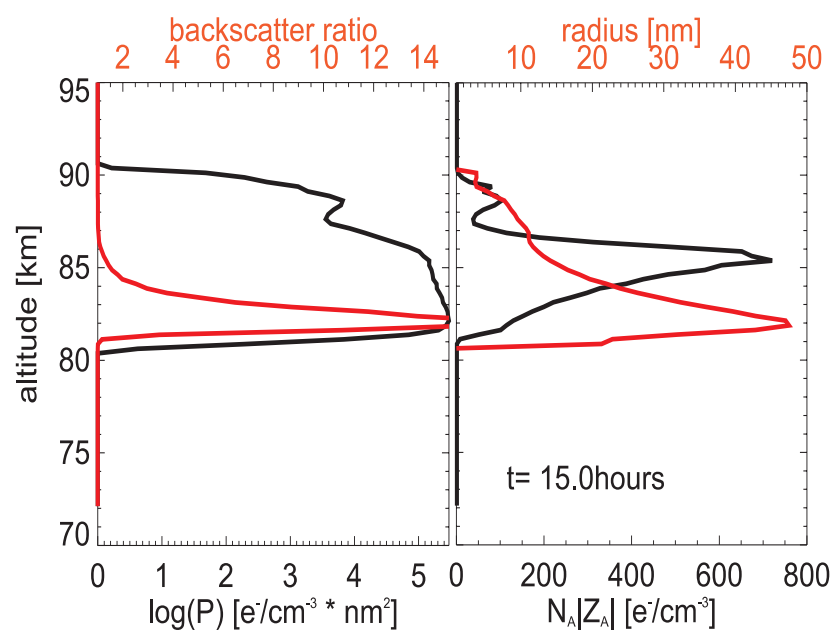

Fig. 25. Model results of the proxy $P$ (black,left), the calculated backscatter ratio that would be seen by a lidar operating at a wavelength of $532 \mathrm{~nm}$ (red, left), the charged particle number density (black, right) and the aerosol particle radius (red, right) (after Rapp et al., 2003c, copyright by the American Geophysical Union).

order of magnitude as the ion diffusion coefficient but shows some dependence on the relative charge number density of particles and electrons. The second diffusion coefficient is roughly given by the aerosol diffusion coefficient and varies with the aerosol radius like $1 / r_{A}^{2}$.

The basic physical idea is now as follows: the charged aerosol particles are transported due to the turbulent velocity field and the accompanying shear (Batchelor, 1959). This transport, however, is equivalent to a charge current that must be compensated by an oppositely directed current of the electrons in order to maintain zero net current and local charge neutrality. This leads to anticorrelated spatial structures in the electron and charged particle distributions (see Sect. 4.4 for experimental evidence for this morphology). The calculations of Rapp and Lübken (2003a) then showed that after a short initial time, the diffusion speed of the electron disturbances is entirely determined by the diffusion speed of the charged aerosol particle disturbances. Note that unlike in Cho et al. (1992)'s treatment this general behaviour is almost independent of the parameter $\Lambda$, i.e., the ratio between the charge number density of aerosol particles and the free electron number density ${ }^{2}$.

These results have been independently confirmed by a comprehensive numerical investigation performed by LieSvendsen et al. (2003). These authors studied the temporal development of structures in the positive ion and electron number density distribution arising as a consequence of a predefined structure in the distribution of aerosol particles

\footnotetext{
${ }^{2}$ Closer inspection of Cho et al. (1992)'s work actually shows that the $\Lambda \gtrsim 1$-criterium is artificially created by an unphysical initial condition for their model calculations (see appendix B in Rapp and Lübken, 2003a, for a detailed discussion).
} 


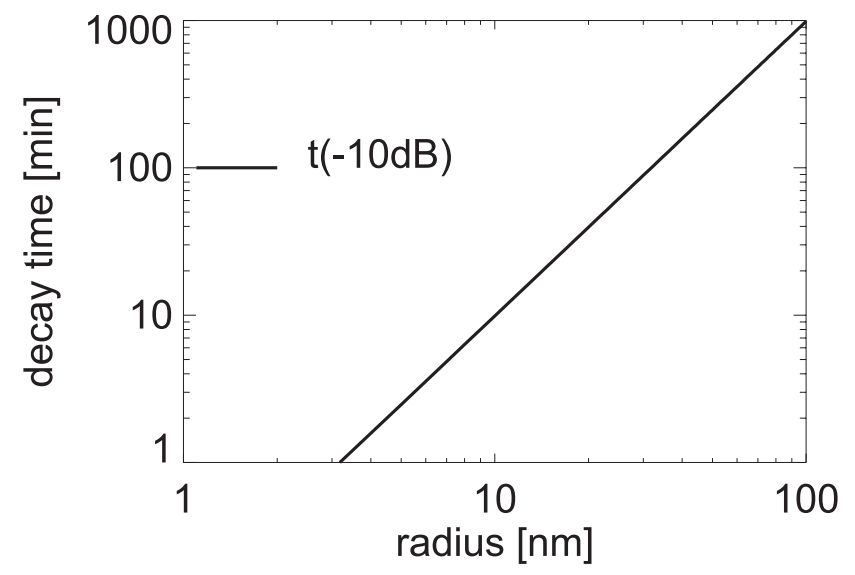

Fig. 26. Radar scatter decay time for a relative reflectivity decrease by $10 \mathrm{~dB}$ after the PMSE generation mechanism has ceased. This figure is reproduced from Rapp et al. (2003b), copyright by COSPAR.

and being subject to all relevant physical processes like diffusion, aerosol charging, production and recombination of charge carriers, transport by a vertical wind, and sedimentation due to gravity.

Rapp and Lübken (2003a) further studied the implications of these results for radio wave scattering. According to Røyrvik and Smith (1984) the volume reflectivity is basically proportional to the power spectral density of the (absolute) electron number density perturbation at the Bragg scale. Using this result, Rapp and Lübken (2003a) were able to derive the decay time of the radar signal once the mechanism that had initially generated the small scale structures in the electron number density had stopped. According to their work, the decay time for a signal decay by $\Phi \mathrm{dB}$ may be written as

$\tau_{\text {diff }}^{-\Phi d B}=\frac{\lambda^{2} \cdot \Phi / 10 \cdot \ln (10)}{8 \pi^{2} \cdot D_{2}^{0}} \approx 0.02 \cdot \Phi \cdot \frac{\lambda^{2} \cdot r_{A}^{2}}{v}$

Here, $D_{2}^{0}$ is the electron diffusion coefficient due to their coupling to the charged aerosol particles, $\lambda$ is the radar wavelength, $r_{A}$ is the aerosol radius, and $v$ is the kinematic viscosity of air. In the approximate formula on the right hand side of Eq. (2), the radar wavelength is in $\mathrm{m}$, the aerosol radius is in $\mathrm{nm}$ and the kinematic viscosity of air is given in $\mathrm{m}^{2} / \mathrm{s}$, resulting in $\tau_{\text {diff }}$ being given in s. Equation (2) shows that the diffusional decay time is proportional to the square of the radius of the charged particles involved and the square of radar wavelength. In Fig. 26 we present this decay time for a decay by $10 \mathrm{~dB}$ as a function of aerosol radius. Evidently, for particles smaller than $10 \mathrm{~nm}$ the decay time is rather short, i.e., only $2.5 \mathrm{~min}$ for particles with a radius of $5 \mathrm{~nm}$ and $10 \mathrm{~min}$ for particles with a radius of $10 \mathrm{~nm}$. Due to the quadratic dependence of the decay time on the aerosol radius, the decay time is already $40 \mathrm{~min}$ for aerosol particles with a radius of $20 \mathrm{~nm}$ and even several hours for particles with a radius of $50 \mathrm{~nm}$ which exist in an NLC environment. These long decay times for particle radii larger than say $15 \mathrm{~nm}$ suggest that PMSE potentially are a manifestation of fossil neutral air turbulence (for details on the term 'fossil turbulence' see Woods et al., 1969), an idea that was first suggested by Cho et al. (1996). However, these authors estimated that the decay time of the radar echo should not exceed $\sim 7 \mathrm{~min}$ such that the repeated absence of neutral air turbulence in the lower altitude range of the echoes (Lübken et al., 2002) was not likely to be explained by this effect. However, the calculations presented by Rapp and Lübken (2003a) strongly suggest that at low altitudes, say below $85 \mathrm{~km}$, where particles are believed to have grown to sizes larger than $15-20 \mathrm{~nm}$ due to growth and sedimentation (see also Fig. 18), the long lifetime of the structure can 'freeze in' turbulent structures for a considerable time such that the observations of Lübken et al. (2002) become understandable. In Sect. 4 we show that these model ideas indeed explain the statistics of PMSE observations based on available data of turbulence observations.

\section{6 'Non-turbulent' theories}

As mentioned above, the proven absence of neutral air turbulence in an altitude range where PMSE was simultaneously observed triggered the formulation of a couple of 'nonturbulent' theories for PMSE. The dust hole scatter theory by Havnes et al. (1992), the opalescence theory by Trakhtengerts and Demekhov (1995) and Trakhtengerts (1994), and the consideration of charged dust diffusive waves (Hocking et al., 1991) were reviewed and abandoned in the previous review article by Cho and Röttger (1997). Hence, we do not repeat their treatment but concentrate on two approaches that were not discussed in depth previously, i.e, the dressed aerosol scatter theory proposed by e.g. Hagfors (1992) and the particle growth-feedback mechanism proposed by Gumbel and Witt (2002).

\subsubsection{Dressed aerosol scatter}

It has been suggested that the PMSE observations in the UHF wavelength range, i.e., at frequencies larger than $224 \mathrm{MHz}$, can be explained by a mechanism called 'dressed aerosol scatter' (Havnes et al., 1990; Cho and Kelley, 1992; Hagfors, 1992). The basic idea is that the charged aerosol particles attract a cloud of electrons (if they are positively charged; if they are negatively charged it is thought that they lead to a clustering of electrons in between the charged aerosol particles) with a typical cloud radius given by the Debyelength. Consequently, if the radar wavelength is larger than the Debye-length, then these electron clouds should lead to coherent scatter, i.e., under certain conditions the cross section is expected to be larger than the incoherent Thomson scattering cross section ${ }^{3}$. The most rigorous treatment of

\footnotetext{
${ }^{3}$ The Thomson scattering cross section due to one electron is given by $2 \pi r_{e}^{2}$ where $r_{e}$ is the classical electron radius.
} 


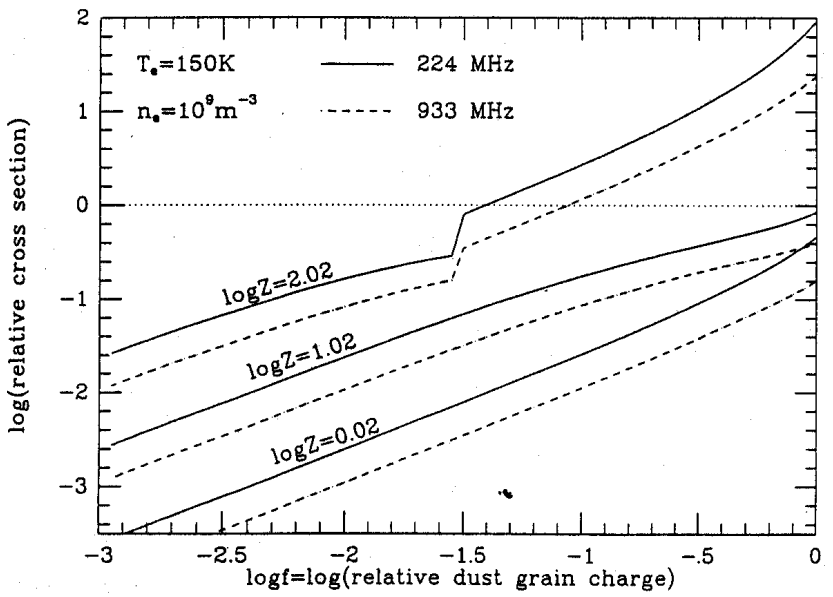

Fig. 27. Scattering cross-section of the charged dust component relative to the Thomson scattering cross section as a function of $f=\left|Z_{A}\right| N_{A} / N_{e}$, with $N_{e}=1000 \mathrm{~cm}^{-3}$ and and an electron temperature $T_{e}=150 \mathrm{~K}$ for three values of the dust charge $\left(Z_{A}=\mathrm{Z}=1,10,100\right)$ for the radar frequencies $224 \mathrm{MHz}$ and $933 \mathrm{MHz}$ (Hagfors, 1992).

this process has so far been presented by Hagfors (1992). Figure 27 shows the scattering cross-section of the charged dust component relative to the Thomson scattering cross section as a function of $\Lambda=f=\left|Z_{A}\right| N_{A} / N_{e}$, with an electron number density $N_{e}=1000 \mathrm{~cm}^{-3}$ for three values of the dust charge $\left(Z_{A}=\mathrm{Z}=1,10,100\right)$ for the radar frequencies $224 \mathrm{MHz}$ and $933 \mathrm{MHz}$ (Hagfors, 1992). Figure 27 shows that also this approach to explain PMSE in the UHF wavelength range is highly problematic: first of all, it becomes clear that the dressed aerosol scattering cross section only becomes larger than the cross section for Thomson scatter if either the aerosol particle charge becomes very high (i.e., $Z_{A}=Z>100$ ) or if $\Lambda=f=\left|Z_{A}\right| N_{A} / N_{e} \gg 1$, i.e., when the overall charge balance is completely dominated by the particle charge number density. While the first possibility (i.e., large $Z_{A}$ ) contradicts the available experimental and theoretical evidence on aerosol particle charging, the second possibility might at least in some cases be fulfilled (see Sect. 2.4.5). However, even if indeed $\Lambda=f=\left|Z_{A}\right| N_{A} / N_{e} \gg 1$, it is clear that the dressed aerosol approach cannot explain the observed reflectivity dependence on the radar frequency (see Table 1) since the observations show that the scattering cross section at $224 \mathrm{MHz}$ is $\sim 2-3$ orders of magnitude larger than the one at $933 \mathrm{MHz}$ whereas the dressed aerosol scatter theory only predicts a factor $<10$. Taken together, the dressed aerosol scatter approach must be considered as problematic and can only explain a small part of the available PMSE observations, i.e., those at the very largest frequencies.

\subsubsection{Particle growth feedback}

Finally, most recently Gumbel and Witt (2002) have proposed a new mechanism for the creation of small scale ir-

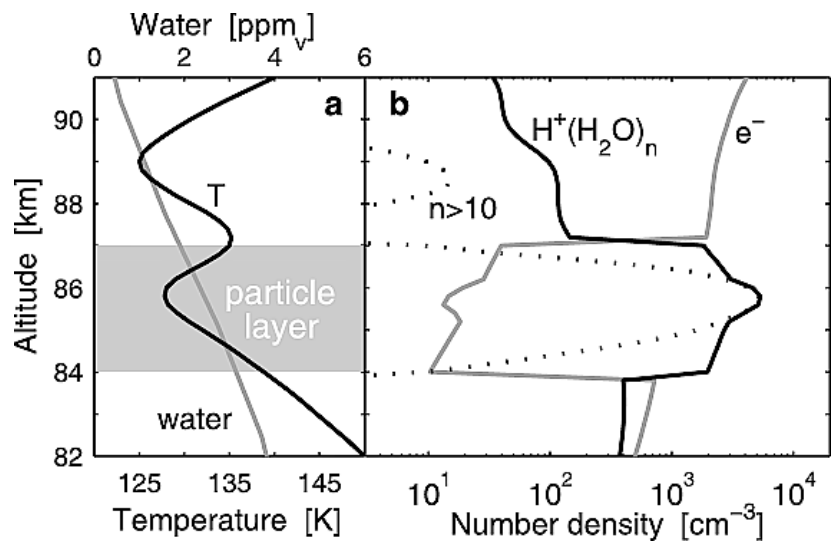

Fig. 28. (a) Input temperature and water vapor mixing ratio profiles for the model simulations by Gumbel and Witt (2002). The grey shaded area indicates the altitude range of an ice particle layer with $10^{4} \mathrm{~cm}^{-3}$ particles of radius $5 \mathrm{~nm}$. (b) Resulting profiles of electron number density and total proton hydrate density. The dashed line denotes the contribution of larger proton hydrates (i.e., with more than $10 \mathrm{H}_{2} \mathrm{O}$-ligands). This figure is reproduced from Gumbel and Witt (2002), copyright by the American Geophysical Union.

regularities in the charged particle number density and hence also in the electron number density. These authors studied the process of ice particle nucleation on large proton hydrate cluster ions (i.e., $\left.\mathrm{H}^{+}\left(\mathrm{H}_{2} \mathrm{O}\right)_{n}\right)$ and identified a positive feedback between the presence of ice particles on the one hand and the growth of cluster ions on the other hand. The basic idea of this positive feedback is depicted in Fig. 28. For positive ion nucleation to become feasible, the clusters need to grow to a sufficient size in order to overcome the free energy barrier after which further growth is thermodynamically favored (also known as Kelvin-effect; see Gumbel et al., 2003, for a concise discussion of the thermodynamics of particle nucleation at around the mesopause). However, growth to sufficient size is governed by a competition between clustering reactions and recombination of the positive ion clusters with free electrons. Since the abundance of free electrons can be strongly reduced by capture to ice particles (see Sect. 3.2 and Fig. 28), the presence of ice particles may enhance the growth of cluster ions. This leads to a positive feedback mechanism with particle nucleation being favored in altitude regions where particles already exist. Gumbel and Witt (2002) further pointed out that this mechanism may potentially amplify irregularities in the ionospheric particle and charge distribution and might hence be of relevance for our understanding of PMSE. While the general picture discussed by Gumbel and Witt (2002) has indeed been experimentally verified, i.e., large scale ( $\sim$ kilometer) enhancements of the positive ion number density at altitudes with the presence of ice particles were indeed observed (Lübken and Rapp, 2001), a more detailed analysis of the feasibility of this process for the creation of small scale structures proves the approach to 


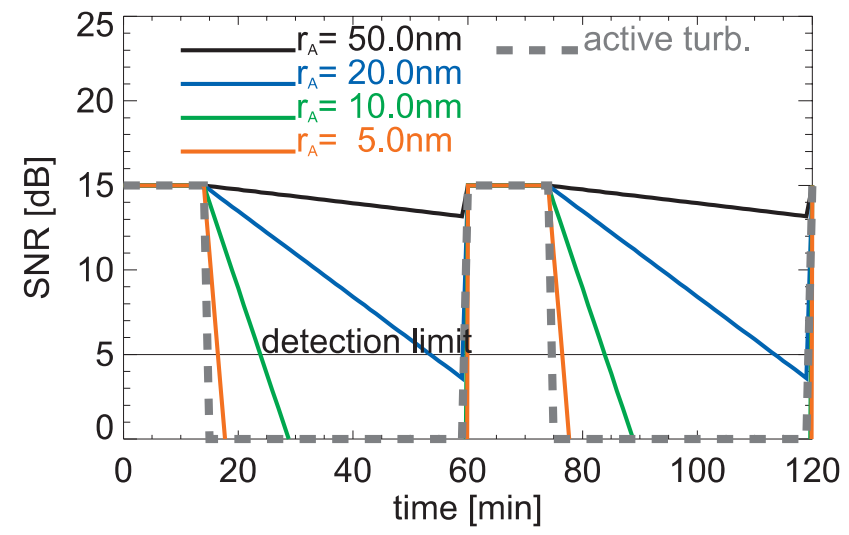

Fig. 29. Temporal development of the radar SNR after regular pulses of neutral air turbulence (indicated by grey dashed lines) leading to a SNR of $15 \mathrm{~dB}$. The colored lines indicate the SNRdecay for different aerosol particle radii assumed. The thin horizontal line at $\mathrm{SNR}=5 \mathrm{~dB}$ indicates the detection limit assumed. This figure is reproduced from Rapp and Lübken (2003a), copyright by the American Geophysical Union.

be problematic: as discussed in Gumbel and Witt (2002), even under optimum conditions (i.e., low temperatures, many particles, and sufficient water vapor) nucleation rates can not exceed $\sim 10 \mathrm{~cm}^{-3} \mathrm{~s}^{-1}$ such that it takes at least several minutes to produce $1000 \mathrm{~cm}^{-3}$ new particles with radii larger than $3-5 \mathrm{~nm}$. This time scale needs to be compared to the diffusion time of ice particles at $3-5 \mathrm{~nm}$ size which is of about the same order of magnitude (Cho et al., 1992). Hence, only under optimum conditions can the particle/cluster feedback provide structure amplification that is sufficient for PMSE generation. If such optimum conditions do exist regularly must however be doubted since for example recent in situ observations have shown PMSE at altitudes where no considerable electron biteouts have been observed (such that particle growth is not favored; see Blix et al., 2003c, and Sect. 2.4.5). In addition, also the demand for sufficient water vapor is problematic since the freeze drying effect is expected to significantly reduce the available water vapor in the presence of ice particles (Inhester et al., 1994; Rapp et al., 2002b; von Zahn and Berger, 2003). All these caveats led Gumbel and Witt (2002) themselves to conclude that 'the particle/cluster feedback to be only a weak candidate for an explanation of PMSE generation'.

\section{An updated hydrodynamic theory of PMSE}

\subsection{Turbulence statistics}

In this section, we discuss if neutral air turbulence in combination with the long lifetime of plasma fluctuations due to the presence of heavy charged particles of low mobility can account for the observed statistics of PMSE observations.
Rapp and Lübken (2003a) have suggested a simple method to estimate the PMSE occurrence frequency based on observed turbulence occurrence frequencies (see Fig. 29 for a schematic illustrating this idea). Neglecting any horizontal transport, they started from a given occurrence frequency of neutral air turbulence, TOR (= Turbulence Occurrence Rate), and assumed that a turbulent event lasts $\tau_{\text {turb }} \sim 15$ min in accordance with model results and observations (Andreassen et al., 1994; Czechowsky and Rüster, 1997). They further assumed that the turbulent events are equally distributed over a given time interval. Then they calculated the decay times for a decay by $10 \mathrm{~dB}$ according to Eq. (2) for aerosol radii as determined with a microphysical aerosol model. Adding now these decay times to the time where turbulence was active and dividing this sum by the total time interval considered, they derived an estimate of the occurrence rate of PMSE, $P_{O R}^{4}$, (= PMSE Occurrence Rate), as

$P O R= \begin{cases}T O R \cdot\left(1+\frac{\tau_{\text {diff }}^{-10 d B}}{\tau_{\text {turb }}}\right) & ; \text { if }<100 \% \\ 100 \% & ; \text { else }\end{cases}$

Note that Eq. (3) is certainly a strong idealization of reality since it assumes Lagrangian observation geometry. In contrast to this, radar observations are certainly performed at a fixed location (i.e., in an Eulerian reference frame), such that horizontal transport further complicates the situation. Still, we consider Eq. (3) useful to demonstrate the following aspects:

Based on the turbulence occurrence frequency determined from the available rocket borne observations (see also Sect. 2.4.2) and a modeled altitude distribution of aerosol radii as shown in the left panel of Fig. 30, Rapp and Lübken (2003a) estimated the PMSE occurrence frequency based on Eq. (3). The result is shown as the thick black line in Fig. 30. Comparing this estimate of $P O R$ with the observed altitude profile of the PMSE occurrence rate, it turns out that the general altitude distribution is well reproduced by the model approach presented here, in fact the model even overestimates the PMSE occurrence frequency at all altitudes (while formerly the problem has been to explain that PMSE can be there at all). Considering, however, the strong idealization underlying this result (i.e., no horizontal transport, assumed permanent existence of ice particles in the polar summer mesopause region, etc.), this minor discrepancy is not surprising. More importantly, the calculations show some other very interesting features: at high altitudes, i.e., above $\sim 88 \mathrm{~km}, P O R$ follows $T O R$ almost one to one. This is due to the fact that ice particles at these altitudes are rather small such that the PMSE decay time (defined by the diffusional decay time by $10 \mathrm{~dB}$ according to Eq. 2) is short compared

\footnotetext{
${ }^{4}$ It is interesting to note that Eq. (3) may also be used to estimate the turbulence occurrence rate $T O R$ provided the PMSE occurrence rate $P O R$ is given, see Lübken et al. (2004)
} 

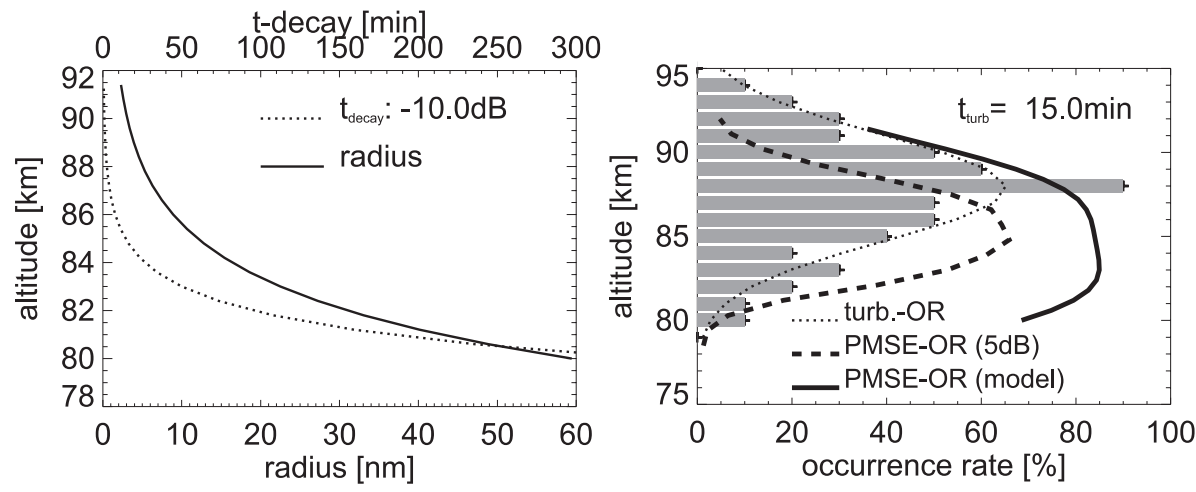

Fig. 30. Left panel: assumed aerosol radii (solid lines, lower abscissa) and corresponding decay times for PMSE for a decay by $10 \mathrm{~dB}$ (dotted lines, upper abscissa). Right panel: Histogram of the measured turbulence occurrence rate from a total of 10 rocket soundings (Lübken et al., 2002) together with a Gaussian fit to the data (dotted line). The thick dashed line shows the PMSE occurrence frequency at Andøya in the period from 1 June 2000-31 July 2000 (only PMSE with SNR > 5 dB were counted) and the thick solid line shows our estimate of the PMSE occurrence frequency. This figure is reproduced from Rapp and Lübken (2003a), copyright by the American Geophysical Union.

to the duration of a typical turbulence event (here assumed to be $15 \mathrm{~min}$ ). This finding is consistent with the fact that neutral air turbulence was almost always observed in the upper part of a PMSE layer (see Sect. 2.4.2). At altitudes below $85 \mathrm{~km}$, however, it is striking that $P O R$ is significantly larger than $T O R$, which is certainly a direct consequence of the enhanced lifetime of plasma structures due to the presence of charged particles with larger radii. These findings can thus readily explain why turbulence was very seldomly observed in the lower part of a PMSE layer (Lübken et al., 2002) and shows that either active or fossil neutral air turbulence (together with the details of charged particle- and electron diffusivity discussed above) can account for all observed PMSE.

\subsection{Absolute volume reflectivities}

It was shown already in Sect. 3.3.2 that observed volume reflectivities can be quantitatively reproduced on the basis of the neutral air turbulence in combination of a large Schmidt number of the electrons. In this section, this question is reconsidered from a more microscopic viewpoint, i.e., we determine absolute volume reflectivities based on the model ideas presented above. It was shown in Rapp and Lübken (2003a) that the volume reflectivity due to an idealized Gaussian disturbances with amplitude $n_{e 0}$ and width $\sigma$ may be written as

$$
\begin{aligned}
\eta(k)=-n \frac{k^{2}}{(8 \pi)^{3}} & \frac{e^{4}}{\epsilon_{0}^{2} m_{e}^{2} f^{4}} \cdot n_{e 0}^{2} \cdot \sigma^{2} \cdot e^{-k^{2} \sigma^{2}} \\
& \cdot\left(\frac{D_{i}-D_{2}^{0}}{D_{1}^{0}-D_{2}^{0}}\right)^{2} \cdot e^{-2 D_{2}^{0} k^{2} t}
\end{aligned}
$$

where $n$ is the typical spectral index at the radar Bragg scale, $k$ is the wavenumber of the radar, $e$ is the electron charge, $\epsilon_{0}$ is the permittivity of space, $m_{e}$ is the electron mass, $\sigma$ is the width of the Gaussian, and $D_{1}^{0}$ and $D_{2}^{0}$ are the diffusion coefficients describing the two diffusion modes of electrons in the presence of charged particles and positive ions (see Sect. 3.5).

Using typical values of $n=-1$ (i.e., from the viscous convective subrange according to Batchelor, 1959), $k=2 \pi / 6 \mathrm{~m}$, $r_{A}=15 \mathrm{~nm}, \Lambda=0.1\left(\Lambda\right.$ enters the calculation of $D_{1}^{0}$ and $\left.D_{2}^{0}\right)$, $f=50 \mathrm{MHz}, \sigma=1.27 \mathrm{~m}$ (yielding a full width at half maximum of $3 \mathrm{~m}), n_{e 0}=250 \mathrm{~cm}^{-3}$ and $\mathrm{t}=100 \mathrm{~s}$ we arrive at a volume reflectivity of $\eta \approx 9 \cdot 10^{-13} \mathrm{~m}^{-1}$. Comparing this value to the absolute reflectivities observed at $\sim 50 \mathrm{MHz}$ stated in Table 1 we see that this value has indeed the correct order of magnitude. This estimate (together with the arguments presented in Sect. 3.3.2) demonstrates that also the absolute volume reflectivities summarized in Table 1 can be readily explained in the scope of the theory by Rapp and Lübken (2003a).

\subsection{Doppler broadening and aspect sensitivity}

As pointed out in Sect. 2.3 one of the most intriguing properties of PMSE is the often very narrow Doppler spectrum of the received signal. The Doppler spectrum is expected to be broad in the presence of active neutral air turbulence due to the turbulent velocity fluctuations. According to GibsonWilde et al. (2000) the width of the Doppler spectrum is directly related to the velocity variance in the volume probed by the radar and can be expressed in terms of the turbulent energy dissipation rate $\epsilon$ as

$w_{r m s}= \pm \sqrt{\frac{\epsilon}{5 \cdot 0.4 \omega_{B}}}$,

where $\omega_{B}$ is the mean Brunt-Väisälä frequency over the altitude range where the turbulent event takes place, and the factor 5 is a correction factor to an earlier formula from Hocking 

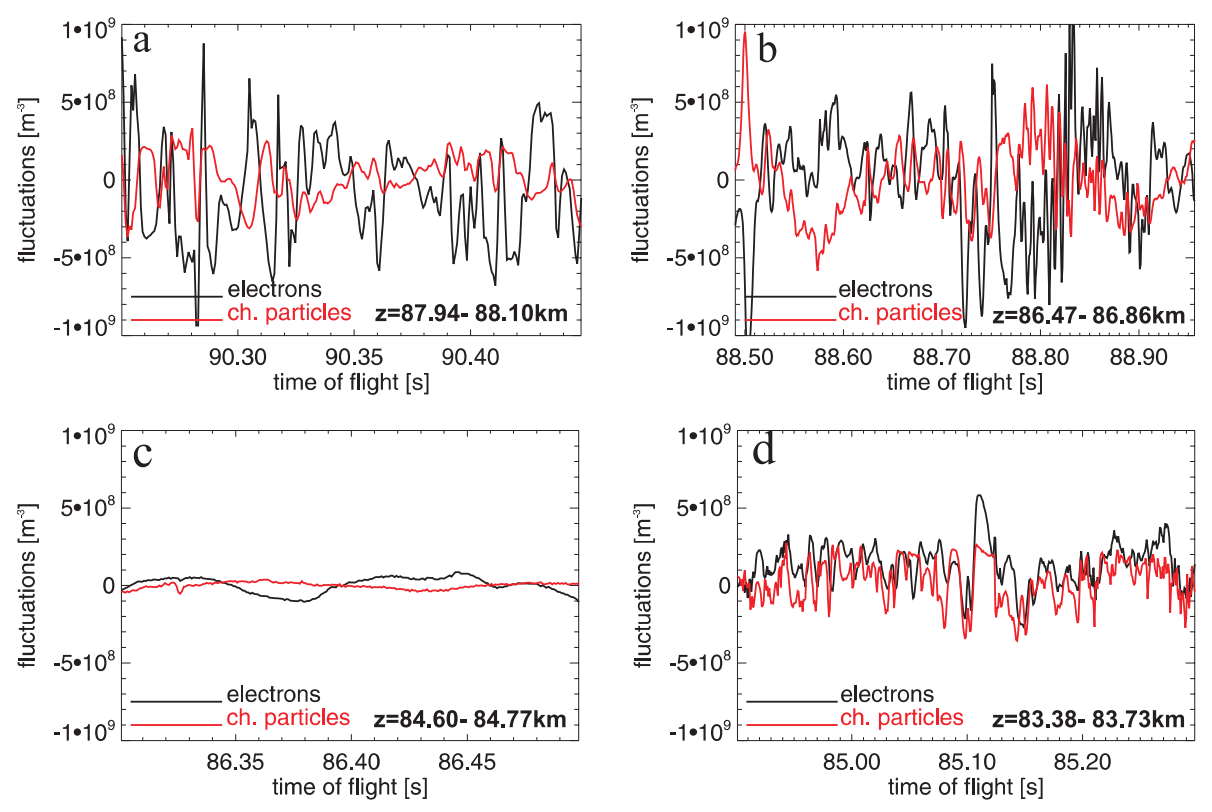

Fig. 31. Perturbations of electron (black line) and aerosol charge number densities (red line) during four selected time intervals during sounding rocket flight ECT02 in July 1994. Note that the two data sets must be shifted by $\sim 2.5 \mathrm{~ms}$ for comparison since one measurement was made at the tip of the sounding rocket and the other in the rear (with a separation of $2.5 \mathrm{~m}$ and a rocket speed of $1000 \mathrm{~m} / \mathrm{s}$ ) (Rapp et al., 2003a).

(1985) which Gibson-Wilde et al. (2000) derived from a direct numerical simulation of the VHF-radio scatter created by mesospheric turbulence. If we use $\omega_{B}=1.5 \cdot 10^{-2} \mathrm{~s}^{-1}$ and a rather large value for $\epsilon$ of $0.5 \mathrm{~m}^{2} / \mathrm{s}^{3}(=0.5 \mathrm{~W} / \mathrm{kg})$ for the polar summer mesopause region (Lübken et al., 2002) we see that $\pm 5.8 \mathrm{~m} / \mathrm{s}$ is a typically expected velocity variance due to relatively strong turbulence. Contrary to this, velocity variances derived from Doppler spectra in PMSE are often less than $\pm 1 \mathrm{~m} / \mathrm{s}$ (Cho and Kelley, 1993). However, in Sect. 3.5 we have made the point that the electron irregularities are expected to prevail a significant time after the neutral air turbulence has ceased. Under these conditions the velocity variance which determines the spectral width of the radar echo is in fact expected to be very small. For example, if we roughly estimate the 'minimum' turbulent energy dissipation rate from $\epsilon_{\min }=\nu \cdot \omega_{B}^{2}$ as suggested by Lübken (1992) and use $\nu=2 \mathrm{~m}^{2} / \mathrm{s}$ and the same Brunt-Väisälä frequency as before, we get $\epsilon_{\min }=0.0005 \mathrm{~m}^{2} / \mathrm{s}^{3}$ resulting in $w_{r m s}=0.1 \mathrm{~m} / \mathrm{s}$ which has the correct order of magnitude. These estimates indicate that the observed spectral width can be explained in the scope of the theory presented here. Furthermore, these ideas also directly explain the altitude dependence of the spectral width as described in Sect. 2.3: with a higher turbulence occurrence rate at the higher altitudes and a rather low turbulence occurrence rate at the lower altitudes (see Sect. 2.4.2) the spectral width is expected to be large at the upper altitudes and small at the lower altitudes, respectively. Taking it the other way round, these results imply that spectral width measured in PMSE can indeed be used to determine turbulent energy dissipation rates (provided also, that other details like the observed spectral shape - see Fig. 6 - are understood). It is though important to note that the information on the turbulence strength comes only from the spectral width and not from the total echo power of the observed signal since the echo power also depends on quantities that are not related to neutral air turbulence like the size of the charged aerosol particles involved.

Regarding observed aspect sensitivities (i.e., large at the bottom and low at the top of the PMSE layer) we further note that at least the low aspect sensitivities at the top of the PMSE layers are understandable in the scope of enhanced turbulent activity at these altitudes. The reason for the enhanced aspect sensitivity at lower altitudes is more difficult to interpret: one reason could be that the turbulent velocity field itself has been anisotropic from the very beginning as suggested by recent theoretical and numerical investigations (Petterson-Reif and Andreassen, 2003; Werne and Fritts, 2001). As another possibility, Thrane et al. (2004) have recently suggested that at the lower altitudes a horizontal layering of small scale structures could take place similar to mechanisms known to acount for specular reflections in the HF-wavelength range (Thrane et al., 1981). For the time being, all these explanations remain speculative and will need closer inspection in the future (see also Sect. 5).

4.4 Small scale structure of plasma species and related power spectra

Recently, Rapp et al. (2003a) have further checked if observed small scale fluctuations in the electrons and charged 
particle distribution show indeed all the features predicted by Rapp and Lübken (2003a). In particular, Rapp et al. (2003a) checked if the small scale fluctuations of electrons and charged particles are indeed anticorrelated and if the spectra of these small scale fluctuations indeed show the spectral form as predicted from a combination of the theory by Batchelor (1959) (in the case of active turbulence) and Rapp and Lübken (2003a) (in the case that the active turbulent activity has stopped, i.e., in the absence of an inertial subrange in the energy spectrum of the velocity fluctuations).

In Fig. 31 data samples of such observed disturbances in the electron and charged aerosol number density as measured during flight ECT02 in 1994 are presented (see Havnes et al., 1996a,b, for more details on this data set). In panels (a) and (b), the anticorrelation between the two data sets is obvious with corresponding correlation coefficients as large as $\sim-0.8$. Panel (c) shows one example, where the instruments did not observe any fine scale structure and panel (d) shows one example where in fact a strong positive correlation between electrons and negatively charged aerosol particles was observed. A possible explanation of such a feature was presented in the model study by Lie-Svendsen et al. (2003) who proposed that a positive correlation could either occur in the in the presence of large and hence quickly sedimenting particles or in the presence of evaporating particles (see Fig. 32). In a recent study, Blix et al. (2003b) analyzed similar observations together with simultaneous temperature measurements and found indeed support for the idea that evaporating ice particles are causing the observed positive correlations. In any case, such features have only been observed at the bottom of PMSE layers and must be considered as a specialty whereas the standard shows indeed the anticorrelation predicted by multipolar diffusion theory.

Rapp et al. (2003a) further considered the spectral shape of small scale disturbances in the electron and charged particle distribution. Based on the model of Rapp and Lübken (2003a) they found that the general spectral shape acquired during a phase of active neutral air turbulence (as described by Batchelor, 1959) should develop according to

$$
\Gamma(k, t)=\underbrace{\frac{2 \chi}{k} \sqrt{\frac{\nu}{\epsilon}} \cdot \exp \left(-2 l_{B}^{2} k^{2}\right)}_{\text {Batchelor, } 1959} \cdot e^{-D_{A} k^{2} t},
$$

where the underbraced part of the equation is the power spectrum at the time the neutral air turbulence stopped (Batchelor, 1959). Here, $\chi$ is the rate at which fluctuations of the considered tracer are dissipated, $l_{B}=\left(v D^{2} / \epsilon\right)^{\frac{1}{4}}$ is the so-called Batchelor-scale, and $D$ denotes the diffusion coefficient of the tracer. Hence, power spectra of electrons and charged particles should reveal a viscous convective subrange with its prominent $k^{-1}$-power law as predicted by Batchelor (1959) even a considerable time after the active neutral air turbulence has stopped. Indeed, the power spectra of the fluctuations shown in Fig. 31 reveal indications of a viscous con-
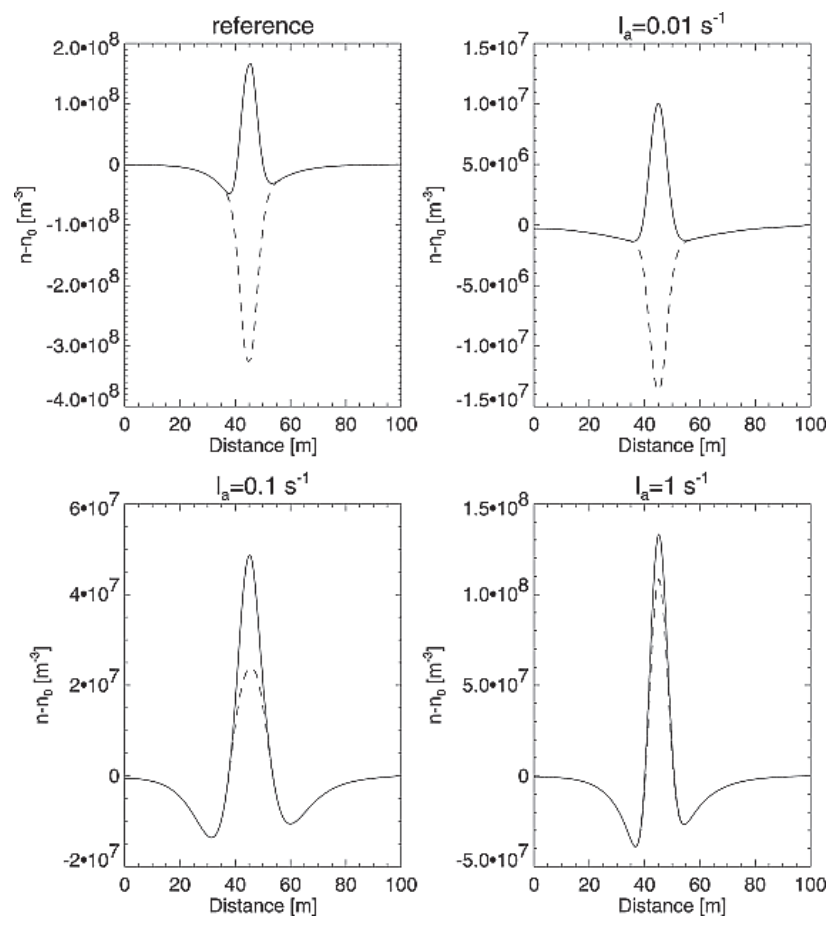

Fig. 32. Electron (dashed curves) and positive ion (solid curves) density perturbations at the end of model runs for different values of the aerosol particle evaporation rate $I_{a}$. For comparison, model results neglecting the influence of particle evaporation are shown in the upper left panel. This figure is reproduced from Lie-Svendsen et al. (2003), copyright by the American Geophysical Union.

vective subrange and hence confirm these ideas (see Fig. 33). Rapp et al. (2003a) also tried to classify the spectra shown in Fig. 33 as 'actively turbulent' or 'fossil' based on neutral air turbulence measurements onboard the same sounding rocket and attributed spectrum (a) as 'active' whereas spectra (b) and (d) were 'fossil'. However, Rapp et al. (2003a) also pointed out that turbulence and plasma measurements were conducted during different parts of the rocket trajectories, i.e., the plasma measurements were made on the ascent and the turbulence measurements were made on the descent part of the rocket trajectory. Hence, this classification must be considered with some caution since the turbulent structure (as well as the structure of the plasma profiles) might be horizontally non-uniform.

In any case, all the results regarding small scale observations of plasma consituents at PMSE altitudes are consistent with the theoretical ideas described above suggesting that PMSE can be explained by a combination of active and fossil turbulence acting on the large and heavy charged aerosol particles which are subsequently mirrored in the electron number density distribution that becomes visible to a VHF radar. 

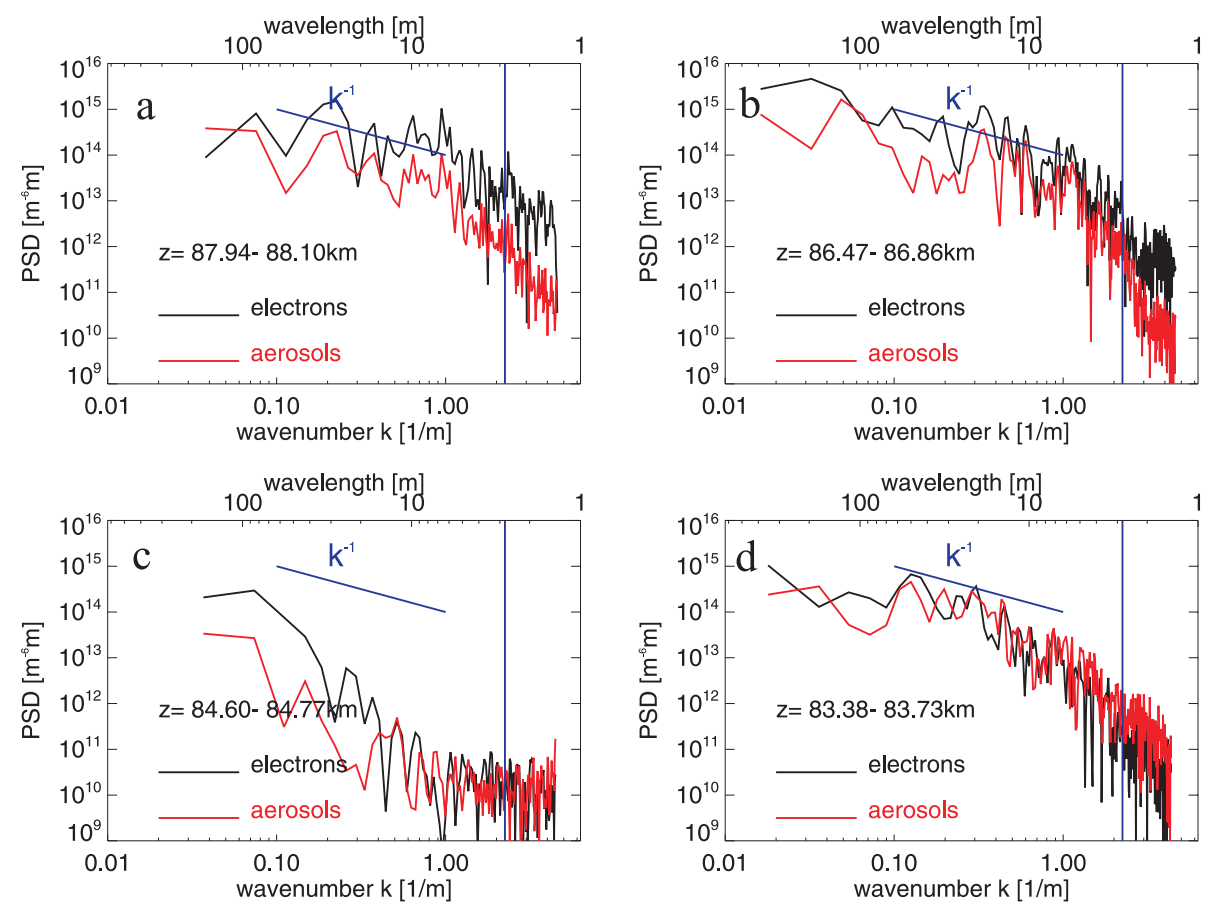

Fig. 33. Power spectra of electron number density (black lines) and particle charge number density fluctuations (red lines) shown in Fig. 31. The inclined line represents a spectral slope of -1 and the vertical line marks the radar Bragg scale (=2.8 $\mathrm{m})$ (Rapp et al., 2003a).

\section{Conclusions}

In the current paper we have reviewed the experimental and theoretical milestones that have led to an advanced understanding of PMSE. Based on experimental results from in situ observations with sounding rockets, ground based observations with radars and lidars, numerical simulations with microphysical models of the life cycle of mesospheric aerosol particles, and theoretical considerations regarding the diffusivity of electrons in the ice loaded complex plasma of the mesopause region, an explanation for the generation of these radar echoes has been described that is consistent with the entire available experimental data base. The main idea is that mesospheric neutral air turbulence in combination with a significantly reduced electron diffusivity due to the presence of heavy charged ice aerosol particles (radii $\sim 5-50 \mathrm{~nm}$ ) lead to the creation of structures at spatial scales significantly smaller than the inner scale of the turbulent velocity field. Importantly, owing to their very low diffusivity, the plasma structures acquire a very long lifetime, i.e., $10 \mathrm{~min}$ to hours, in the presence of particles with radii between 10 and $50 \mathrm{~nm}$. This leads to a temporal decoupling of active neutral air turbulence and the existence of small scale plasma structures and PMSE and thus readily explains observations proving the absence of neutral air turbulence at PMSE altitudes.

With this explanation at hand, it becomes clear that PMSE are a unique geophysical phenomenon from many different points of view: Through their close relationship to ice parti- cles, PMSE are a direct indicator for extremely low temperatures (i.e., less than $\sim 150 \mathrm{~K}$ ) at mesopause altitudes. Importantly, radar observations of PMSE are independent from tropospheric weather conditions in contrast to optical soundings from the ground for example with lidars. Long term observations of PMSE have the potential to yield insight into the long term behaviour of the mesopause temperature, a quantity that has been suspected to change due to anthropogenic action. From a more technical point of view, the observation of PMSE allows for consistency checks with remote sensings of temperatures from satellites (e.g., Mertens et al., 2004) in an altitude range where other direct measurements of temperatures are almost unavailable (with the exception of in situ temperature measurements from sounding rockets that due to their significant costs can only be performed sporadically). In addition, these ice particles are conservative and passive tracers for the background wind field to a very good approximation, such that the observation of PMSE also allows for the derivation of winds and its short term variability induced for example by gravity waves. Owing to their usually very high signal to noise ratio (often in excess of $30 \mathrm{~dB}$ ) PMSE observations allow to track wave motions in the atmosphere on the shortest time scales (down to a couple of minutes) that can otherwise not be accessed at all. Since these wave motions are usually excited in the troposphere and lower stratosphere (Fritts and Alexander, 2003), PMSE also provide a suitable tool for the study of the coupling of different atmospheric altitude regions. As described in the 
current manuscript, Doppler spectral width measurements in PMSE further allow for a near continuous characterization of mesospheric turbulence which is a significant contribution to the energy budget at these altitudes with corresponding heating rates in excess of the radiative input. Finally, apart from its obvious importance for the study of the Earth's middle atmosphere, PMSE further allow to study basic physical processes with significance far beyond atmospheric physics: Being caused by the transport of charged particles, electrons and positive ions due to the turbulent velocity field, the study of PMSE also allow insights into the characteristics of turbulence itself and the behaviour of complex plasmas which are both areas of current intensive research.

\section{Outlook}

As far as future work on PMSE is concerned we see the following promising areas:

1.) Simultaneous and continuous observations of mesospheric turbulence strength (for example with a narrow beam MF radar as introduced by Hocking, 1983, and recently further developed by Latteck et al., submitted, 2004 $)$, PMSE (observed with a VHF radar) and aerosol particles sizes (with a multi-color lidar) should be conducted in order to check the above described scenario with frequent turbulent activity and small ice particles in the upper portion of the PMSE layer and only occasional turbulent activity but large ice particles in the lower part of the layer. The same experiment could also yield useful data to check the relation between spectral width in PMSE and turbulent activity.

2.) The recently performed active experiments to modify PMSE with a powerful HF-heater are very promising and should be further continued and expanded in the future. As pointed out by Havnes et al. (2003), such experiments have the potential to teach us more details about the charging characteristics of the ice particles, as well as intrinsic properties of the particles themselves (like radii and number densities) and the background ionosphere.

3.) Only very little is known so far about the degree of isotropy of mesospheric turbulence as well as its horizontal homogeneity. Indications for anisotropy and horizontal inhomogeneity come from the details of radar Doppler spectra (see Sect. 2.3.2), the observed aspect sensitivity (see Sect. 2.3.3), and comparisons between electron number density profiles and PMSE (see Rapp et al., 2003a). In order to study these issues, sounding rocket payloads carrying several small 'daughter' payloads should be developed that are to be ejected from the main payload during the traverse

\footnotetext{
${ }^{5}$ Latteck, R., Singer, W., and Hocking, W. K.: Measurement of turbulent kinetic energy dissipation rates in the mesosphere by a $3 \mathrm{MHz}$ Doppler radar, Adv. Space Res., submitted, 2004.
}

of a PMSE layer and hence yield a horizontal picture of the turbulent irregularity field. First attempts have been made before (Blix and Thrane, 1985), however, at that time experiments were just at the edge of feasibility. Today, the miniaturization of electronics allows for a much more robust design of such rocket probes so that the success-rate should be much better than during previous attempts.

4.) Regarding the microphysics of the involved ice particles the most important remaining open question is about the actual origin of the ice particles. It has long been assumed that the ice particles nucleate on meteoric smoke particles, however, direct experimental evidence for the existence of these particles is not available. In order to confirm the existence of these nuclei, Rapp et al. (2003d) have recently proposed a rocket experiment that is based on the idea to charge the particles photo-electrically by the radiation of a UV-flashlamp and subsequently detect them by a sensitive electrometer. Should this attempt be successful, further work should be done in order to identify the composition of the particles and their creation through the ablation of meteorides in the mesopause region and the subsequent microphysical processes.

5.) Both from rocket borne experiments (Mitchell et al., 2001; Croskey et al., 2001; Chesworth and Hale, 1974) and from the observation of so called polar mesosphere winter echoes (Kirkwood et al., 2002a, 2003) evidence is emerging for the existence of aerosol particles throughout the entire mesosphere during all times of the year. At altitudes below $80 \mathrm{~km}$ and outside the summer season temperatures are far to warm to allow for the existence of ice particles (Lübken, 1999). Hence, rocket borne experiments should be designed to identify the nature of these aerosol particles that may have influences on both the local chemistry (through the possibility for heterogeneous reactions) but also the radiative transfer and hence the energy budget of the middle atmosphere. This is particularly important for the interpretation of observed significant temperature trends in the mesosphere (Beig et al., 2003).

Last not least, it should be mentioned that given the physical understanding of PMSE presented in this manuscript, these layers are a perfect tool to study the dynamics and thermal structure of the mesopause region. Actually, it turns out that the complex interplay between turbulence, ice particles, and multipolar diffusion of the plasma constituents provides us with a monitoring tool (with a typical signal to noise ratio of $\sim 30 \mathrm{~dB}$ or three orders of magnitude!) that allows to study the polar summer mesopause region almost permanently by just applying standard radar technique that is nowadays commercially available. In summary, PMSE will also in the future be an intriguing geophysical phenomenon in its own right, and a useful tool in order to gather insight into the complex behaviour of the polar summer mesopause region. 
Acknowledgements. This work was supported by the Bundesministerium für Bildung und Forschung under DLR grants 50 OE 9802 and $50 \mathrm{OE}$ 9901, and the AFO-2000 grant 07ATF41.

Edited by: W. Ward

\section{References}

Andreassen, O., Wasberg, C., Fritts, D., and Isler, J.: Gravity wave breaking in two and three dimensions 1 . Model description and comparison of two-dimensional evolutions, J. Geophys. Res., 99, 8095-8108, 1994.

Balsley, B. B. and Huaman, M.: On the relationship between seasonal occurrence of northern hemispheric polar mesosphere summer echoes and mean mesopause temperatures, J. Geophys. Res., 102, 2021-2024, 1997.

Balsley, B. B., Ecklund, W. L., and Fritts, D. C.: VHF echoes form the high-latitude mesosphere and lower thermosphere: observations and interpretations, J. Atmos. Sci., 40, 2451-2466, 1983.

Balsley, B. B., Woodman, R. F., Sarango, M., Urbina, J., Rodriguez, R., Ragaini, E., and Carey, J.: Southern-hemisphere PMSE: where are they ?, Geophys. Res. Lett., 20, 1983-1985, 1993.

Balsley, B. B., Woodman, R. F., Sarango, M., Rodriguez, R., Urbina, J., Ragaini, E., Carey, J., Huaman, M., and Giraldez, A.: On the lack of southern-hemisphere PMSE, J. Geophys. Res., 100, $11685-11693,1995$.

Batchelor, G. K.: Small-scale variation of convected quantities like temperature in a turbulent fluid, J. Fluid Mech., 5, 113-133, 1959.

Becker, E. and Schmitz, G.: Climatological effects of orography and land-sea heating contrasts on the gravity wave driven circulation of the mesosphere, J. Atmos. Sci., 60, 103-118, 2003.

Beig, G., Keckhut, P., Lowe, R. P., Roble, R., Mlynczak, M. G., Scheer, J., Formichev, V., Offermann, D., French, W. J. R., Shepherd, M. G., Semenov, A. I., Remsberg, E. E., She, C. Y., Lübken, F. J., Bremer, J., Clemesha, B. R., Stegman, J., Sigernes, F., and Fadnavis, S.: Review of mesospheric temperature trends, Rev. Geophys., 41 (4), 1015, doi:10.1029/2002RG000121, 2003.

Belova, E., Chilson, P., Rapp, M., and Kirkwood, S.: Electron temperature dependence of PMSE power: experimental and modelling results, Adv. Space Res., 28 (7), 1077-1082, 2001.

Belova, E., Chilson, P. B., Kirkwood, S., and Rietveld, M. T.: The response time of ionospheric heating to PMSE, J. Geophys. Res., 108 (D8), 8446, doi:10.1029/2002JD002385, 2003.

Berger, U. and von Zahn, U.: Icy particles in the summer mesopause region: 3-d modelling of their environment and 2-d modelling of their transport, J. Geophys. Res., 107(A11), 1366, doi:10.1029/2001JA000316, 2002.

Blix, T. A.: The importance of charged aerosols in the polar mesosphere in connection with noctilucent clouds and polar mesosphere summer echoes, Adv. Space Res., 24/12, 1645-1654, 1999.

Blix, T. A. and Thrane, E. V.: Turbulence characteristics as determined by cross correlation analysis, Proceedings of the 7th ESA Symposium on European Rocket and Balloon Programmes and Related Research, Loen, Norway (ESA SP-229), 275-278, 1985.

Blix, T. A., Bekkeng, J. K., Latteck, R., Lübken, F.-J., Rapp, M., Schöch, A., Singer, W., Smiley, B., and Strelnikov, B.:
Rocket probing of PMSE and NLC - results from the recent MIDAS/MACWAVE campaign, Adv. Space Res., 31, 2061-2067, $2003 a$.

Blix, T. A., Lie-Svendsen, O., Hoppe, U. P., and Rapp, M.: In situ observations of small scale structure in electrons, positive ions and charged aerosols in the presence of noctilucent clouds and polar mesosphere summer echoes, Proceedings of the 16th ESA Symposium on European Rocket and Balloon Programmes and Related Research, St. Gallen, Switzerland (ESA SP-530), 327332, 2003 b.

Blix, T. A., Rapp, M., and Lübken, F.-J.: Relations between small scale electron number density fluctuations, radar backscatter and charged aerosol particles, J. Geophys. Res., 108 (D8), 8450, doi:10.1029/2002JD002430, 2003c.

Bogucki, D., Domaradzki, J. A., and Yeung, P. K.: Direct numerical simulations of passive scalars with $\operatorname{Pr}>1$ advected by turbulent flow, J. Fluid Mech., 343, 111-130, 1997.

Bremer, J., Hoffmann, P., and Hansen, T. L.: Geomagnetic control of polar mesosphere summer echoes, Ann. Geophys., 18, 202208, 1996a,

\section{SRef-ID: 1432-0576/ag/2000-18-202.}

Bremer, J., Hoffmann, P., Manson, A., Meek, C., Rüster, R., and Singer, W.: PMSE observations at three different frequencies in northern Europe during summer 1994, Ann. Geophys., 14, 13171327, 1996b,

\section{SRef-ID: 1432-0576/ag/1996-14-1317.}

Bremer, J., Hansen, T. L., Hoffmann, P., and Latteck, R.: Dependence of polar mesosphere summer echoes on solar and geomagnetic activity, Adv. Space Res., 28, 1071-1076, 2001.

Bremer, J., Hoffmann, P., Latteck, R., and Singer, W.: Seasonal and long term variation of PMSE from VHF radar observations at Andenes, Norway, J. Geophys. Res., 108 (D8), 8438, doi:10.1029/2002JD002369, 2003.

Chaxel, Y.: Radar and modelling studies of polar mesospheric summer echoes, PhD thesis, University College London, 1997.

Chesworth, E. T. and Hale, L. C.: Ice particulates in the mesosphere, Geophys. Res. Lett., 1, 347-350, 1974.

Chilson, P. B., Czechowsky, P., Klostermeyer, J., Rüster, R., and Schmidt, G.: An investigation of measured temperature profiles and VHF mesosphere summer echoes at midlatitudes, J. Geophys. Res., 102, 23 819-23 828, 1997.

Chilson, P. B., Belova, E., Rietveld, M., Kirkwood, S., and Hoppe, U.-P.: First artificially induced modulation of PMSE using the EISCAT heating facility, Geophys. Res. Lett., 27, 3801-3804, 2000.

Chilson, P. B., Yu, T. Y., Palmer, R. D., and Kirkwood, S.: Apsect sensitivity measurements of polar mesosphere summer echoes using coherent radar imaging, Ann. Geophys., 20, 213-223, 2002 ,

SRef-ID: 1432-0576/ag/2002-20-213.

Cho, J., Swartz, W., Kelley, M., and Miller, C.: CUPRI observations of PMSE during salvo B of NLC-91: evidence of both partial reflection and turbulent scatter, Geophys. Res. Lett., 20, 22912294, 1993.

Cho, J. Y. and Kelley, M. C.: Polar mesosphere summer radar echoes, Rev. Geophys., 31, 243-265, 1993.

Cho, J. Y., Alcala, C. M., Kelley, M. C., and Swartz, W. E.: Further effects of charged aerosols on summer mesospheric radar scatter, J. Atmos. Terr. Phys., 58, 661-672, 1996. 
Cho, J. Y. N. and Kelley, M. C.: Enhancement of Thomson scatter by charged aerosols in the polar mesosphere: measurements with a 1.29-GHz radar, Geophys. Res. Lett., 19, 1097-1100, 1992.

Cho, J. Y. N. and Röttger, J.: An updated review of polar mesosphere summer echoes: Observation, theory, and their relationship to noctilucent clouds and subvisible aerosols, J. Geophys. Res., 102, 2001-2020, 1997.

Cho, J. Y. N., Hall, T. M., and Kelley, M. C.: On the role of charged aerosols in polar mesosphere summer echoes, J. Geophys. Res., 97, 875-886, 1992.

Chu, X., Gardner, C. S., and Roble, R. G.: Lidar studies of interannual, seasonal, and diurnal variations of polar mesospheric clouds at the South pole, J. Geophys. Res., 108 (D8), 8447, doi:10.1029/2002JD002524, 2003.

Croskey, C., Mitchell, J., Friedrich, M., Torkar, K., Hoppe, U.-P., and Goldberg, R.: Electrical structure of PMSE and NLC regions during the DROPPS program, Geophys. Res. Lett., 28, 14271430, 2001.

Czechowsky, P. and Rüster, R.: VHF radar observations of turbulent structures in the polar mesopause region, Ann. Geophys., 15, 1028-1036, 1997,

\section{SRef-ID: 1432-0576/ag/1997-15-1028.}

Czechowsky, P., Rüster, R., and Schmidt, G.: Variations of mesospheric structures in different seasons, Geophys. Res. Lett., 6, 459-462, 1979.

Czechowsky, P., Reid, I. M., and Rüster, R.: VHF radar measurements of the aspect sensitivity of the summer polar mesospaus echoes over Andenes $\left(69^{\circ} \mathrm{N}, 16^{\circ} \mathrm{E}\right)$, norway, Geophys. Res. Lett., 15, 1259-1262, 1988.

Dowdy, A., Vincent, R. A., Igarashi, K., Murayama, Y., and Murphy, D. J.: A comparison of mean winds and gravity wave activity in the northern and southern MLT, Geophys. Res. Lett., 28, 1475-1478, 2001.

Driscoll, R. J. and Kennedy, L. A.: A model for the spectrum of passive scalars in an isotropic turbulence field, Phys. Fluids, 28, 72-80, 1985.

Ecklund, W. L. and Balsley, B. B.: Long-term observations of the arctic mesosphere with the MST radar at Poker Flat, Alaska, J. Geophys. Res., 86, 7775-7780, 1981.

Friedrich, M. and Torkar, K. M.: FIRI: A semiempirical model of the lower ionosphere, J. Geophys. Res., 106 (A10), 21409 $21418,2001$.

Friedrich, M., Torkar, K. M., Thrane, E. V., and Blix, T. A.: Common features of plasma density profiles during NLC, Adv. Space Res., 14 (9), 161-164, 1994.

Fritts, D. C. and Alexander, M. J.: Gravity wave dynamics and effects in the middle atmosphere, Rev. Geophys., 41 (1), 1003, doi:10.1029/2001RG000106, 2003.

Gadsden, M.: The north-west europe data on noctilucent clouds: a survey, J. Atmos. Sol. Terr. Phys., 60, 1163-1174, 1998.

Gadsden, M. and Schröder, W.: Noctilucent clouds, SpringerVerlag, New York, 1989.

Garcia, R. R. and Solomon, S.: A new numerical model of the middle atmosphere 2. ozone and related species, J. Geophys. Res., 99, 12937-12951, 1994.

Gibson, C. H. and Schwartz, W. H.: The universal equilibrium spectra of turbulent velocity and scalar fields, J. Fluid Mech., 16, 365-384, 1963.

Gibson, C. H., Lyon, R. R., and Hirschsohn, I.: Reaction product fluctuations in a sphere wake, AIAA J., 8, 1859-1863, 1970.

Gibson-Wilde, D., Werne, J., Fritts, D., and Hill, R.: Direct numerical simulation of VHF radar measurements of turbulence in the mesosphere, Radio Sci., 35, 783-798, 2000.

Giebeler, J.: In-situ Messungen zur Untersuchung der Rolle von Turbulenz bei der Erzeugung von Radarechoes in der polaren Mesosphäre im Sommer, PhD thesis, Universität Bonn, 1995.

Goldberg, R., Kopp, E., Witt, G., and Swartz, W.: An overview of NLC-91: A rocket/radar study of the polar summer mesosphere, Geophys. Res. Lett., 20, 2443-2446, 1993.

Goldberg, R., Pfaff, R., Holzworth, R., Schmidlin, F., Voss, H., Tuzzolino, A., Croskey, C., Mitchell, J., Friedrich, M., Murtagh, D., Gumbel, J., von Zahn, U., Singer, W., and Hoppe, U.-P.: Dropps: A study of the polar summer mesosphere with rocket, radar and lidar, Geophys. Res. Lett., 28, 1407-1410, 2001.

Gumbel, J. and Witt, G.: Cluster ions and ice particle nucleation: positive feedback at the summer mesopause, Geophys. Res. Lett., 29, doi:10.1029/2002GL015146, 2002.

Gumbel, J., Siskind, D. E., Witt, G., Torkar, K. M., and Friedrich, M.: Influence of ice particles on the ion chemistry of the polar summer mesosphere, J. Geophys. Res., 108 (D8), 8436, doi:10.1029/2002JD002413, 2003.

Hagfors, T.: Note on the scattering of electromagnetic waves from charged dust particles in a plasma, J. Atmos. Terr. Phys., 54, 333338, 1992.

Havnes, O.: Polar mesospheric summer echoes PMSE overshoot effect due to cycling of electron heating, J. Geophys. Res., 109, A02309, doi:10.1029/2003JA010159, 2004.

Havnes, O., de Angelis, U., Bingham, R., Goertz, C. K., Morfill, G. E., and Tsytovich, V.: On the role of dust in the summer mesopause, J. Atmos. Terr. Phys., 52, 637-643, 1990.

Havnes, O., Melandsø, F., Hoz, C. L., Aslaksen, T. K., and Hartquist, T.: Charged dust in the Earth's mesopause: Effects on radar backscatter, Phys. Scr., 45, 535-544, 1992.

Havnes, O., Næsheim, L. I., Hartquist, T., Morfill, G. E., Melandsø, F., Schleicher, B., Trøim, J., Blix, T., and Thrane, E.: Meter-scale variations of the charge carried by mesospheric dust, Planet. Space Sci., 44, 1191-1194, 1996a.

Havnes, O., Trøim, J., Blix, T., Mortensen, W., Næsheim, L. I., Thrane, E., and Tønnesen, T.: First detection of charged dust particles in the Earth's mesosphere, J. Geophys. Res., 101, 10839 $10847,1996 \mathrm{~b}$.

Havnes, O., Brattli, A., Aslaksen, T., Singer, W., Latteck, R., Blix, T., Thrane, E., and Trøim, J.: First common volume observations of layered plasma structures and polar mesospheric summer echoes by rocket and radar, Geophys. Res. Lett., 28, 1419-1422, 2001.

Havnes, O., LaHoz, C., Naesheim, L., and Rietveld, M.: First observation of the PMSE overshoot effect and its use for investigating the conditions in the summer mesosphere, Geophys. Res. Lett., 30 (23), 2229, doi:10.1029/2003GL018429, 2003.

Heisenberg, W.: Zur statistischen Theorie der Turbulenz, Z. Physik, 124, 628-657, 1948.

Hervig, M., Thompson, R., McHugh, M., Gordley, L., Russell III, J., and Summers, M.: First confirmation that water ice is the primary component of polar mesospheric clouds, Geophys. Res. Lett., 28, 971-974, 2001.

Hill, R. J.: Nonneutral and quasi-neutral diffusion of weakly ionized multiconstituent plasma, J. Geophys. Res., 83, 989-998, 1978. 
Hill, R. J., Gibson-Wilde, D. E., Werne, J. A., and Fritts, D. C.: Turbulence-induced fluctuations in ionization and application to PMSE, Earth Plan. Space, 51, 499-513, 1999.

Hocking, W.: Target parameter estimation, in: Handbook for MAP volume 30, SCOSTEP, edited by: Fukao, S., Urbana, 228-268, 1989.

Hocking, W. K.: Mesospheric turbulence intensities measured with a HF radar at $35^{\circ}$ - ii, J. Atmos. Terr. Phys., 45, 89-102, 1983.

Hocking, W. K.: Measurement of turbulent energy dissipation rates in the middle atmosphere by radar techniques: A review, Radio Sci., 20, 1403-1422, 1985.

Hocking, W. K. and Röttger, J.: Studies of polar mesosphere summer echoes over EISCAT using calibrated signal strengths and statistical parameters, Radio Sci., 32, 1425-1444, 1997.

Hocking, W. K., Rüster, R., and Czechowsky, P.: Absolute reflectivities and aspect sensitivities of VHF radio waves scatterers measured with the SOUSY radar, J. Atmos. Terr. Phys., 48, 131-144, 1986.

Hocking, W. K., Fukao, S., Yamamoto, M., Tsuda, T., and Kato, S.: Viscosity waves and thermal-conduction waves as a cause of 'specular' reflectors in radar studies of the atmosphere, Radio Sci., 26, 1281-1303, 1991.

Hoffmann, P., Singer, W., and Bremer, J.: Mean seasonal and diurnal variation of PMSE and winds from 4 years of radar observations at ALOMAR, Geophys. Res. Lett., 26, 1525-1528, 1999.

Holzworth, R., Pfaff, R., Goldberg, R., Bounds, S., Schmidlin, F., Voss, H., Tuzzolino, A., Croskey, C., Mitchell, J., von Cossart, G., Singer, W., Hoppe, U.-P., Murtagh, D., Witt, G., Gumbel, J., and Friedrich, M.: Large electric potential perturbations in PMSE during DROPPS, Geophys. Res. Lett., 28, 1435-1438, 2001.

Hoppe, U.-P. and Fritts, D.: On the downward bias in vertical velocity measurements by VHF radars, Geophys. Res. Lett., 22, 619-622, 1994.

Hoppe, U.-P. and Fritts, D. C.: High resolution measurements of vertical velocity with the european incoherent scatter VHF radar 1. motion field characteristics and measurement biases, J. Geophys. Res., 100, 16813-16825, 1995.

Hoppe, U.-P. and Hansen, T. L.: Studies of vertical motions in the upper mesosphere using the EISCAT UHF radar, Ann. Geophys., 6 (2), 181-186, 1988.

Hoppe, U.-P., Hall, C., and Röttger, J.: First observations of summer polar mesospheric backscatter with a $224 \mathrm{MHz}$ radar, Geophys. Res. Lett., 15, 28-31, 1988.

Hoppe, U. P., Fritts, D. C., Reid, I. M., Czechowski, P., Hall, C. M., and Hansen, T. L.: Multiple frequency studies of the highlatitude summer mesosphere: implications for scattering process, J. Atmos. Terr. Phys., 52 (10/11), 907-926, 1990.

Hosokawa, K., Ogawa, T., Yukimatu, A. S., Sato, N., and Iyemori, T.: Statistics of antarctic mesospheric echoes observed with the SuperDARN Syowa radar, Geophys. Res. Lett., 31, L02106, doi:10.1029/2003GL018776, 2004.

Huaman, M. M., Kelley, M. C., Hocking, W. K., and Woodman, R. F.: Polar mesosphere summer echo studies at $51.5 \mathrm{MHz}$ at Resolute Bay, Canada: Comparison with Poker Flat results, Radio Sci., 36, 1823-1837, 2001.

Hunten, D. M., Turco, R. P., and Toon, O. B.: Smoke and dust particles of meteoric origin in the mesosphere and stratosphere, J. Atmos. Sci., 37, 1342-1357, 1980.
Inhester, B., Ulwick, J., Cho, J., Kelley, M., and Schmidt, G.: Consistency of rocket and radar electron density observations: implications about the anisotropy of turbulence, J. Atmos. Terr. Phys., 52, 855-873, 1990.

Inhester, B., Klostermeyer, J., Lübken, F.-J., and von Zahn, U.: Evidence for ice clouds causing polar mesosphere summer echoes, J. Geophys. Res., 99, 20 937-20 954, 1994.

Jensen, E. and Thomas, G. E.: A growth-sedimentation model of polar mesospheric clouds: Comparions with SME measurements, J. Geophys. Res., 93, 2461-2473, 1988.

Jensen, E. and Thomas, G. E.: Charging of mesospheric particles: implications of electron density and particle coagulation, J. Geophys. Res., 96, 18 603-18 615, 1991.

Jensen, E. and Thomas, G. E.: Numerical simulations of the effects of gravity waves on noctilucent clouds, J. Geophys. Res., 99, 3421-3430, 1994.

Jensen, E., Thomas, G. E., and Toon, O. B.: On the diurnal variation of noctilucent clouds, J. Geophys. Res., 94, 14 693-14 702, 1989.

Jesse, O.: Auffallende Erscheinungen am Abendhimmel, Met. Zeit., 2, 311-312, 1885 .

Johannessen, A. and Krankowsky, D.: Positive ion composition measurement in the upper mesosphere and lower thermosphere at a high latitude during summer, J. Geophys. Res., 77, 28882901, 1972.

Karashtin, A. N., abd V. I. Abramov, Y. V. S., Belov, I. F., Bychkov, V. V., Eryshev, E. B., and Komrakov, G. P.: First HF radar measurements of summer mesopause echoes at SURA, Ann. Geophys., 15, 935-941, 1997,

SRef-ID: 1432-0576/ag/1997-15-935.

Kelley, M. C. and Ulwick, J. C.: Large- and small-scale organization of electrons in the high-latitude mesosphere: implications of the STATE data, J. Geophys. Res., 93, 7001-7008, 1988.

Kelley, M. C., Farley, D. T., and Röttger, J.: The effect of cluster ions on anomalous VHF backscatter from the summer polar mesosphere, Geophys. Res. Lett., 14, 1031-1034, 1987.

Kelley, M. C., Huaman, M., Chen, C. Y., Ramos, C., Djuth, F., and Kennedy, E.: Polar mesosphere summer observations at HF frequencies using the HAARP Gakona Ionospheric Observatory, Geophys. Res. Lett., doi:10.1029/2001GL013411, 2002.

Kirkwood, S. and Rechou, A.: Planetary-wave modulation of PMSE, Geophys. Res. Lett., 25 (24), 4509-4512, 1998.

Kirkwood, S., Barabash, V., Chilson, P., Rechou, A., Stebel, K., Espy, P., Witt, G., and Stegman, J.: The 1997 pmse season - its relation to wind, temperature and water vapour, Geophys. Res. Lett., 25, 1867-1870, 1998.

Kirkwood, S., Barabash, V., Belova, E., Nilsson, H., Rao, N., Stebel, K., Osepian, A., and Chilson, P. B.: Polar mesosphere winter echoes during solar proton events, Adv. Pol. Up. Atmos. Res., 16, 111-125, 2002a.

Kirkwood, S., Barabash, V., Brändström, B. U. E., Moström, A., Stebel, K., Mitchell, N., and Hocking, W.: Noctlilucent clouds, PMSE and 5-day planetary waves: a case study, Geophys. Res. Lett., 29 (10), doi:10.1029/2001GL014022, 2002 b.

Kirkwood, S., Belova, E., Dalin, P., Fricke, K. H., Blum, U., Schmidlin, F.: and Goldberg, R. A., Polar mesosphere winter echoes during MacWave, Proceedings of the 16th ESA Symposium on European Rocket and Balloon Programmes and Related Research, St. Gallen, Switzerland (ESA SP-530), 357-362, 2003. 
Klostermeyer, J.: A height- and time-dependent model of polar mesosphere summer echoes, J. Geophys. Res., 102, 6715-6727, 1997.

Klostermeyer, J.: On the diurnal variation of polar mesosphere summer echoes, Geophys. Res. Lett., 26, 3301-3304, 1999a.

Klostermeyer, J.: Comparison between observed and computed polar mesosphere summer echoes, J. Geophys. Res., 104, $11883-$ 11890,1999 b.

Kopp, E., Eberhardt, P., Herrmann, U., and Björn, L.: Positive ion composition of the high latitude summer D-region with noctilucent clouds, J. Geophys. Res., 90, 13 041-13 051, 1985.

Körner, U. and Sonnemann, G.: Global 3d-modelling of the water vapor concentration of the mesosphere/mesopause region and implications with respect to the NLC region, J. Geophys. Res., 106, 9639-9651, 2001.

Latteck, R., Singer, W., and Bardey, H.: The ALWIN MST radar: technical design and performance, Proceedings of the 14th ESA Symposium on European Rocket and Balloon Programmes and Related Research, Potsdam, Germany (ESA SP-437), 179-184, 1999a.

Latteck, R., Singer, W., and Höffner, J.: Mesosphere summer echoes as observed by VHF radar at Kühlungsborn, Geophys. Res. Lett., 26, 1533-1536, 1999b.

Leslie, R. J.: Sky glows, Nature, 33, 245, 1885.

Lie-Svendsen, O., Blix, T. A., Hoppe, U., and Thrane, E.: Modelling the plasma response to small-scale particle perturbations in the mesopause region, J. Geophys. Res., 108 (D8), 8442, doi:10.1029/2002JD002753, 2003.

Lübken, F., Hillert, W., Lehmacher, G., and von Zahn, U.: Experiments revealing small impact of turbulence on the energy budget of the mesosphere and lower thermosphere, J. Geophys. Res., 98, 20369-20384, 1993a.

Lübken, F.-J.: On the extraction of turbulent parameters from atmospheric density fluctuations, J. Geophys. Res., 97, 20385 20395, 1992.

Lübken, F.-J.: Seasonal variation of turbulent energy dissipation rates at high latitudes as determined by insitu measurements of neutral density fluctuations, J. Geophys. Res., 104, 1344113 456, 1997.

Lübken, F.-J.: Thermal structure of the Arctic summer mesosphere, J. Geophys. Res., 104, 9135-9149, 1999.

Lübken, F.-J. and Rapp, M.: Modelling of particle charging in the polar summer mesosphere: Part 2 - application to measurements, J. Atmos. Sol. Terr. Phys., 63, 771-780, 2001.

Lübken, F.-J., Lehmacher, G., Blix, T., Hoppe, U.-P., Thrane, E., Cho, J., and Swartz, W.: First in-situ observations of neutral and plasma density fluctuations within a PMSE layer, Geophys. Res. Lett., 20, 2311-2314, 1993b.

Lübken, F.-J., Giebeler, J., Blix, T., Thrane, E., Singer, W., and Bremer, J.: In-situ measurement of the Schmidt number within a PMSE layer, Geophys. Res. Lett., 21, 1651-1654, 1994.

Lübken, F.-J., Rapp, M., Blix, T., and Thrane, E.: Microphysical and turbulent measurements of the Schmidt number in the vicinity of polar mesosphere summer echoes, Geophys. Res. Lett., 25, 893-896, 1998.

Lübken, F.-J., Jarvis, M. J., and Jones, G. O. L.: First insitu temperature measurements at the Antarctic summer mesopause, Geophys. Res. Lett., 26, 3581-3584, 1999.

Lübken, F.-J., Rapp, M., and Hoffmann, P.: Neutral air tur- bulence and temperatures in the vicinity of polar mesosphere summer echoes, J. Geophys. Res., 107 (D15), doi:10.1029/2001JD000915, 2002.

Lübken, F.-J., Zecha, M., Höffner, J., and Röttger, J.: Temperatures, polar mesosphere summer echoes, and noctlilucent clouds over Spitsbergen $\left(78^{\circ}\right.$ N), J. Geophys. Res., in print, 2004.

Marti, J. and Mauersberger, K.: A survey and new measurements of ice vapor pressure at temperatures between 170 and $250 \mathrm{~K}$, Geophys. Res. Lett., 20, 363-366, 1993.

Mauersberger, K. and Krankowsky, D.: Vapor pressure above ice at temperatures below $170 \mathrm{~K}$, Geophys. Res. Lett., 30 (3), 1121, doi:10.1029/2002GL016183, 2003.

McHugh, M., Hervig, M., Magill, B., Thompson, R. E., Remsberg, E., Wrotny, J., and Russell III, J.: Improved mesospheric temperature, water vapor and polar mesospheric cloud extinctions from HALOE, Geophys. Res. Lett., 30 (8), 1440, doi:10.1029/2002GL016859, 2003.

Mertens, C. J., Schmidlin, F. J., Goldberg, R. A., Remsberg, E. E., Pesnell, W. D., III, J. M. R., Mlynczak, M. G., Lopez-Puertas, M., Wintersteiner, P. P., Picard, R. H., Winick, J. R., and Gordley, L. L.: SABER observations of mesospheric temperatures and comparisons with falling sphere measurements taken during the 2002 summer MaCWAVE campaign, Geophys. Res. Lett., 31, L03105, doi:10.1029/2003GL018605, 2004.

Mitchell, J., Croskey, C., and Goldberg, R.: Evidence for charged aerosol particles and associated meter-scale structure in identified PMSE/NLC regions, Geophys. Res. Lett., 28, 1423-1426, 2001.

Mitchell, J. D., Croskey, C. L., Goldberg, R. A., and Friedrich, M.: Charged particles in the polar mesopause region: probe measurements from the MaCWAVE and DROPPS programs, Proceedings of the 16th ESA Symposium on European Rocket and Balloon Programmes and Related Research, St. Gallen, Switzerland (ESA SP-530), 351-356, 2003.

Mlynczak, M. G.: A contemporary assessment of the mesospheric energy bugget, Geophys. Monogr. Ser., 123, 37-52, 2000.

Müllemann, A., Rapp, M., and Lübken, F.-J.: Morphology of turbulence in the polar summer mesopause region during the MIDAS/SOLSTICE campaign 2001, Adv. Space Res., 31 (9), 2069-2074, 2003.

Natanson, G. L.: On the theory of the charging of amicroscopic aerosol particles as a result of capture of gas ions, Sov. Phys. Tech. Phys., (engl. Transl.), 5, 538-551, 1960.

Nussbaumer, V., Fricke, K.-H., Langer, M., Singer, W., and von Zahn, U.: First simultaneous and common-volume observations of NLC and PMSE by lidar and radar, J. Geophys. Res., 101, 19 161-19 167, 1996.

Ogawa, T., Nishitani, N., Sato, H., Yamagishi, H., and Yukimatu, A. S.: Upper mesosphere echoes observed with the Antarctic Syowa HF radar, Geophys. Res. Lett., 29 (7), doi:10.1029/2001GL014094, 2002.

Ogawa, T., Arnold, N. F., Kirkwood, S., Nishitani, N., and Lester, M.: Finnland HF and Esrange MST radar observations of polar mesosphere summer echoes, Ann. Geophys., 21, 1047-1055, 2003,

SRef-ID: 1432-0576/ag/2003-21-1047.

Pedersen, A., Troim, J., and Kane, J.: Rocket measurement showing removal of electrons above the mesopause in summer at high latitudes, Planet. Space Sci., 18, 945-947, 1969. 
Petterson-Reif, B. A. and Andreassen, Ø.: On local isotropy in stratified homogeneous turbulence, Siam. J. Appl. Math., 64 (1), 309321, 2003.

Pfaff, R., Holzworth, R., Goldberg, R., Freudenreich, H., Voss, H., Croskey, C., Mitchell, J., Gumbel, J., Bounds, S., Singer, W., and Latteck, R.: Rocket probe observations of electric field irregulatities in the polar summer mesosphere, Geophys. Res. Lett., 28, 1431-1434, 2001.

Rapp, M. and Lübken, F.-J.: Modelling of positively charged aerosols in the polar summer mesopause region, Earth Plan. Space, 51, 799-807, 1999.

Rapp, M. and Lübken, F.-J.: Electron temperature control of PMSE, Geophys. Res. Lett., 27, 3285-3288, 2000.

Rapp, M. and Lübken, F.-J.: Modelling of particle charging in the polar summer mesosphere: Part 1 - general results, J. Atmos. Sol. Terr. Phys., 63, 759-770, 2001.

Rapp, M. and Lübken, F.-J.: On the nature of PMSE: Electron diffusion in the vicinity of charged particles revisited, J. Geophys. Res., 108 (D8), 8437, doi:10.1029/2002JD002857, 2003a.

Rapp, M. and Lübken, F.-J.: Comment on "The response time of PMSE to ionospheric heating" by Belova, E. et al., J. Geophys. Res., 108 (D23), 4727, doi:10.1029/2003JD003638, 2003b.

Rapp, M., Gumbel, J., and Lübken, F.-J.: Absolute density measurements in the middle atmosphere, Ann. Geophys., 19, 571580, 2001,

\section{SRef-ID: 1432-0576/ag/2001-19-571.}

Rapp, M., Gumbel, J., Lübken, F.-J., and Latteck, R.: Dregion electron number density limits for the existence of polar mesosphere summer echoes, J. Geophys. Res., 107 (D14), doi:10.1029/2001JD001323, 2002a.

Rapp, M., Lübken, F.-J., Müllemann, A., Thomas, G. E., and Jensen, E. J.: Small scale temperature variations in the vicinity of NLC: Experimental and model results, J. Geophys. Res., 107 (D19), doi:10.1029/2001JD001241, 2002b.

Rapp, M., Lübken, F.-J., and Blix, T. A.: Small scale density variations of electrons and charged particles in the vicinity of polar mesosphere summer echoes, Atmos. Chem. Phys., 3, 13991407, 2003a,

\section{SRef-ID: 1680-7324/acp/2003-3-1399.}

Rapp, M., Lübken, F.-J., and Blix, T. A.: The role of charged ice particles for the creation of PMSE: a review of recent developments, Adv. Space Res., 31 (9), 2033-2043, 2003 b.

Rapp, M., Lübken, F.-J., Hoffmann, P., Latteck, R., Baumgarten, G., and Blix, T. A.: PMSE dependence on aerosol charge number density and aerosol size, J. Geophys. Res., 108 (D8), 8450, doi:10.1029/2002JD002650, 2003c.

Rapp, M., Strelnikov, B., Wilms, S., Lübken, F.-J., Gumbel, J., and Henkel, H.: A new detector for the in situ measurement of meteoric dust particles in the middle atmosphere, Proceedings of the 16th ESA Symposium on European Rocket and Balloon Programmes and Related Research, St. Gallen, Switzerland (ESA SP-530), 379-384, 2003d.

Rapp, M., Strelnikov, B., Müllemann, A., Lübken, F.-J., and Fritts, D. C.: Turbulence measurements and implications for gravity wave dissipation during the macwave/midas rocket program, Geophys. Res. Lett., in print, doi:10.1029/2003GL019325, 2004.

Reid, G. C.: Ice particles and electron "bite-outs" at the summer polar mesopause, J. Geophys. Res., 95, 13 891-13 896, 1990.

Reid, I. M., Czechowsky, P., Rüster, R., and Schmidt, G.: First
VHF radar measurements of mesopause summer echoes at midlatitudes, Geophys. Res. Lett., 16, 135-138, 1989.

Rietveld, M. T., Kopka, H., and Stubbe, P.: D-region characteristics deduced from pulsed ionospheric heating under auroral electrojet conditions, J. Atmos. Terr. Phys., 45, 311-326, 1986.

Roble, R. G. and Dickinson, R. E.: How will changes in carbon dioxide and methane modify the mean structure of the mesosphere and thermosphere?, Geophys. Res. Lett., 16, 1441-1444, 1989.

Röttger, J.: Observations of the polar D-region and the mesosphere with the EISCAT Svalbard Radar and the SOUSY Svalbard Radar, Mem. Nat. Inst. Pol. Res., 54, 9-20, 2001.

Röttger, J. and LaHoz, C.: Characteristics of polar mesosphere summer echoes (PMSE) observed with the EISCAT $224 \mathrm{MHz}$ radar and possible explanations of their origin, J. Atmos. Terr. Phys., 52, 893-906, 1990.

Röttger, J., Hoz, C. L., Kelley, M. C., Hoppe, U.-P., and Hall, C.: The structure and dynamics of polar mesosphere summer echoes observed with the EISCAT $224 \mathrm{MHz}$ radar, Geophys. Res. Lett., 15, 1353-1356, 1988.

Röttger, J., Rietveld, M. T., LaHoz, C., Hall, C., Kelley, M. C., and Swartz, W.: Polar mesosphere summer echoes observed with the EISCAT 933-MHz radar and the CUPRI 46.9MHz radar, their similarity to $224 \mathrm{MHz}$ radar echoes and their relation to turbulence and electron density profiles, Radio Sci., 25, 671-687, 1990.

Røyrvik, O. and Smith, L. G.: Comparison of mesospheric VHF radar echoes and rocket probe electron concentration measurements, J. Geophys. Res., 89, 9014-9022, 1984.

Rüster, R., Czechnowsky, P., Hoffmann, P., and Singer, W.: Gravity wave signatures at mesopause heights, Ann. Geophys., 14, 11861191, 1996,

SRef-ID: 1432-0576/ag/1996-14-1186.

Rüster, R., Röttger, J., Schmidt, G., Czechowski, P., and Klostermeyer, J.: Observation of mesospheric summer echoes at VHF in the polar cap region, Geophys. Res. Lett., 28, 1471-1474, 2001.

Sato, T.: Radar principles, in: Handbook for MAP volume 30, SCOSTEP, edited by: Fukao, S., Urbana, 19-53, 1989.

Schmidlin, F. J.: The inflatable sphere: A technique for the accurate measurement of middle atmosphere temperatures, J. Geophys. Res., 96, 22 673-22 682, 1991.

Seele, C. and Hartogh, P.: Water vapor of the polar middle atmosphere: Annual variation and summer mesosphere conditions as observed by ground-based microwave spectroscopy, Geophys. Res. Lett., 26, 1517-1520, 1999.

Singer, W., Keuer, D., Hoffmann, P., Czechowsky, P., and Schmidt, G.: The ALOMAR-SOUSY-radar: technical design and further developments, Proceedings of the 12th ESA Symposium on European Rocket and Balloon Programmes and Related Research, Lillehammer, Norway (ESA SP-370), 409-415, 1995.

Siskind, D. E., Eckermann, S. D., Cormack, J. P., Alexander, M. J., and Backmeister, J. T.: Hemispheric differences in the temperature of the summertime stratosphere and mesosphere, J. Geophys. Res., 108 (D2), 4051, doi:10.1029/2002JD002095, 2003.

Smiley, B., Robertson, S., Horanyi, M., Blix, T., Rapp, M., Latteck, R., and Gumbel, J.: Measurement of negatively and positively charged particles inside PMSE during MIDAS SOLSTICE 2001, J. Geophys. Res., 108 (D8), 8444, doi:10.1029/2002JD002425, 2003. 
Strelnikov, B., Rapp, M., and Lübken, F.-J.: A new technique for the analysis of neutral air density fluctuations measured in situ in the middle atmosphere, Geophys. Res. Lett., 30 (20), 2052, doi:10.1029/2003GL018271, 2003.

Summers, M. E., Gordley, L. L., and McHugh, M. J.: Discovery of a water vapor layer in the Arctic summer mesosphere: Implications for polar mesospheric clouds, Geophys. Res. Lett., 28 (18), 3601-3604, 2001.

Swartz, W., Cho, J., and Miller, C.: CUPRI system configuration for NLC-91 and observations of PMSE during Salvo A, Geophys. Res. Lett., 20, 2287-2290, 1993.

Tatarskii, V. I.: The Effects of the Turbulent Atmosphere on Wave Propagation, Isr. Program for Sci. Transl., Jerusalem, 1971.

Thomas, G. E.: Mesopheric clouds and the physics of the mesopause region, Rev. Geophys, 29, 553-575, 1991.

Thomas, G. E., Olivero, J. J., Jensen, E. J., Schröder, W., and Toon, O. B.: Relation between increasing methane and the presence of ice clouds at the mesopause, Nature, 338, 490-492, 1989.

Thomas, G. E., Olivero, J. J., DeLand, M., and Shettle, E. P.: A response to the article by U. von Zahn, "Are noctilucent clouds truly a miner's canary of global change?", Eos, Transactions, American Geophysical Union, 84 (36), 352-353, 2003.

Thomas, L., Astin, I., and Prichard, I. T.: The characteristics of VHF echoes from the summer mesopause region at midlatitudes, J. Atmos. Terr. Phys., 54, 969-977, 1992.

Thrane, E. V., Grandal, B., Fla, T., and Brekke, A.: Fine structure in the ionospheric d-region, Nature, 292, 221-223, 1981.

Thrane, E. V., Blix, T. A., and Lie-Svendsen, Ø.: Can horizontal advection cause specular partial reflections of radio waves in the ionospheric d-region?, paper presented at the 35th COSPAR Scientific Assembly, Paris, France, 18-25 July, 2004.

Trakhtengerts, V. Y.: Generation mechanism of polar mesosphere summer echoes, J. Geophys. Res., 99, 21 083-21 088, 1994.

Trakhtengerts, V. Y. and Demekhov, A. G.: Nonequilibrium electron density fluctuations and wave scattering in the mesosphere, J. Atmos. Terr. Phys., 57, 1153-1164, 1995.

Turco, R. P., Toon, O. B., Whitten, R. C., Keesee, R. G., and Hollenbach, D.: Noctilucent clouds: Simulation studies of their genesis, properties and global influences, Planet. Space Sci., 3, $1147-$ 1181, 1982.

Ulwick, J. C., Baker, K. D., Kelley, M. C., Balsley, B. B., and Ecklund, W. L.: Comparison of simultaneous MST radar and electron density probe measurements during STATE, J. Geophys. Res., 93, 6989-7000, 1988.

Ulwick, J. C., Kelley, M. C., Alcala, C., Blix, T., and Thrane, E. V.: Evidence for two different structuring and scattering mechanisms and the associated role of aerosols in the polar summer mesosphere, Geophys. Res. Lett., 20, 2307-2310, 1993. von Cossart, G., Fiedler, J., and von Zahn, U.: Size distributions of NLC particles as determined from 3-color observations of NLC by ground-based lidar, Geophys. Res. Lett., 26, 1513-1516, 1999.

von Zahn, U.: Are noctilucent clouds truly a "miner's canary" of global change?, Eos, Transactions, American Geophysical Union, 84 (28), 261-268, 2003.

von Zahn, U. and Berger, U.: Persistent ice cloud in the midsummer upper mesosphere at high latitudes: three-dimensional modeling and cloud interactions with ambient water vapor, J. Geophys. Res., 108 (D8), 8451, doi:10.1029/2002JD002409, 2003.

von Zahn, U. and Bremer, J.: Simultaneous and common-volume observations of noctilucent clouds and polar mesosphere summer echoes, Geophys. Res. Lett., 26, 1521-1524, 1999.

von Zahn, U., von Cossart, G., Fiedler, J., and Rees, D.: Tidal variations of noctilucent clouds measured at $69^{\circ}$ latitude by groundbased lidar, Geophys. Res. Lett., 25, 1289-1292, 1998.

von Zahn, U., von Cossart, G., Fiedler, J., Fricke, K., Nelke, G., Baumgarten, G., Rees, D., Hauchecorne, A., and Adolfsen, K.: The ALOMAR Rayleigh/Mie/Raman lidar: Objectives, configuration, and performance, Ann. Geophys., 18, 815-833, 2000, SRef-ID: 1432-0576/ag/2000-18-815.

Werne, J. and Fritts, D. C.: Anisotropy in stratified shear layer, Phys. Chem. Earth (B), 26, 263-268, 2001.

Woodman, R. F. and Guillen, A.: Radar observations of winds and turbulence in the stratosphere and mesosphere, J. Atmos. Sci., 31, 493-505, 1974.

Woodman, R. F., Balsley, B. B., Aquino, F., Flores, L., Vazquez, E., Sarango, M., Huaman, M., and Soldi, H.: First observations of pmse in antarctica, J. Geophys. Res., 104, 22 577-22 590, 1999.

Woods, J. D., Högström, V., Misme, P., Ottersten, H., and Phillips, O. M.: Fossil turbulence, Radio Sci., 4, 1365-1367, 1969.

Zadorozhny, A. M., Tyutin, A. A., Witt, G., Wilhelm, N., Wälchli, U., Cho, J., and Swartz, W. E.: Electric field measurements in the vicinity of noctilucent clouds and PMSE, Geophys. Res. Lett., 20, 2299-2302, 1993.

Zadorozhny, A. M., Vostrikov, A. A., Witt, G., Bragin, O. A., Dubov, D. Y., Kazakov, V. G., Kikhtenko, V. N., and Tyutin, A. A.: Laboratory and in situ evidence for the presence of ice particles in a PMSE region, Geophys. Res. Lett., 24, 841-844, 1997.

Zecha, M., Röttger, J., Singer, W., Hoffmann, P., and Keuer, D.: Scattering properties of PMSE irregularities and refinement of velocity estimates, J. Atmos. Sol. Terr. Phys., 63, 201-214, 2001.

Zecha, M., Bremer, J., Latteck, R., and Singer, W.: Properties of midlatitude mesosphere summer echoes after three seasons of VHF radar observations at $54^{\circ} \mathrm{N}$, J. Geophys. Res., 108 (D8), 8439, doi:10.1029/2002JD002442, 2003. 